OPEN ACCESS

Edited by:

Mathilda Mommersteeg, University of Oxford, United Kingdom

Reviewed by:

Yuki Shimizu,

National Institute of Advanced Industrial Science and Technology,

Japan

Lazaro Centanin

Heidelberg University, Germany

${ }^{*}$ Correspondence:

Shih-Lei Lai

ben.s.lai@ibms.sinica.edu.tw

Specialty section:

This article was submitted to Evolutionary Developmental Biology, a section of the journal

Frontiers in Ecology and Evolution

Received: 27 September 2021

Accepted: 10 January 2022

Published: 01 February 2022

Citation:

Chowdhury K, Lin S and Lai S-L (2022) Comparative Study in Zebrafish and Medaka Unravels the Mechanisms of Tissue Regeneration

Front. Ecol. Evol. 10:783818. doi: $10.3389 /$ fevo.2022.783818

\section{Comparative Study in Zebrafish and Medaka Unravels the Mechanisms of Tissue Regeneration}

\author{
Kaushik Chowdhury ${ }^{1,2}$, Shi Lin ${ }^{1,3}$ and Shih-Lei Lai ${ }^{1,2 *}$ \\ ${ }^{1}$ Institute of Biomedical Sciences, Academia Sinica, Taipei, Taiwan, ${ }^{2}$ Taiwan International Graduate Program in Molecular \\ Medicine, National Yang Ming Chiao Tung University and Academia Sinica, Taipei, Taiwan, ${ }^{3}$ Department of Integrative \\ Biology and Museum of Vertebrate Zoology, University of California, Berkeley, Berkeley, CA, United States
}

Tissue regeneration has been in the spotlight of research for its fascinating nature and potential applications in human diseases. The trait of regenerative capacity occurs diversely across species and tissue contexts, while it seems to decline over evolution. Organisms with variable regenerative capacity are usually distinct in phylogeny, anatomy, and physiology. This phenomenon hinders the feasibility of studying tissue regeneration by directly comparing regenerative with non-regenerative animals, such as zebrafish (Danio rerio) and mice (Mus musculus). Medaka (Oryzias latipes) is a fish model with a complete reference genome and shares a common ancestor with zebrafish approximately 110-200 million years ago (compared to 650 million years with mice). Medaka shares similar features with zebrafish, including size, diet, organ system, gross anatomy, and living environment. However, while zebrafish regenerate almost every organ upon experimental injury, medaka shows uneven regenerative capacity. Their common and distinct biological features make them a unique platform for reciprocal analyses to understand the mechanisms of tissue regeneration. Here we summarize current knowledge about tissue regeneration in these fish models in terms of injured tissues, repairing mechanisms, available materials, and established technologies. We further highlight the concept of inter-species and inter-organ comparisons, which may reveal mechanistic insights and hint at therapeutic strategies for human diseases.

\section{Keywords: zebrafish, medaka (Oryzias latipes), tissue regeneration, heart, retina, fin, evolution, comparative genomics}

\section{INTRODUCTION: TISSUE REGENERATION IN MODEL ORGANISMS}

Reparative regeneration refers to replacing damaged or lost body parts with new tissue, an injury response that restores the tissue homeostasis and function in the optimal scenario (Iismaa et al., 2018). By studying regeneration, scientists can devise biological concepts for tissue repairing and apply them to traumatic injury and degenerative diseases in humans/patients. The studies encompass the strategy to stimulate the repair mechanism to replace the damaged tissues and organs, involve cross-discipline practices, and serves as a bridge between developmental biology and clinical study. A common way to study regeneration is to introduce experimental injury to the model animals and observe how they repair the tissue and recover from the injury. 
In the Kingdom Animalia, the loss of regenerative ability coincides with the evolution of new and complex cell and tissue types (Brockes et al., 2001; Maginnis, 2006; Bely and Nyberg, 2010; Elchaninov et al., 2021). Anatomically simple organisms, such as hydra and planarians, can regenerate their entire body when cut into multiple pieces (Reddien and Alvarado, 2004; Reddy et al., 2019). Considerable members of early branching vertebrate lineages (like bony fish and amphibians) can also regrow various organs upon experimental injuries (Yun, 2015; Khyeam et al., 2021). In striking contrast, mammals (like mice and humans), retain a limited regenerative capacity only in some tissues and organs (Iismaa et al., 2018; Figure 1). The differences in regeneration capacity solely rely on the cellular source for replenishing lost or damaged tissue, which may come from one of three mechanisms, including the proliferation of progenitor/stem cells, dedifferentiation of mature cells into progenitors, and transdifferentiation from one cell type to another (Jopling et al., 2011). Regenerative species usually possess the pool of progenitor cells or the potential of dedifferentiation and transdifferentiation upon activating the regenerative program within the injured tissue. Taking the heart for example, most cardiomyocytes stop proliferating soon after birth, and there is no stem-like or progenitor cell population identified in the adult hearts (Bely and Nyberg, 2010; Steinhauser and Lee, 2011; Mollova et al., 2013; Bergmann et al., 2015). Instead, mature cardiomyocytes were stimulated to dedifferentiate, proliferate, and re-differentiate to replenish the lost tissue upon injury (Eschenhagen et al., 2017). Over the years, investigations across the animal kingdom have led us to compile a list of masters in tissue regeneration who also have comparable organ systems to humans, including zebrafish (Marques et al., 2019), newts (Laube et al., 2006), and Axolotl (Cano-Martinez et al., 2010; Simon and Tanaka, 2013; Figure 1).

Since regenerative capacity exists unevenly among species and their respective organs, an exciting way to uncover the mechanisms of tissue regeneration is by comparing the repair processes in animals with differential regenerative capacities. Such comparisons have been carried out in two ways: "Interspecies" comparing the repair of the same tissue/organ that is regenerative in one species (could also be age or living condition) but non-regenerative in another; Or "inter-organ" comparing two regenerative tissues within the same species to identify a central regenerative program (Potts et al., 2021). However, the regenerative species are usually quite distant in phylogeny, anatomy, and physiology from those non-regenerative ones, such as zebrafish and mice. It is thus essential to find more comparable species to overcome these shortcomings. In search of such comparative systems that can justify the disadvantages of comparing fish with mammals, zebrafish and medaka represent a more simplistic and feasible platform for comparing tissue repair and regeneration.

Zebrafish and medaka are two commonly used vertebrate models in biomedical research, given the homology with mammals and the availability of a wide range of research tools (Furutani-Seiki and Wittbrodt, 2004). Despite diverged 115-200 Mya, zebrafish and medaka are similar in anatomy, physiology, and genetics, with many conserved gene regulatory elements. In addition, zebrafish shares more than $70 \%$ of homologous genes with humans, and conserved signaling pathways and metabolic networks, making it a valuable model for biomedical research (Howe et al., 2013). Interestingly, medaka possesses regenerative capacity in fin (Katogi et al., 2004), kidney (Watanabe et al., 2009), liver (Van Wettere et al., 2013), pancreas (Otsuka and Takeda, 2017), lateral line neuromasts (Seleit et al., 2017b), and gills (Stolper et al., 2019) but is impaired to regenerate the heart (Ito et al., 2014; Lai et al., 2017), retina (Lust and Wittbrodt, 2018), brain (Shimizu and Kawasaki, 2021), and posterior lateral line (pLL) nerve cells (Seleit et al., 2022). This uneven regenerative capacity across organs is in sharp contrast with zebrafish, which can regenerate almost all organs, including the heart (Poss et al., 2002), retina (Vihtelic and Hyde, 2000; Sherpa et al., 2008), brain (Kroehne et al., 2011; Marz et al., 2011; Kishimoto et al., 2012), spinal cord (Becker et al., 1997; Ghosh and Hui, 2018), notochord (Garcia et al., 2017; Lopez-Baez et al., 2018), fin (Poss et al., 2003), kidney (Diep et al., 2011), liver (Sadler et al., 2007), pancreas (Moss et al., 2009), gills (Mierzwa et al., 2020), and lateral line (Hair cells) (Lush and Piotrowski, 2014; Cruz et al., 2015). These features make them great models for studying tissue regeneration by inter-species comparisons. Even for the inter-organ comparisons, common vs. tissue-specific regenerative programs could be revealed in zebrafish, while tissue-specific injury responses relevant to regeneration may be explored in medaka, which will be further elaborated in this review.

Here, we highlight the potential of this comparative platform by summarizing the current knowledge from published work, available tools and techniques, and elaborate on current limitations and future outlooks. This platform may provide a new opportunity for investigating the intrinsic mechanisms of tissue regeneration at the organism level and in an unbiased manner. The constraints and triggers of tissue regeneration may further translate toward novel therapeutics for related human diseases.

\section{EVOLUTION OF THE REGENERATIVE CAPACITY}

Deciphering the underlying mechanisms of tissue regeneration across phylogeny requires the integrative knowledge of evolutionary biology since the trait (regeneration) changes over the course of evolution (Zattara et al., 2019). This phenomenon is due to the fact that maintaining regenerative capacities requires selective pressures, in terms of the frequency and severity of major damages in an extreme living environment (Morgan, 1901; Lin et al., 2017; Elchaninov et al., 2021). These damages may compromise the fitness of the organisms, but they are not always detrimental for survival and propagation as a selective pressure (Fox and McCoy, 2000; Bernardo and Agosta, 2005). As a result, a critical phylogenetic trend identified across the animal phyla reveals declined regenerative capacity instead of preservation (Bely, 2010; Bely and Nyberg, 2010).

Various theories have been proposed to explain the declined regenerative capacity, including low damage intensity over the evolution mentioned above and the changes in adaptive value 

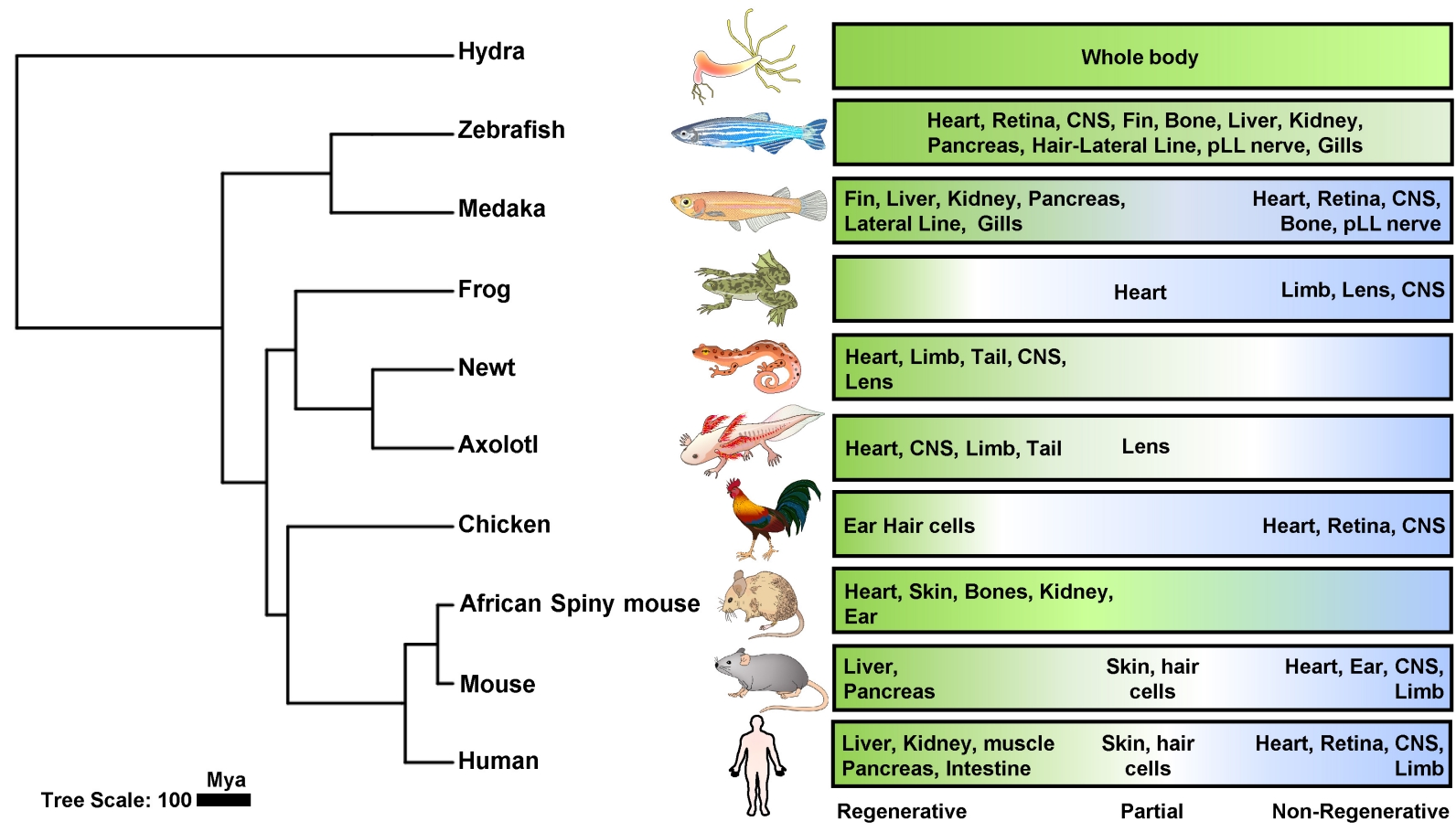

FIGURE 1 | Phylogenetic analysis of tissue regeneration. Phylogenetic tree of animal models tested for regenerative capacities including cnidaria, teleost's, amphibians, aves and mammals were generated using TimeTree (TimeTree::The Timescale of Life) (Kumar et al., 2017) and later organized by iTOL (Letunic and Bork, 2021). Regenerative (green), partial (white), and non-regenerative (blue) organs were depicted in the panels for each category.

of organs (Elchaninov et al., 2021). In addition, the loss of capacity in myocardial regeneration in adult mammals could be an evolutionary trade-off related to energy metabolism (Elhelaly et al., 2016). In a different context, the regenerative capacity of limbs in amphibians but lost in other tetrapods may result from the semiautonomous module of limb development, so their limb may regenerate as a separate organ in adults without the interactions with other transient structures during development (Galis et al., 2003). Another interesting observation is that the declined regenerative capacity seems to inversely correlate with complex immune systems during development and evolution (Mescher and Neff, 2005). For example, the development and maturation of the immune system strongly correlate with the decline of regenerative capacity during frog metamorphosis (Robert and Ohta, 2009; Godwin and Rosenthal, 2014) and mammalian cardiac maturation (Porrello et al., 2011; Vivien et al., 2016). Thus, the selection pressure of the immune system may have underlying influences on the regenerative capacity that reflect at the tissue or organismic levels. However, the immune system does not always obstruct regeneration. It even acts as a critical tissue regeneration component as a coordinated innate immune response is indispensable for regenerating the axolotl limb and neonatal mouse heart (Godwin et al., 2013; Aurora et al., 2014). Moreover, the current knowledge indicates the capacity to regenerate is not only confined to organ-specific or tissue-specific levels but a coordinated involvement of systemic responses (Aurora et al., 2014; Lai et al., 2017; Sanz-Morejon et al., 2019; Bevan et al., 2020).
It is known that the loss/gain of tissue regenerative ability has evolved independently several times over the course of evolutionary history (Zattara et al., 2019). Given this, it is of paramount importance to examine and compare regeneration in a lineage-specific context (Dwaraka and Voss, 2021). Despite the availability of systematic reviews on the evolutionary origin of regeneration, only a handful of studies have addressed the regenerative potential in a lineage-specific context and have reconstructed routes of the ancestral states with the organ of interests (Zattara et al., 2019; Dwaraka and Voss, 2021). Fortunately, growing research groups are proposing comparative analyses of tissue regeneration across animal phylogeny. Comparative phylogenetic studies investigating the regenerative capacity of diverse animal taxa bring invaluable insights into the origin and preservation of regeneration throughout evolution. Novel inferences may be drawn only by comparing a wide range of organisms covering major branches/lineages of interest.

Such a study was recently reported by Hirose et al. (2019) who used cardiomyocyte ploidy as an indicator of heart regeneration and assessed the ploidy of cardiomyocytes in 41 vertebrate species. They found that the diploid cardiomyocyte frequency inversely correlated with the energy metabolism process modulated by the thyroid signaling, an evolutionary trade-off for acquiring endothermy in mammals compared to fish (Hirose et al., 2019). Evolutionary trade-offs are the manifestation of loss or gain of a particular functional trait caused by opposing selections resulting from different environments at an apparent cost (Agrawal et al., 2010). More 
examples of the trade-off between regenerative capacity and metabolism can be observed in Mexican cavefish (Stockdale et al., 2018). Stockdale et al. (2018) reported that the surface- and cavefish possessed similar levels of cardiomyocyte proliferative capacity, but the cave-fish showed differential upregulation of immune and scarring responses with downregulated metabolic genes compared to their surface-dwelling counterparts. These switch in metabolic regulation might play an essential role in the regenerative capacity of the cavefish when it fails to regenerate its heart and instead forms a fibrotic scar overtime. Furthermore, this intra-species comparative study nicely depicts that successful heart regeneration relies on the interplay of cardiomyocytes (CM) proliferation and scarring, which is absent in the cave-dwelling species (Stockdale et al., 2018). Moreover, the current evidence for heart regeneration further suggests that the loss of mammalian regenerative capacity is a onetrait evolutionary trade-off for higher energy metabolism in cardiac output and failure in cardiomyocyte proliferation as a capacity for heart regeneration (Elhelaly et al., 2016). The switch in metabolic reprogramming can be further correlated with cardiomyocyte proliferation observed during zebrafish heart regeneration switching from oxidative phosphorylation to glycolysis (Honkoop et al., 2019). These events, in turn, if activated in mouse hearts by ErbB2 signaling, can induce cardiomyocyte proliferation and improve functional recovery post-ischemic injury (Honkoop et al., 2019). Interestingly, medaka possesses the potential for testing these theories and makes people wonder the mechanisms underlying their uneven regenerative capacity amongst different organs, especially when compared to zebrafish.

\section{ZEBRAFISH AND MEDAKA: POWERFUL MODELS FOR COMPARATIVE STUDY}

Among various model systems used to study regeneration, fish species are extensively investigated. Fish is a phylogenetically "inclusive" term that encompasses four major vertebrate lineages: Sarcopterygii (lobe-finned fish), Actinopterygii (ray-finned fish), Chondrichthyes (cartilaginous fish), and Agnatha (jawless fish). Interestingly, these primitive vertebrates exhibit uneven regenerative capacity among different organs, living conditions, and between phylogenetically close species, making them perfect models to reveal how regeneration works and how to preserve or rehabilitate it in other vertebrates that have lost the capacity. Among actinopterygian fish, zebrafish are natives of the river basins in India and a well-established animal model used extensively for scientific research since the 1980s (Streisinger et al., 1981, 1986). Over the decades, zebrafish has stood out as a powerful tool for studying developmental biology, evolution, human genetics, and diseases. The advantages of the zebrafish model include a small size for manipulation, short reproductive cycle, large clutches of embryos, rapid development, cheap maintenance, comparable organs to mammals, and fully sequenced genome with well-annotated genes (Gemberling et al., 2013; Howe et al., 2013; Beffagna, 2019). Most importantly, zebrafish regenerate almost all organs upon experimental injury
(Marques et al., 2019). On the other hand, medaka species are small egg-laying freshwater teleost fish home to Asia with native diversity from Japan, Korea, Taiwan, and China (Hilgers and Schwarzer, 2019). They live in rice paddy fields, rivers, and creeks in Japan, thus also named "Japanese Rice fish." As a resident of the temperate zone, medaka can tolerate a temperature range from 4 to $40^{\circ} \mathrm{C}$ for both embryos and adults in the wild. In particular, Japanese medaka (Oryzias latipes) is highly tolerant to inbreeding, ideal for laboratory conditions with $14 \mathrm{~h}$ light and $10 \mathrm{~h}$ dark circles for mating conditions, with simple dietary and habitat requirements (Kirchmaier et al., 2015). They were established as a genetic model as early as 1975 (Yamamoto, 1975) and were one of the first model organisms for genetic manipulations (Ozato et al., 1986). Additionally, medaka is an ideal model organism owning to short development (7-9 days) and reproduction cycle (2-3 months), fully sequenced genome (three strains), and a transparent body throughout the juvenile stage (Ishikawa, 2000; Wittbrodt et al., 2002; Kirchmaier et al., 2015). Although zebrafish and medaka are distant relatives that got separated around 110-200 million years ago during evolution (Wittbrodt et al., 2002), they are similar in size, anatomy, and physiology, allowing them to be raised in the same laboratory conditions in terms of feeding, light-dark cycle, water temperature/quality, and propagation (Furutani-Seiki and Wittbrodt, 2004). In addition to orthologous gene-sets for genome-wide profiling and reciprocal analyses, many materials and methods can be applied equally to both zebrafish and medaka, making them ideal for comparative studies than more distantly related species (Figure 2).

\section{Inter-Species Comparisons: Cardiac Regeneration}

As one of the most vital organs, mammalian hearts have a minimal capacity for regeneration upon disease or injury in the post-natal period, especially for replenishing cardiac muscle cells (cardiomyocytes, CMs). Instead, the infarcted hearts undergo fibrotic repair, which in turn deteriorates tissue contractility and function, eventually leading to heart failure and organismal death (Kong et al., 2014). In contrast to the limited regenerative capacity of adult mammals, certain fishes and amphibians, and even neonatal mice can regenerate their hearts after injury (Vivien et al., 2016). This is an excellent example of how the regenerative capacity of hearts exists unevenly across species and developmental stages, as mammals possess the regenerative capacity only for a short time window after birth (Porrello et al., 2011; Haubner et al., 2012, 2016). These mammalian and non-mammalian models provide unique opportunities to study the intrinsic capacity and mechanisms of heart regeneration. Amongst, extensive knowledge was gained from the zebrafish studies. Since the ground-breaking discovery of zebrafish heart regeneration by Poss et al. (2002), researchers have made in-depth investigations to understand the mechanisms of heart regeneration in zebrafish (Marques et al., 2019; Jaźwińska and Blanchoud, 2020; Potts et al., 2021). Briefly, zebrafish hearts mount a robust immune response in the recruitment of macrophages and neutrophils immediately after injury (Lai et al., 2017) and fast revascularization that expands 

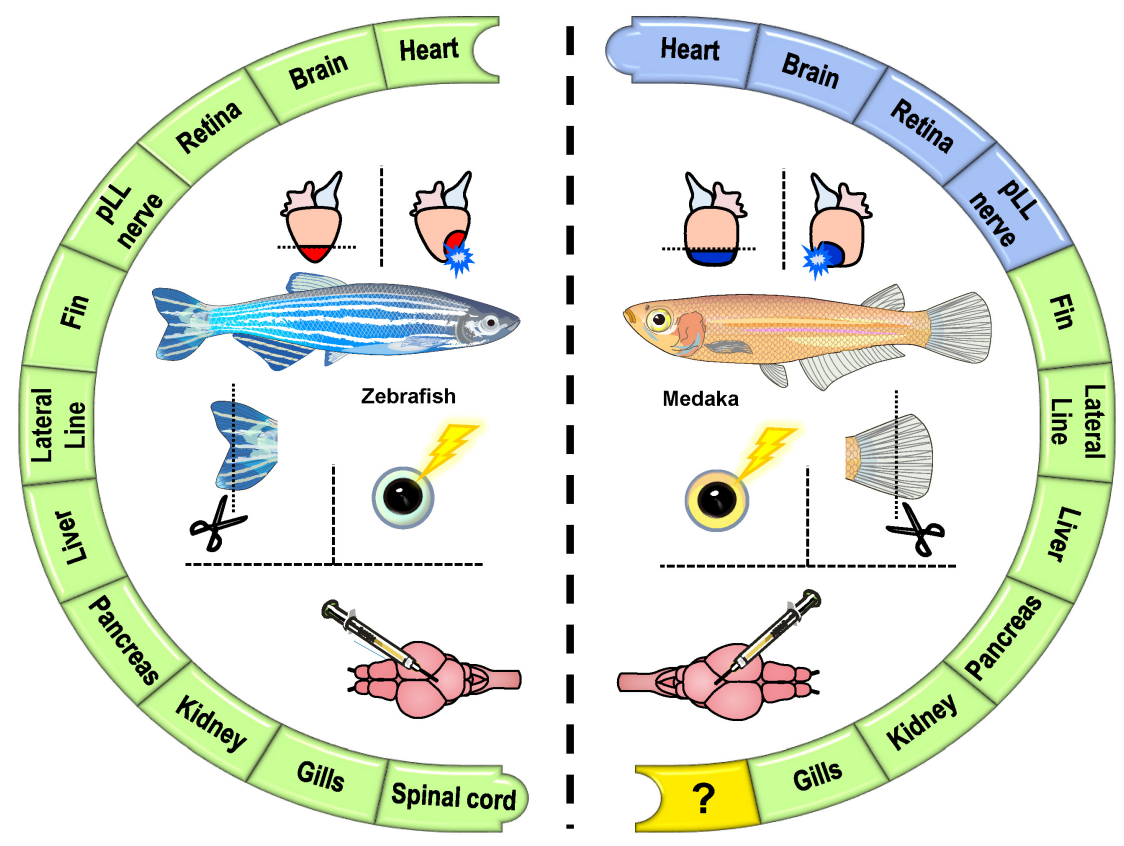

FIGURE 2 | The comparative analyses of tissue regeneration in zebrafish and medaka. A summary of the regenerative (green) vs. non-regenerative (blue) organs and the comparisons (mostly inter-species) of tissue regeneration in zebrafish and medaka.

superficially and intraventricularly and serve as the scaffold for CM repopulation (Marín-Juez et al., 2016, 2019). Almost concurrently, epicardium activates and expands by proliferation to cover the injured area and serve as a signaling hub to stimulate CM de-differentiation and proliferation in the border zone of the injured area (Kikuchi et al., 2010, 2011a,b; Jopling et al., 2011; González-Rosa et al., 2012; Cao and Poss, 2018). Newly formed CMs gradually replace scar tissue coincident with ECM remodeling (Sanchez-Iranzo et al., 2018) and scar resolution (Bevan et al., 2020; Simoes et al., 2020), eventually restoring the morphology and function of the heart. Conserved processes have been shown in neonatal mouse heart regeneration, particularly the source of regenerated CMs (Porrello et al., 2011; Vivien et al., 2016). Furthermore, hints gained from zebrafish studies have been applied to mice models to accelerate cardiac repair (Chen et al., 2016; Honkoop et al., 2019). A comparative study in zebrafish and mouse injured hearts even revealed microRNA dynamics that may regulate $\mathrm{CM}$ proliferation and cardiac repair (Crippa et al., 2016). However, considering the taxonomy distance between zebrafish and mice, a comparative approach may be more feasible for more closely related species with similar physiology and structure.

Unlike zebrafish, medaka showed impaired heart regeneration, indicated by a lack of revascularization, low CM proliferation, and a permanent fibrotic scar in the injured area after resection (Ito et al., 2014). To understand the differences in cardiac repair in zebrafish and medaka, Lai and colleagues performed a global transcriptomic analysis and revealed a robust immune response and angiogenic revascularization exist preferentially in zebrafish (Lai et al., 2017). Coincidently, they observed a reduced macrophage infiltration and prolonged neutrophil recruitment/retention in medaka hearts compared to zebrafish. The blunted immune response in medaka encouraged the investigation of the acute immune response and timely macrophage recruitment in heart regeneration. Indeed, in a loss-of-function setting, delayed macrophage recruitment by clodronate liposome pre-depletion abolished the regenerative capacity in zebrafish (Lai et al., 2017), which correspond nicely with findings in neonatal mice (Aurora et al., 2014). These results support an essential role of macrophage function in heart regeneration across species and encore the requirement of the macrophage function in the regeneration of other organs, including fin, retina, optic tectum, brain, and spinal cord reviewed elsewhere (Var and Byrd-Jacobs, 2020). They further identified the immunostimulant poly I:C as one of the upstream candidates that may trigger the differential transcriptomic response found between zebrafish and medaka. Indeed, they further showed that stimulating immune response by poly I:C administration promotes heart regeneration in medaka in a gain-of-function setting (Lai et al., 2017). These results support the strength of comparative analysis using fish models to gain knowledge conserved across species and identify proregenerative factors. However, it remains unclear how poly I:C (or other immunostimulants) promote heart regeneration in medaka and whether the same principle may apply to mammals, awaiting further investigation.

\section{Inter-Species Comparisons: Retina Regeneration}

The capacity to regenerate retinal neurons after injury also varies drastically among vertebrate species. While mammalian Müller 
glia (MG) do not spontaneously regenerate lost retinal neurons, zebrafish MG cells possess a robust capacity to regenerate all retinal cell types and recover their visual ability (Vihtelic and Hyde, 2000; Sherpa et al., 2008; Goldman, 2014; Gorsuch and Hyde, 2014; Lenkowski and Raymond, 2014). Several pluripotent factors, including ascl1a, lin-28, and sox2, regulate the dedifferentiation, reprogramming, and proliferation of $\mathrm{MG}$ cells into various retinal cell types during retina regeneration in zebrafish (Ramachandran et al., 2010a; Gorsuch et al., 2017). Sox 2 is also one of the four Yamanaka factors that induced pluripotent stem cell status (Takahashi et al., 2007). In addition to retina, retinal pigment epithelium (RPE) regeneration was also recently described in zebrafish (Leach et al., 2021). Similar to heart regeneration, the immune response, particularly the macrophages and microglia cells, responds to injury and plays a critical role in retina and $\mathrm{RPE}$ regeneration, potentially associated with phagocytotic debris clearance and cytokine secretion (Mitchell et al., 2019; Leach et al., 2021).

During retina development, medaka neural stem cells behave similarly to those in zebrafish (Martinez-Morales et al., 2009; Centanin et al., 2011, 2014). However, Lust and Wittbrodt discovered that medaka showed limited regenerative capacity in the retina. The MG cells proliferate but fail to self-renew and reprogram, eventually giving rise to only photoreceptor cells (Lust and Wittbrodt, 2018). Moreover, by comparing medaka with zebrafish, they identified that medaka MG cells fail to maintain sox 2 expression after injury and demonstrated that sustained sox2 expression in medaka MGs confers regenerative response (Lust and Wittbrodt, 2018). Similar to the abovementioned reciprocal analyses in heart regeneration, Lust and Wittbrodt were able to identify the critical factor and demonstrated the functional relevance of sox 2 expression in promoting retina regeneration.

More recently, Hoang et al. (2020) identified the evolutionarily conserved and species-specific gene regulatory networks that control the quiescent, reactive, and proliferative MG transition after retinal injury in another cross-species comparison between mice, chick, and zebrafish. They further demonstrated that deleting the factors maintaining the quiescent state may promote MG reprogramming into regeneration-competent cells in adult mice (Hoang et al., 2020).

\section{Inter-Species Comparisons: Central Nervous System Regeneration}

Unlike mammals, zebrafish respond to injury or degeneration by inducing specific neurogenic programs and constitutive neurogenesis for tissue regeneration (Diotel et al., 2020). Learning the regenerative mechanisms occurring in zebrafish will be invaluable for developing therapeutics for brain injury and degenerative diseases. In contrast to target-oriented studies, new knowledge may come from side-by-side and unbiased comparisons of animal models with divergent regenerative capacities. Unfortunately, mice brains and zebrafish brains show distinct features other than regenerative capacity, including the overall anatomy and neurogenic niches, thus preventing direct comparisons (Diotel et al., 2020; Labusch et al., 2020). Therefore, it is relevant to explore the mechanisms of brain regeneration in more closely related models.

The regenerative capacity of zebrafish central nervous system (CNS) has been investigated in the optic tectum (Ito et al., 2010; Shimizu et al., 2018; Lindsey et al., 2019) and telencephalon (Kroehne et al., 2011; Marz et al., 2011; Kishimoto et al., 2012). In the adult zebrafish CNS, both MG and the radial glia (RG) cells are activated to proliferate and differentiate into new neuronal cells following injury (Raymond et al., 2006; Ito et al., 2010; Shimizu et al., 2018). These regenerative responses seem to be induced and facilitated by immune responses (Kyritsis et al., 2012; Caldwell et al., 2019), while a specific inflammatory signaling cascade is stimulated by microglia during zebrafish brain repair (Kanagaraj et al., 2020).

A comparative study of brain regeneration in medaka and zebrafish has also been reported very recently (Shimizu and Kawasaki, 2021). Medaka shares a similar brain structure with zebrafish and neural stem cells (NSCs) niche for brain development and growth (Adolf et al., 2006; Grandel et al., 2006; Alunni et al., 2010; Kuroyanagi et al., 2010). Main NSCs exist in the optic tectum of both zebrafish and medaka, including the proliferative neuroepithelial-like stem (NE) cells and the quiescent RG cells (Alunni et al., 2010; Ito et al., 2010; Takeuchi and Okubo, 2013; Dambroise et al., 2017). However, medaka could not regenerate their optic tectum after stab injury and thus leaving a permanent scar (Shimizu and Kawasaki, 2021). In medaka, RG cells were similarly activated for proliferation upon tectum injury, but they failed to differentiate into neuron cells. Unlike the scenario in the retina, sox2 is substantially expressed in both zebrafish and medaka optic tectum and does not associate with the differential regenerative ability. Instead, the expression of pro-regenerative transcriptional factors asclia and oct 4 were missing in the medaka. As a result, glial scar-like structures composed of GFAP+ radial fibers filled the injured area of the medaka optical tectum. Follow-up studies might be required to test the functional relevance of the ectopic expression of asclla and oct4 in promoting RG differentiation and optic tectum regeneration in medaka.

\section{Inter-Species Comparisons: Fin Regeneration}

Among various tissues and organs, appendage regeneration draws major attention early on in the field as teleost fish, urodeles, and amphibians all can regenerate their fins, arms, and legs following amputation (Daponte et al., 2021). Compared to limbs of urodeles and amphibians, fish fin structure is simpler and consists of bony fin rays covered by thin epidermal cells (Grandel and Schulte-Merker, 1998). Nevertheless, limb and fin are homologous tissue across vertebrate species (Yano and Tamura, 2013). A forward-genetic screen done in zebrafish identified a novel and conserved regulator of appendage patterning. When mutated, zebrafish formed limb-like bones in fins, suggesting the conservation in skeleton development and the potential of fin-to-limb transition (Hawkins et al., 2021). The regenerative capacity of the fish fin was examined as early as the 1700 s to understand appendage regeneration with 
the first reports by French naturalist Broussonet (Broussonet, 1786; Broussonet, 1789). Like the limb regeneration in urodeles and amphibians, zebrafish repair their caudal fin by blastemamediated epimorphic regeneration (Poss et al., 2003). In this context, blastema originates from dedifferentiated mesenchymal cells and is the primary source for growing new tissues, including bone, nerve, and vessel (Poss et al., 2003; Straube and Tanaka, 2006; Pfefferli and Jazwinska, 2015). Conserved pathways, including the $\mathrm{Wnt} / \beta$-catenin pathway, were shown to regulate appendage regeneration across different vertebrate species, including zebrafish, Xenopus, and axolotl (Kawakami et al., 2006; Yokoyama et al., 2007).

Like zebrafish, medaka also regenerates their fin after amputation via blastema-mediated epimorphic regeneration (Katogi et al., 2004; Nakatani et al., 2007). It will be interesting to learn if medaka fin regeneration shares a conserved regenerative program with zebrafish in a cross-species study. In addition, inflammation and macrophages play a central role in both heart and fin regeneration in zebrafish but seem deficient/blunt in medaka hearts upon injury (Petrie et al., 2014; Lai et al., 2017). One may wonder whether systemic inflammation and immune response contribute differently upon fin and heart injury in medaka, which will be further discussed and await future investigation.

Overall, all these studies highlight the strength of interspecies comparisons between zebrafish (regenerative) and medaka (non-regenerative) organs to identify (and in some cases also to validate) the potential triggers of tissue regeneration. It is worth mentioning that other comparisons of organisms/conditions exhibiting diverse regenerative capacity have also been reported. For example, Stockdale and colleagues identified genes fundamental to heart regeneration by comparing the injury response of regenerative Astyanax mexicanus surface fish with their non-regenerative counterparts Pachón cave-dwelling fish (Stockdale et al., 2018). Following such regenerative traits among other species, researchers have also explored the evolutionary concept of regeneration amongst other teleost species (Table 1). In addition, comparing the transcriptomes and open chromatin landscapes of the cardiac cells isolated from the regenerative neonatal vs. non-regenerative adult mice hearts, Wang $Z$. et al. (2020) revealed the gene regulatory networks in diverse cardiac cell types and extracellular mediators for cardiomyocyte proliferation, angiogenesis, and fibroblast activation. Furthermore, mammals like the African spiny mouse (Acomys) can regenerate their ear, skin, heart, and bones in contrast to the house mouse (Mus musculus), providing more opportunities for cross-species analyses (Seifert et al., 2012; Matias Santos et al., 2016; Simkin et al., 2017; Qi et al., 2021).

Comparing organisms with similar regenerative properties may also identify the conserved regenerative programs. For example, from an inter-species comparison of zebrafish and African killifish (Nothobranchius furzeri) following fin amputation, Wang and colleagues identified the evolutionary conserved regenerative response elements (RRE) (Wang W. et al., 2020). Activation of inhba, a gene downstream of the RRE, is essential for both fin and heart regeneration and requires
TABLE 1 | Fish models and organs for regeneration research.

\begin{tabular}{|c|c|}
\hline Species & Organs \\
\hline Zebrafish (Danio rerio) & $\begin{array}{l}\text { Heart (Poss et al., 2002) } \\
\text { Retina (Vihtelic and Hyde, 2000; Sherpa et al., 2008) } \\
\text { Brain (Kroehne et al., 2011; Marz et al., 2011; } \\
\text { Kishimoto et al., 2012) } \\
\text { Fin (Poss et al., 2003) } \\
\text { Kidney (Diep et al., 2011) } \\
\text { Liver (Sadler et al., 2007) } \\
\text { Pancreas (Moss et al., 2009) } \\
\text { Notochord (Garcia et al., 2017; Lopez-Baez et al., } \\
\text { 2018) } \\
\text { Lateral line (Hair cells) (Lush and Piotrowski, 2014; } \\
\text { Cruz et al., 2015) } \\
\text { Gills (Mierzwa et al., 2020) } \\
\text { Intestine (Schall et al., 2015) } \\
\text { Spinal cord (Becker et al., 1997; Ghosh and Hui, } \\
\text { 2018) }\end{array}$ \\
\hline $\begin{array}{l}\text { Giant Danio (Devario } \\
\text { aequipinnatus) }\end{array}$ & $\begin{array}{l}\text { Heart (Lafontant et al., 2012) } \\
\text { Lateral Line (Mekdara et al., 2018) }\end{array}$ \\
\hline $\begin{array}{l}\text { Goldfish (Carassius } \\
\text { auratus) }\end{array}$ & $\begin{array}{l}\text { Heart (Grivas et al., 2014) } \\
\text { Retina (Raymond et al., 1988) } \\
\text { Fin (Jh, 1947; Darnet et al., 2019) } \\
\text { Spinal cord (Bernstein, 1964) }\end{array}$ \\
\hline $\begin{array}{l}\text { Grass carp } \\
\text { (Ctenopharyngodon } \\
\text { idella) }\end{array}$ & $\begin{array}{l}\text { Heart (Long et al., 2019) } \\
\text { Gonads (Underwood et al., 1986) }\end{array}$ \\
\hline $\begin{array}{l}\text { Medaka (Oryzias } \\
\text { latipes) }\end{array}$ & $\begin{array}{l}\text { Heart (Ito et al., 2014; Lai et al., 2017) } \\
\text { Retina (Lust and Wittbrodt, 2018) } \\
\text { Brain (optic tectum) (Shimizu and Kawasaki, 2021) } \\
\text { Caudal Fin (Katogi et al., 2004) } \\
\text { Kidney (Watanabe et al., 2009) } \\
\text { Liver (Van Wettere et al., 2013) } \\
\text { Pancreas (Otsuka and Takeda, 2017) } \\
\text { Notochord (Seleit et al., 2020) } \\
\text { Lateral Line (Seleit et al., 2017b) } \\
\text { Posterior lateral line (pLL) nerve (Seleit et al., 2022) } \\
\text { Gill (Stolper et al., 2019) }\end{array}$ \\
\hline $\begin{array}{l}\text { African Killifish } \\
\text { (Nothobranchius furzeri) }\end{array}$ & $\begin{array}{l}\text { Fin (Wendler et al., 2015) } \\
\text { Heart and fin (Wang W. et al., 2020) } \\
\text { Brain (Van Houcke et al., 2021) }\end{array}$ \\
\hline Platyfish (Xiphophorus & Fin (Offen et al., 2008) \\
\hline
\end{tabular}

maculatus)

Atlantic Salmon (Salmo Heart (Ferguson et al., 2005)

salar L.)

Mexican cave/surface

Skin (Sveen et al., 2019)

fish (Astyanax

mexicanus)

Senegal bichir Heart (Kikuchi et al., 2011b)

(Polypterus senegalus) Pectoral Fin (Cuervo et al., 2012)

the binding motifs of activator protein 1 (AP-1) complex. Such enhancer is also present in mammals, shares Ap-1 binding motifs, and responds to injury, although it cannot promote regeneration. These results suggest that RREs might have been repurposed in regeneration-incompetent animals during evolution and only promote tissue repair but not regeneration (Yang and Kang, 2019; Wang W. et al., 2020). Of note, killifish possess the regenerative capacity in multiple organs, including the heart (Wang W. et al., 2020), fin (Wendler et al., 2015), and brain (Van Houcke et al., 2021) while being phylogenetically 
TABLE 2 | Injury models developed in zebrafish and medaka.

\begin{tabular}{|c|c|c|c|}
\hline Tissue type & Injury Type & Zebrafish references & Medaka references \\
\hline \multirow[t]{3}{*}{ Heart } & Resection & Poss et al., 2002 & Ito et al., 2014 \\
\hline & Cryoinjury & Chablais et al., 2011; Gonzalez-Rosa et al., 2011; Schnabel et al., 2011 & Lai et al., 2017 \\
\hline & Genetic ablation & Cardiomyocytes (Wang J. et al., 2011) & Not available \\
\hline \multirow[t]{2}{*}{ Fin } & Resection & Géraudie et al., 1994; Poleo et al., 2001 & Katogi et al., 2004 \\
\hline & Cryoinjury & Chassot et al., 2016 & Not available \\
\hline \multirow[t]{3}{*}{ Retina } & Light, Laser & Vihtelic and Hyde, 2000; DiCicco et al., 2014 & Lust and Wittbrodt, 2018 \\
\hline & Stabbing & Senut et al., 2004 & \\
\hline & Chemical & Fimbel et al., 2007; Powell et al., 2016 & Not available \\
\hline \multirow[t]{3}{*}{ Brain } & Stabbing & Kroehne et al., 2011; Marz et al., 2011 & Shimizu and Kawasaki, 2021 \\
\hline & Traumatic Brain Injury & Maheras et al., 2018 & Not available \\
\hline & Genetic ablation & $\begin{array}{l}\text { Hypocretin Neurons (Elbaz et al., 2012); Radial glial specific (Shimizu } \\
\text { et al., 2015); dopaminergic neuron-specific (Godoy et al., 2015) }\end{array}$ & Not available \\
\hline Spinal Cord & Transection & Becker et al., 1997 & Not available \\
\hline Bone & Genetic ablation & Osteoblasts (Singh et al., 2012) & Osteoblasts (Willems et al., 2012) \\
\hline \multirow[t]{3}{*}{ Notochord } & Laser & Goldstein and Fishman, 1998 & Seleit et al., 2020 \\
\hline & Stabbing & Lopez-Baez et al., 2018 & Not available \\
\hline & Genetic ablation & Vacuolated cells (Garcia et al., 2017) & Not available \\
\hline \multirow[t]{2}{*}{ Lateral Line } & Chemical & Harris et al., 2003 & Not available \\
\hline & Laser Ablation & Schuck and Smith, 2009; Cruz et al., 2015 & Seleit et al., 2017b, 2022 \\
\hline Kidney & Chemical & Reimschuessel and Williams, 1995 & Watanabe et al., 2009 \\
\hline \multirow[t]{3}{*}{ Liver } & Chemical & Cox et al., 2014 & Van Wettere et al., 2013 \\
\hline & Resection & Sadler et al., 2007 & Not available \\
\hline & Genetic ablation & Hepatocytes (Curado et al., 2007) & Not available \\
\hline \multirow[t]{2}{*}{ Gills } & Resection & Mierzwa et al., 2020 & Stolper et al., 2019 \\
\hline & Cryoinjury & Ramel et al., 2021 & Not available \\
\hline Pancreas & Genetic ablation & Beta cells (Pisharath et al., 2007) & $\begin{array}{l}\text { Beta cells (Otsuka and Takeda, } \\
\text { 2017) }\end{array}$ \\
\hline Intestine & Resection & Schall et al., 2015 & Not available \\
\hline
\end{tabular}

closer to medaka (Terzibasi et al., 2007), represent an alternative model for inter-species comparison.

\section{Inter-Organ Comparisons in Medaka and Zebrafish (Regenerative Programs, Regulatory Elements, and Systemic Immune Responses)}

In addition to the availability of progenitor/stem cell populations in each tissue/organ, we wonder how systemic responses, including immune response, neural innervation, hormonal regulation, metabolic shift, contribute differently to the respective injured tissues/organs of the same organism and lead to uneven regenerative capacity. The problem is especially apparent when one teleost zebrafish can regenerate organs such as the heart, retina, and brain, while another teleost medaka cannot. Taking the heart for example, the blunt immune response seems to be the major obstacle for medaka to initiate regenerative programs, but how does the same systemic (immune) response sustain the regeneration of other organs, for example, the fin? Are there tissue-specific contributions/responses, for example, residential immune cells, tissue-specific injury response elements, or even changes in the epigenomic landscape? These questions may be best addressed in medaka where the organ-specific regenerative capacities are uneven and well studied, including the regenerative fin (Katogi et al., 2004), kidney (Watanabe et al., 2009), liver (Van Wettere et al., 2013), and pancreas (Otsuka and Takeda, 2017), and non-regenerative heart (Ito et al., 2014; Lai et al., 2017), retina (Lust and Wittbrodt, 2018), and brain (Shimizu and Kawasaki, 2021). The potential findings can be cross-species compared and further validated in zebrafish loss-of-function and medaka gainof-function experiments. A similar concept could also apply to other species. Differential regenerative capacity can be observed in lower vertebrates where some lizards can replace their tail but not their limb (Alibardi and Toni, 2005). Even in mice, the uneven regenerative capacity exists ranging from active (intestine and skin), partial (liver, pancreas, muscle), to none (CNS, heart, and most other internal organs) (Iismaa et al., 2018; Figure 1).

Even between two regenerative organs, researchers have identified common and tissue-specific regeneration responsive elements/enhancers by inter-organ comparisons. For example, Kang et al. (2016) have performed such a comparative study identifying a tissue regeneration enhancer element (TREE) from zebrafish heart and fin, which locates upstream of lepb gene and activates following injury. This element could also be activated in neonatal mouse tissues upon injury and may be engineered to modulate the regenerative potential of vertebrate organs. Another study by Pfefferli and Jaźwińska (2017) identified a $3.18 \mathrm{~kb}$ regulatory element upstream of ctgfa gene, named as careg element that drives the regenerative response in both zebrafish 
TABLE 3 | Visualization tools developed in zebrafish and medaka.

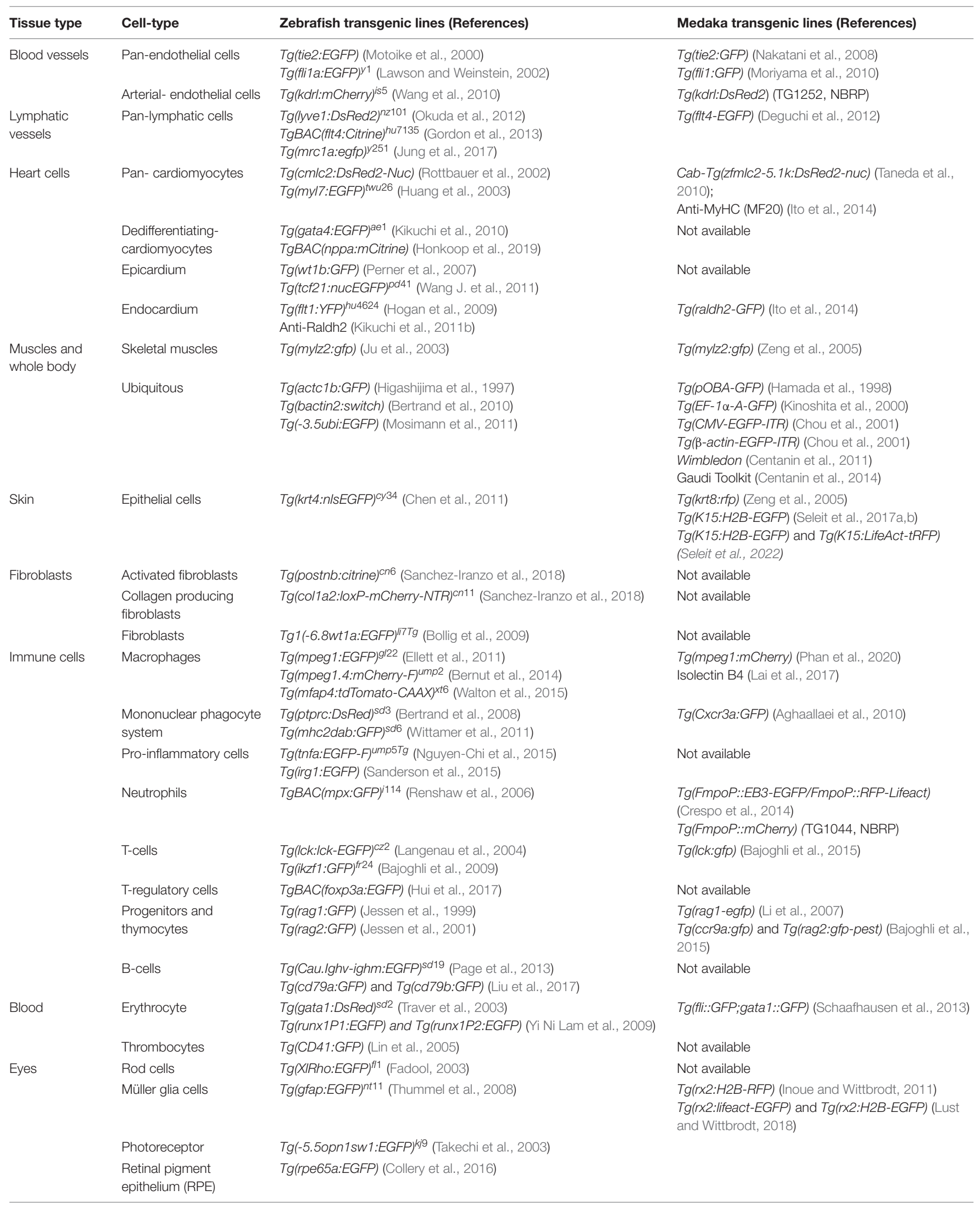


TABLE 3 | (Continued)

\begin{tabular}{|c|c|c|c|}
\hline Tissue type & Cell-type & Zebrafish transgenic lines (References) & Medaka transgenic lines (References) \\
\hline \multirow[t]{4}{*}{ CNS } & Pan-neurons & Tg(huC:GFP) (Park et al., 2000) & Tg(kif5a:gfp) (Kawasaki et al., 2012) \\
\hline & Radial glial cells & $\begin{array}{l}\text { Tg(gfap:GFP)mi200-1 (Raymond et al., 2006) } \\
\text { Tg(cyp19a1b:cyp19a1b-GFP) (Tong et al., 2009) }\end{array}$ & $\begin{array}{l}\text { Anti-Gfap immunostaining, Tg(cyp19a1b-GFP) } \\
\text { (Takeuchi and Okubo, 2013) }\end{array}$ \\
\hline & Neural stem cells & Tg(-1.7Cau.Tuba1:GFP) (Goldman et al., 2001) & $\begin{array}{l}\text { Tg(rx2::H2B-RFP) (Inoue and Wittbrodt, 2011; } \\
\text { Reinhardt et al., 2015) } \\
\text { Tg(wdr12:GFP) (Dambroise et al., 2017) } \\
\text { Tg(cndp::eGFP-caax) (Becker et al., 2021) }\end{array}$ \\
\hline & Oligodendrocyte & Tg(olig2:DsRed2) and Tg(sox10:mRFP) (Kucenas et al., 2008) & Not available \\
\hline \multirow[t]{3}{*}{ Notochord } & Sheath cells & Tg(col9a2:GFPCaaX)pd1151 (Garcia et al., 2017) & Tg(desmogon:EGFP) (Seleit et al., 2020) \\
\hline & Vacuolated cells & Tg(col8a1a:GFPCaaX) (Garcia et al., 2017) & \\
\hline & Intervertebral disk & Tg(twhh:gfp) (Du and Dienhart, 2001) & Not available \\
\hline Lateral Line & Neuromast & Tg(brn3c:GAP43-GFP)s356t (Xiao et al., 2005) & $\begin{array}{l}\text { Tg(eya1:EGFP), Tg(eya1:mECFP), } \\
\operatorname{Tg}(\text { K15:H2B-EGFP), and } \operatorname{Tg}(\text { K15:H2B-RFP) (Seleit } \\
\text { et al., 2017a,b) } \\
\operatorname{Tg}(\text { K15:LifeAct-tRFP) (Seleit et al., 2022) }\end{array}$ \\
\hline \multirow[t]{2}{*}{ Fin and Bone } & $\begin{array}{l}\text { Osteoblasts and } \\
\text { precursors }\end{array}$ & $\operatorname{Tg}(s p 7: E G F P)^{b 1212}$ (DeLaurier et al., 2010) & $\begin{array}{l}\text { Tg(osx-mCherry) (Renn and Winkler, 2009) } \\
\text { Tg(col10a1:n/GFP) (Renn et al., 2013) }\end{array}$ \\
\hline & Osteoclasts & TgBAC(ctsk:Citrine) (Bussmann and Schulte-Merker, 2011) & $\begin{array}{l}\text { Tg(ctsk:mEGFP) (To et al., 2012) } \\
\text { Tg(TRAP:GFP) (Chatani et al., 2011) }\end{array}$ \\
\hline \multirow[t]{2}{*}{ Pancreas } & $\begin{array}{l}\text { Pancreatic endocrine } \\
\text { cells }\end{array}$ & $\begin{array}{l}\text { Tg(-6.5pdx1:GFP) (Huang et al., 2001) } \\
\text { Tg(-8.5nkx2.2a:GFP) (Zecchin et al., 2007) } \\
\text { Tg(-4.Oins:GFP) (Huang et al., 2001) }\end{array}$ & $\begin{array}{l}\text { Tg(pdx1-EGFP) (Otsuka et al., 2015) } \\
\text { Tg(insulin-EGFP-NTR) (Otsuka et al., 2015) }\end{array}$ \\
\hline & Pancreatic exocrine cells & Tg(elaA:gfp) (Wan et al., 2006) & Tg(ptf1a-mCherry) (Otsuka et al., 2015) \\
\hline Liver & Hepatocytes & $\begin{array}{l}\text { Tg(-2.8fabp10a:EGFP) (Her et al., 2003) } \\
\text { Tg(-1.7apoa2:GFP) (Wang R. et al., 2011) }\end{array}$ & Tg(chg-L1.5 kb/GFP-emgb/RFP) (Ueno et al., 2004) \\
\hline
\end{tabular}

fin and heart via TGF $\beta$ /Activin- $\beta$ signaling pathway. This type of study paved the way for identifying evolutionarily conserved RREs, which can also be analyzed in medaka to decipher how these RREs exist and regulate the regenerative programs in a tissue-specific manner.

\section{MATERIALS AND METHODS AVAILABLE FOR COMPARATIVE STUDY IN ZEBRAFISH AND MEDAKA}

Here, we highlight the materials and methods selected from published studies to accelerate comparative studies in tissue regeneration using zebrafish and medaka, including the injury methods, visualization of gene expression and specific cell types, and functional assays by drug delivery and genetic modifications. Online resources and new experimental models will also be summarized in this section.

\section{Injury Models}

Various injury models have been established in fish models to introduce tissue injury and investigate the reparative process. In addition to the feasibility and reproducibility, these methods were often established based on the similarity to the human diseases or trauma conditions to gain translational value (Table 2). The resection or amputation model is one of the most commonly used injury models, involving surgical removal of a part of the tissue for observing the restoration of size, morphology/structure, and function of the injured tissue. Resection is straightforward, cheap, and reproducible and has been widely adopted to fin (Poss et al., 2003; Nakatani et al., 2007) and heart (Poss et al., 2002; Ito et al., 2014) regeneration studies in both zebrafish and medaka. However, resection is often accompanied by excessive bleeding and open wounds, which leads to infection and high mortality. Also, resection is sometimes infeasible for internal organs or tissues those unexposed or too small. Similar models include stabbing and transection, which works by surgically disrupting the integrity without removing any tissue and are well established in the retina, brain, and spinal cord regeneration in both zebrafish (Becker et al., 1997; Marz et al., 2011; Shimizu et al., 2018) and medaka (Shimizu and Kawasaki, 2021).

Slightly different from resection, researchers adapted the cauterization method in fish models to mimic the fibrotic repair in mammalian organs, which is highly associated with the inflammatory response (Strungs et al., 2013; Polizzotti et al., 2016). The cauterization technique involves burning or freezing the target tissue with electric or metal probes and introducing necrotic and apoptotic cell death. Cryoinjury is popular in heart regeneration studies in both zebrafish (Gonzalez-Rosa et al., 2011; Schnabel et al., 2011; Dyck et al., 2020) and medaka (Lai et al., 2017) as it mimics the myocardial infarction in mammals better than resection model (Chablais et al., 2011; Darehzereshki et al., 2015). This technique can also be applied to external organs, such as the fin (Chassot et al., 2016) and gills (Ramel et al., 2021). However, cauterization is technically challenging and less reproducible compared to resection. Also, the wound usually takes a longer time to recover as the cell debris needs to be cleared before regeneration occurs (Schnabel et al., 2011). To increase the 
accuracy and reproducibility, cauterization can also be performed by using high-powered lasers in fish tissues, including the retina (Conedera et al., 2017; Lust and Wittbrodt, 2018) and skin (Richardson et al., 2013). The target tissue has to be exposed or transparent for laser penetration in this case. Overall, most physical injuries are invasive to cause high mortality and take practice to be consistent.

Apart from physical injury models, genetic cell ablation models in fish were established by expressing enzymes that catabolize cytotoxic products added to the system or induce cell death directly (Table 2). The former method was developed by expressing the bacterial enzyme Nitroreductase (NTR), which alone is not toxic but can catabolize the prodrug metronidazole (Mtz) to induce cytotoxicity (Lindmark and Müller, 1976). This system can achieve spatial (tissue-specific expression of NTR) and temporal control (the timing of adding Mtz), and labeling the target cells (co-expression with reporter system) at the same time. NTR/Mtz system has been used to tease out the functions of specific cell types in a complex process of organ regeneration in zebrafish, including the heart (Curado et al., 2007; Wang et al., 2013; Zhang et al., 2013), fin (Petrie et al., 2014), pancreatic $\beta$-cells (Pisharath et al., 2007), bone (Willems et al., 2012) and RPE regeneration (Hanovice et al., 2019). This system is also applicable to medaka, demonstrated by accessing regeneration capacity using NTR/Mtz mediated genetic ablation of the pancreatic $\beta$-cell population (Otsuka and Takeda, 2017), osteoblasts (Willems et al., 2012), and bone progenitor cells (Dasyani et al., 2019) in fin regeneration.

The latter genetic ablation tool to study zebrafish development and regeneration involves diphtheria toxin A (DTA) expression under a tissue-specific promoter, exampled by crystallin promoter-driven DTA expression in lens (Kurita et al., 2003), elastase A promoter-driven DTA expression in exocrine pancreas (Wan et al., 2006), and myl7 promoter-driven DTA expression in cardiomyocytes (Wang J. et al., 2011). Though the DTA approach lacks temporal control for activation, it is highly toxic for killing the target cells efficiently. In a modified method, the temporal control can be achieved by expressing the human diphtheria toxin receptor (DTR) and further activate cytotoxicity by diphtheria toxin injection (Jimenez et al., 2021). The genetic ablation models are technically simpler with faster recovery. These models can be used combined with physical injury to tease the role of a specific cell type during complex organ regeneration. For example, Sanchez-Iranzo et al. (2018) depleted fibroblast cells after cardiac cryoinjury and demonstrated how fibroblasts contribute to heart regeneration. Overall, most of these injury models developed in zebrafish may also apply to medaka in comparative studies of tissue regeneration.

\section{Visualization Tools}

One of the best attributes of using zebrafish and medaka as research models is the tools and techniques available for visualizing specific cell types and biological processes in vivo. Here, we summarize the visualization tools that have been established in fish models, especially in zebrafish and correspondingly in medaka, with a focus on the transgenic reporter lines (Table 3 ) and alternative approches.
Since fluorescence reporter driven by tissue-specific gene promoter is applicable and efficient in zebrafish and medaka, many transgenic lines have been generated to study specific tissues/organs in development and diseases. Here we summarize tissue-specific reporters described in major tissue regeneration studies previously mentioned in Table 3 . In addition to tissuespecific reporter lines, researchers can also use antibodies against cell-specific transcription factors or cytosolic proteins to assess cellular dynamics in growth, development, and regeneration. For example, Mef-2 (sc-313), nkx2.5 (GTX128357) or MF20 (Fischman, D.A., DSHB) antibody can be used in combination with proliferation/cell cycle markers PCNA (GTX124496), Antiphospho-Histone H3 (Ser10) (06-670, Merck), and BrdU/EdU (C10086, ThermoFisher, Eugene, OR, United States) to label the proliferating CMs (Chablais et al., 2011; Chablais and Jaźwińska, 2012a). Similarly, transgenic medaka lines have also been generated to facilitate cardiac research using zebrafish cmlc2 regulatory elements for myocardial expression (Taneda et al., 2010). In addition to labeling cardiac tissues, researchers have successfully developed medaka reporters utilizing zebrafish skeletal specific mylz2 promoter to label skeletal muscles (Zeng et al., 2005). Vice versa, medaka mylz2 promoter can also recapitulate GFP expression in zebrafish (Zeng et al., $2005)$. On the same note, medaka $\beta$-actin promoter can drive ubiquitous gene expression in both medaka and zebrafish (Yoshinari et al., 2012), while zebrafish $k r t 8$ promoter can label both skin and intestinal epithelium in medaka, as almost identical to zebrafish (Zeng et al., 2005). These examples showed that the transcriptional regulation of many genes is highly conserved in both species, with many tissue-specific transgenes developed to facilitate research, as summarized in Table 3.

Restoring vasculature and circulation is one of the first steps during tissue regeneration (Jung and Kleinheinz, 2013). Both these blood vessels and lymphatic vessels that regulate tissue homeostasis and immune cell trafficking can be visualized by reporters and have been used extensively for regenerative studies in zebrafish (Table 3). To name a few of the most commonly used reporter lines, tie2 reporter for pan-endothelial cells (Motoike et al., 2000), fli1a reporter for endothelial and endocardial cells (Lawson and Weinstein, 2002), $k d r l$ reporter for arterial vessels (Wang et al., 2010), and lyve1 (Okuda et al., 2012) reporter for lymphatic vessels in zebrafish. Correspondingly, a wide range of transgenic reporter strains has been generated in medaka based on orthologous gene promoters (Table 3). Moreover, one can also use staining methods to label the vasculature when transgenic animals are inaccessible. One of the widely adopted vasculature staining methods involves alkaline phosphatase (AP) staining, which relies on the endogenous AP activity to convert NBT/BCIP into purple precipitates in endothelial cells for rapid visualization in larvae (Childs et al., 2002) and heart (Lai et al., 2017). In addition, the Fli1 antibody (ab133485) can be used to mark endothelial cell nuclei in zebrafish by immunostaining (Bensimon-Brito et al., 2020). Aside from post-fixation staining, angiography can be achieved by fluorescent dextran injection into the circulation of larval (Hoeppner et al., 2015; Takanezawa et al., 2021) and adult fish (Pugach et al., 2009). 
Immune response, especially inflammatory cell infiltration and resolution, is a critical component of tissue regeneration to prevent infection, clear damaged tissue, maintain tissue integrity, and sometimes even is associated with the fibrotic response and cell proliferation (Julier et al., 2017). On top of the tremendous capacity in regeneration, zebrafish possess both innate and adaptive immunity comparable to mammals (Trede et al., 2004), making it a powerful model to study the role of immune response in tissue repair and regeneration (Var and Byrd-Jacobs, 2020). Inflammatory cells, including neutrophils and macrophages, are among the first responders recruited to the injured tissue by chemokines and damage-associated molecular patterns (DAMPs) (McDonald et al., 2010; Soehnlein and Lindbom, 2010). Some of the zebrafish reporter lines have been used to visualize these innate immune cells, including fluorescent genes expression driven by neutrophil-specific $m p x$ promoter (Renshaw et al., 2006) and macrophages specific mpeg1.1/mpeg1.4 (Ellett et al., 2011) and mfap4 (Walton et al., 2015) promoters. Taking advantage of the transparent tissue at the larval stage, zebrafish have been extensively used for studying the dynamic and function of these inflammatory cells in tissue repair/regeneration ( $\mathrm{Li}$ et al., 2012). Apart from the innate immune system, some adaptive immune cell reporters were also established in zebrafish (Table 3). Materials for zebrafish immune research have also been previously reviewed (Martins et al., 2019). The immune system in medaka is less studied compared to zebrafish. Still, some immune cell reporters have been generated in medaka based on zebrafish orthologous genes (Table 3), including neutrophil-specific mpo reporter (alias to $m p x$ ) (Grabher et al., 2007; Crespo et al., 2014), macrophages specific mpeg1.1 reporter (Phan et al., 2020), and pan mononuclear phagocytes cxcr3.2 reporter (Aghaallaei et al., 2010). For the adaptive immune cells, medaka gained interest for studying T-cell development where $\mathrm{Tg}$ lines were developed respectively (Bajoghli et al., 2019). Given the importance of immune response in tissue repair/regeneration and the amount of knowledge gained in zebrafish, it is pretty evident that corresponding transgenic reporter lines in medaka await future development for comparative studies. Specifically, it would be interesting to learn more about the critical roles of immune cells that plays similarly or differently in these two model systems.

Due to the limited resource of antibodies against fish proteins and reporters for labeling immune cells, other approaches can be applied to label and even isolate immune cells. For example, isolectin B4 (IB4) and liposome-uptake may label macrophage and other phagocytes in both zebrafish and medaka. In a comparative study, IB4 labels mainly macrophages in zebrafish and medaka and show colocalized signals with zebrafish mpeg1 reporter signals (Lai et al., 2017). On the other hand, DiI liposomes can label the phagocytes efficiently in both zebrafish and medaka based on their properties of macrophage ablation when loaded with clodronate (Lai et al., 2017). Despite in limited numbers, some antibodies work in both fish models in labeling the immune cells, including Lcp1 (GTX124420) (Redd et al., 2006), Lyz (GTX132379) for leukocytes, Spi/Pu.1 for myeloid cells (GTX128266), Mpx (GTX128379) for neutrophils (Lai et al., 2017), Mpeg1 (GTX54246) for macrophages (Simoes et al., 2020), and anti-4C4 for microglia (Becker and Becker, 2001).
Here, we have tabulated the most widely used fish reporter and transgenic lines in Table 3. More transgenic lines that label different tissues can be easily looked up in the Zebrafish Information Network (ZFIN ${ }^{1}$ ) and accessed from the Zebrafish International Resource Center $\left(\mathrm{ZIRC}^{2}\right)$ and the European Zebrafish Resource Center $\left(\right.$ EZRC $\left.^{3}\right)$, or the NBRP Medaka website ${ }^{4}$. Overall, common regulatory elements between zebrafish and medaka support that the activation of zebrafishspecific factors can be well recapitulated in the medaka and vice-versa. This evidence further highlights the conserved generegulatory networks between zebrafish and medaka, making them excellent models to perform comparative studies in tissue regeneration.

\section{Genetic Manipulations in Zebrafish and Medaka}

Taking advantage of being model organisms and a broad research community, zebrafish and medaka are well-equipped with tools for genetic manipulations for generating animal models for specific cell ablations, visualization, and functional manipulations introduced previously. Here, we summarize these toolsets established in zebrafish and medaka (Table 4) to investigate the cellular and molecular mechanisms of tissue regeneration.

Genetic manipulation in forward genetic screening has been established in fish models early on (Driever et al., 1996; Wienholds et al., 2003). As a standard method, ENU (ethylnitrosourea) treatment introduced point mutations via base alkylation that give rise to single base mutations (often called ENU mutants) in zebrafish (Driever et al., 1996) and medaka (Loosli et al., 2000; Furutani-Seiki et al., 2004). Lacking efficient methods for targeted gene mutagenesis used to be a weak spot of zebrafish reverse genetics, but was recently overcome by the invention of zinc-finger nucleases (ZFN) (Doyon et al., 2008), transcription activator-like effector nucleases (TALENs) (Huang et al., 2011; Bedell et al., 2012), and the Clustered, Regularly Interspaced, Short Palindromic Repeat (CRISPR)/CRISPR-associated 9 (Cas9) technology (Hruscha et al., 2013; Hwang et al., 2013). CRISPR became the favorable genetic manipulation strategy given its ease to generate and assemble, and application in almost all eukaryotic cells. In addition to gene knockout/mutagenesis, CRISPR technology was further modified for generating knock-in/transgenic zebrafish carrying reporter/functional genes under endogenous gene regulation (Kimura et al., 2014). Like zebrafish, genome editing using TALEN (Ansai et al., 2013, 2014) and CRISPR/Cas9 (Ansai and Kinoshita, 2014) have been established in medaka. CRISPR/Cas9 mediated gene knock-in via NHEJ was used to generate transgenic and mutant medaka with a high germline transmission rate (Watakabe et al., 2018). In addition, the knock-in method using CRISPR was also applied to generate conditional knockout zebrafish by targeted insertion of loxP sites

\footnotetext{
${ }^{1}$ https://zfin.org/

${ }^{2}$ https://zebrafish.org/home/guide.php

${ }^{3} \mathrm{https} / / /$ www.ezrc.kit.edu/

${ }^{4}$ https://shigen.nig.ac.jp/medaka/
} 
TABLE 4 | Genetic manipulation tools in zebrafish and medaka.

\begin{tabular}{|c|c|c|}
\hline Tools & $\begin{array}{l}\text { Zebrafish } \\
\text { (References) }\end{array}$ & Medaka (References) \\
\hline $\begin{array}{l}\text { ENU (ethylnitrosourea) } \\
\text { mutagenesis }\end{array}$ & Driever et al., 1996 & $\begin{array}{l}\text { Loosli et al., 2000; } \\
\text { Furutani-Seiki et al., } \\
2004\end{array}$ \\
\hline ENU tiling & Moens et al., 2008 & Taniguchi et al., 2006 \\
\hline ENU screens & $\begin{array}{l}\text { Kettleborough et al., } \\
2013\end{array}$ & $\begin{array}{l}\text { Furutani-Seiki et al., } \\
2004\end{array}$ \\
\hline $\begin{array}{l}\text { ZFN (zinc-finger } \\
\text { nucleases) }\end{array}$ & Meng et al., 2008 & Ansai et al., 2012 \\
\hline $\begin{array}{l}\text { TALENs (transcription } \\
\text { activator-like effector } \\
\text { nucleases) }\end{array}$ & $\begin{array}{l}\text { Huang et al., 2011; } \\
\text { Sander et al., } 2011\end{array}$ & Ansai et al., 2013, 2014 \\
\hline CRISPR/Cas9: NHEJ & $\begin{array}{l}\text { Hruscha et al., 2013; } \\
\text { Hwang et al., } 2013\end{array}$ & $\begin{array}{l}\text { Ansai and Kinoshita, } \\
2014\end{array}$ \\
\hline CRISPR/Cas9: HDR & Kimura et al., 2014 & Murakami et al., 2017 \\
\hline Tol2 transposon system & $\begin{array}{l}\text { Kawakami and Shima, } \\
1999\end{array}$ & $\begin{array}{l}\text { Koga et al., 2002; } \\
\text { Kawakami, } 2007\end{array}$ \\
\hline TgBAC cloning & Suster et al., 2011 & Nakamura et al., 2008 \\
\hline I-Scel meganuclease & Grabher et al., 2004 & $\begin{array}{l}\text { Thermes et al., 2002; } \\
\text { Grabher and Wittbrodt, } \\
2007\end{array}$ \\
\hline Frog Prince & Miskey et al., 2003 & Sano et al., 2009 \\
\hline Ac/Ds system & $\begin{array}{l}\text { Ng and Gong, 2011; } \\
\text { Froschauer et al., } 2012\end{array}$ & Emelyanov et al., 2006 \\
\hline Sleeping Beauty & Davidson et al., 2003 & Grabher et al., 2003 \\
\hline PhiC31 & Mosimann et al., 2013 & Kirchmaier et al., 2013 \\
\hline Morpholinos & $\begin{array}{l}\text { Nasevicius and Ekker, } \\
2000\end{array}$ & Carl et al., 2002 \\
\hline $\begin{array}{l}\text { Toolkits for } \\
\text { transactivation }\end{array}$ & $\begin{array}{l}\text { GENEWELD toolbox } \\
\text { (Wierson et al., 2020) }\end{array}$ & $\begin{array}{l}\text { Gaudi toolbox } \\
\text { (Centanin et al., 2014) }\end{array}$ \\
\hline Cre/loxP system & $\begin{array}{l}\text { Thummel et al., 2005; } \\
\text { Le et al., } 2007\end{array}$ & Okuyama et al., 2013 \\
\hline Gal4/UAS & $\begin{array}{l}\text { Asakawa and } \\
\text { Kawakami, } 2008\end{array}$ & $\begin{array}{l}\text { Grabher and Wittbrodt, } \\
2004\end{array}$ \\
\hline Tet system & Knopf et al., 2010 & Hosoya et al., 2021 \\
\hline Mtz/NTR ablation & Curado et al., 2007 & Willems et al., 2012 \\
\hline DTA ablation & Kurita et al., 2003 & Not available \\
\hline $\begin{array}{l}\text { siRNA mediated } \\
\text { transient knockdown }\end{array}$ & Xiao et al., 2018 & Not available \\
\hline $\begin{array}{l}\text { Viral mediated } \\
\text { transduction }\end{array}$ & Gulías et al., 2019 & Suehiro et al., 2010 \\
\hline
\end{tabular}

(Burg et al., 2018). Instead of NHEJ mediated knock-in which is error-prone, Wierson et al. (2020) have further developed knock-in method based on homology mediated end joining (HMEJ) repair for a more efficient and precise genome editing in zebrafish known as the GENEWELD method. Likewise, homology-directed repair (HDR) mediated knock-in strategies were also feasible in medaka (Murakami et al., 2017).

This concurrent development of technologies in zebrafish and medaka highlights the reciprocal nature of exchanging tools and methods between these model systems, facilitating the advancement of scientific research. Besides mutagenesis, genetic manipulation via stable transgenesis was first demonstrated in medaka (Ozato et al., 1986). Later, Kawakami and Shima (1999) identified the Tol2 transposon system in Medaka and adapted this system in zebrafish for transgenesis which revolutionized the field. To better recapitulate the endogenous gene expression patterns, insertion of BAC constructs by Tol2 transposase has been widely used in generating zebrafish reporter lines (Suster et al., 2011). Despite the fact that Tol2 was originally identified in medaka, it is more efficient in zebrafish (Kawakami, 2007). Therefore, another method for insertional transgenesis was developed in fish models using I-SceI meganuclease and greatly facilitated transgenesis in medaka (Thermes et al., 2002; Grabher and Wittbrodt, 2008).

As applications, spatial (e.g., specific tissue) and temporal regulation of ectopic gene expression can be achieved by combining transgenic lines generated by the above-mentioned methods (Tables 4, 5). For example, the Cre/lox system is widely used to perform reverse genetics, ectopic gene expression, and lineage tracing experiments in multicellular organisms, including zebrafish (Felker and Mosimann, 2016). To achieve spatial-temporal control, the Cre recombinase gene is fused with a human estrogen receptor (ER) domain and expressed under tissue-specific promoter, resulting in recombination of lox sequences in specific tissue upon estrogen stimulation (Metzger et al., 1995; Feil et al., 1996). Since then, there have been growing numbers of tissue-specific Cre lines generated in zebrafish (Jungke et al., 2013, 2015). Within the scope of tissue repair and regeneration, we have summarized a list of Cre driver and switch lines applied in previously described studies (Table 5). Additionally, robust co-expression of multiple genes following switch cassette can be accomplished by placing polycistronic ORFs separated by short viral 2A peptides (Provost et al., 2007). In contrast to zebrafish, there is way fewer medaka Cre/lox transgenic lines that we found and summarized with respect to the comprehensive list in zebrafish with available databases like CreZoo (Jungke et al., 2013, 2015). Fortunately, the advances of CRISPR technology allow genetic manipulation in both fish models and generate powerful tools for fate mapping and functional experiments (Liu et al., 2019). Overall, our review encompasses a portion of tools and strategies commonly used in zebrafish and medaka, which were extensively reviewed elsewhere for medaka (Kirchmaier et al., 2015) and zebrafish (Sassen and Köster, 2015), respectively.

\section{Delivery of Pharmaceutical Reagents}

Since zebrafish and medaka are routinely used for drug screening and validations, developing various routes of pharmaceutic administration is essential (Table 6). As these fish are tiny compared to mice, the development of administration methods requires further optimization to mimic the delivery route in mice.

Intraperitoneal (IP) injection was one of the first delivery methods introduced to deliver reagents in adult zebrafish and is adapted from veterinary practice in bigger fishes (Kinkel et al., 2010). The injection is performed using a $31 \mathrm{G}$ needle with a small injection volume (usually $<10-15 \mu \mathrm{l}$ ) into the abdominal cavity posterior to the pelvic girdle and midline to the pelvic fins in zebrafish (Kinkel et al., 2010). The reagents administrated by IP injection will distribute majorly to the spleen and liver within $72 \mathrm{~h}$ and later into the circulation, making it a favorable method for studying biochemical modulation in 
TABLE 5 | The Cre drivers and switch lines for studying tissue regeneration.

\begin{tabular}{|c|c|c|}
\hline Tissue type & $\begin{array}{l}\text { Zebrafish transgenic } \\
\text { lines (References) }\end{array}$ & $\begin{array}{l}\text { Medaka transgenic } \\
\text { lines (References) }\end{array}$ \\
\hline Cardiomyocytes & $\begin{array}{l}\text { Tg(myl7:creERT2) (Kikuchi } \\
\text { et al., 2010) } \\
\text { Tg(gata4:creERT2) (Kikuchi } \\
\text { et al., 2011a) }\end{array}$ & Not available \\
\hline Skeletal muscles & $\begin{array}{l}\text { Tg(cry:mCherry;- } \\
\text { 1.9mylz2:CreERT2) } \\
\text { (Mukherjee and Liao, 2018) }\end{array}$ & $\begin{array}{l}\text { Tg(myl2::n/sCreCherry) } \\
\text { (TG938, NBRP) }\end{array}$ \\
\hline Endothelial cells & $\begin{array}{l}\text { Tg(fli1a:CreERT2) }{ }^{c n 9} \\
\text { (Sanchez-Iranzo et al., } \\
\text { 2018) }\end{array}$ & Not available \\
\hline Epicardial cells & $\begin{array}{l}\text { Tg(tcf21:CreERT2)pd42Tg } \\
\text { (Kikuchi et al., 2011a) }\end{array}$ & Not available \\
\hline Neuronal cells & $\begin{array}{l}\text { Tg(Cau.tuba1a:CreERT2, } \\
\text { Cau.tuba1a:CFP)mi19/+ } \\
\text { (Ramachandran et al., } \\
\text { 2010b) }\end{array}$ & $\begin{array}{l}\text { Tg(rx2::CreERT2) } \\
\text { (Reinhardt et al., 2015) } \\
\text { Tg(K15:Ert2-Cre) (Seleit } \\
\text { et al., 2017b) } \\
\text { Tg(cndp::CreERT2) } \\
\text { (Becker et al., 2021) }\end{array}$ \\
\hline Macrophages & $\begin{array}{l}\text { Tg(mpeg:Cre) })^{\text {fh506 }} \\
\text { (Roh-Johnson et al., 2017) } \\
\text { Tg(mfap4:iCre:p2A- } \\
\text { tdTomato)xt8 (Walton et al., } \\
\text { 2015) }\end{array}$ & Not available \\
\hline $\begin{array}{l}\text { Fibroblast and } \\
\text { collagen producing } \\
\text { cells }\end{array}$ & $\begin{array}{l}\text { Tg(periostin:CreERT2) } \\
\text { and Tg(wt1a:CreERT2) } \\
\text { (Sanchez-Iranzo et al., } \\
\text { 2018) }\end{array}$ & Not available \\
\hline Bone & $\begin{array}{l}\text { Tg(Ola.Sp7:CreERT2-P2A- } \\
\text { mCherry) } \\
\text { 2011) }\end{array}$ & Not available \\
\hline $\begin{array}{l}\text { Heat-shock } \\
\text { (temporal) }\end{array}$ & $\begin{array}{l}\text { Tg(hsp70l:mCherry, } \\
\text { Cre-ERT2) } \\
\text { et al., 2011) }\end{array}$ & $\begin{array}{l}\text { Gaudi'HspCRE.A (Centanin } \\
\text { et al., 2014) }\end{array}$ \\
\hline $\begin{array}{l}\text { Pan-cells switch } \\
\text { type }\end{array}$ & $\begin{array}{l}\text { (ubi:Switch) and } \\
\text { Tg(-3.5ubb:CreErT2, } \\
\text { myl7:EGFP)cz1702 } \\
\text { (Mosimann et al., 2011) } \\
\text { Tg(bactin2:loxp-DsRed- } \\
\text { STOP-loxp-EGFP) (Kikuchi } \\
\text { et al., 2010) }\end{array}$ & $\begin{array}{l}\text { GaudiRSG toolkit } \\
\text { (Centanin et al., 2014) } \\
\text { Tg(Olactb:IoxP-dsR2- } \\
\text { loxP-EGFP) (Yoshinari } \\
\text { et al., 2012) }\end{array}$ \\
\hline $\begin{array}{l}\text { Switch ablation } \\
\text { line }\end{array}$ & $\begin{array}{l}\text { Tg(bactin2:IoxP-mCherry- } \\
\text { STOP-loxP-DTA176)pd36 } \\
\text { (Wang J. et al., 2011) }\end{array}$ & Not available \\
\hline
\end{tabular}

zebrafish over multiple injections or an extended period (Ruyra et al., 2014). IP is widely used for systemic administration of drugs, small-molecule inhibitors, nanoparticles, reagents in regeneration studies, including clodronate liposomes for ablating macrophages (de Preux Charles et al., 2016), poly I:C for immune-stimulation in medaka (Lai et al., 2017), mTORinhibitor rapamycin for autophagy inhibition (Chavez et al., 2020), IWR-1-endo for Wnt inhibition (Chen et al., 2009; Zhao et al., 2019), and tamoxifen for Cre-mediated recombination (Hans et al., 2009).

On the other hand, intravenous (IV) injection is effective for drug delivery in mice but has been technically challenging for zebrafish, due to the small vessel diameter and poor vasculature visibility. To improve vessel visibility, transparent casper fishes can be injected intravenously through their cardinal vein described in cancer research in zebrafish (Benjamin and Hynes, 2017). As alternative methods for direct access to the circulation, the intra-cardiac injection has been tested but showed high mortality (White et al., 2008), while the retro-orbital (RO) injection is suitable for delivering both reagents and cells into the blood circulation (Pugach et al., 2009; Simoes et al., 2020).

For more tissue/organ-localized delivery methods, intratissue injections may be applied. For example, intrathoracic (IT) injections were developed in zebrafish to test the effects of exogenous factors on adult heart regeneration, including nanoparticles encapsulated siRNAs (Xiao et al., 2018; Bise and Jazwinska, 2019). Cerebroventricular microinjection (CVMI) was also developed to deliver reagents to the adult zebrafish brain (Kizil and Brand, 2011). Intravitreal injections for the targeted delivery to the vitreous space of the retina (Fimbel et al., 2007) and intraspinal injection to the spinal cord were also developed in zebrafish (Wehner et al., 2018).

In contrast to invasive methods, which sometimes lead to tissue damage and mortality, a straightforward and convenient way for pharmaceutic delivery is immersion/incubation. Although immersion/incubation can be applied to both larvae and adults, it is more costly for incubating adults due to a large amount of reagent needed to reach the same dose. The biodistribution from immersion varies among reagents and different stages. In adults, the reagent is mainly intake through gills and ingestion, then absorbed/digested in the intestine and liver, which resembles oral uptake in the mice model (Ruyra et al., 2014). Examples of incubation experiments include tamoxifen treatment for Cre activation and Erbb2 inhibitor AG1478 in heart regeneration of both zebrafish larvae and adults (de Koning et al., 2015; Gemberling et al., 2015). Incubation of Alk5/4 inhibitor SB431542 has also been used in adult fin (Jaźwińska et al., 2007) and heart (Chablais and Jaźwińska, 2012b) to understand the dynamics of fibrosis in tissue regeneration.

Overall, based on the size and anatomic similarities between zebrafish and medaka, most of these delivery methods (Table 6) can be adapted in medaka and are regularly used in our laboratory as well as in other studies (Maekawa et al., 2016; Lai et al., 2017; Marín-Juez et al., 2019).

\section{Genomics Resources for Zebrafish and Medaka}

Due to the interest in exploring cellular and molecular mechanisms throughout the last few decades, both zebrafish $(\sim 1,412 \mathrm{Mb})$ (Howe et al., 2013) and medaka genome ( $800 \mathrm{Mb}$ ) (Kasahara et al., 2007; Kobayashi and Takeda, 2008) have been sequenced and are publicly available in the databases, including Ensembl for zebrafish ${ }^{5}$ (see footnote 1) and medaka ${ }^{6}$ (Table 7). Like zebrafish, medaka has emerged as one of the most popular and influential animal models to investigate development and disease. At the genomic level, the regenerative capacity of zebrafish might rely on gene regulatory networks, which might be repressed in other non-regenerative

\footnotetext{
${ }^{5}$ http://asia.ensembl.org/Danio_rerio/Info/Index

${ }^{6}$ https://asia.ensembl.org/Oryzias_latipes/Info/Annotation
} 
TABLE 6 | Tutorials/protocols for injury and drug delivery for zebrafish and medaka.

\begin{tabular}{|c|c|c|}
\hline Description & Website & References \\
\hline $\begin{array}{l}\text { Dissection of different organs from the } \\
\text { Adult Zebrafish }\end{array}$ & Dissection of Organs from the Adult Zebrafish | Protocol (jove.com) & Gupta and Mullins, 2010 \\
\hline Dissection of the Adult Zebrafish Kidney & Dissection of the Adult Zebrafish Kidney | Protocol (jove.com) & Gerlach et al., 2011 \\
\hline $\begin{array}{l}\text { Induction of myocardial infarction in } \\
\text { adult zebrafish using cryoinjury }\end{array}$ & $\begin{array}{l}\text { Induction of Myocardial Infarction in Adult Zebrafish Using Cryoinjury | Protocol } \\
\text { (jove.com) }\end{array}$ & $\begin{array}{l}\text { Chablais and Jaźwińska, } \\
\text { 2012a }\end{array}$ \\
\hline $\begin{array}{l}\text { Brain injury model by stabbing in Adult } \\
\text { Zebrafish }\end{array}$ & $\begin{array}{l}\text { Stab Wound Injury of the Zebrafish Adult Telencephalon: A Method to Investigate } \\
\text { Vertebrate Brain Neurogenesis and Regeneration | Protocol (jove.com) }\end{array}$ & Schmidt et al., 2014 \\
\hline $\begin{array}{l}\text { Spinal cord injury by transection in } \\
\text { larval zebrafish }\end{array}$ & $\begin{array}{l}\text { Spinal Cord Transection in the Larval Zebrafish | Protocol (jove.com) } \\
\text { Zebrafish In Situ Spinal Cord Preparation for Electrophysiological Recordings from } \\
\text { Spinal Sensory and Motor Neurons | Protocol (jove.com) }\end{array}$ & $\begin{array}{l}\text { Briona and Dorsky, 2014; } \\
\text { Moreno et al., } 2017\end{array}$ \\
\hline $\begin{array}{l}\text { Laser-induced retinal injury model in } \\
\text { zebrafish }\end{array}$ & $\begin{array}{l}\text { Müller Glia Cell Activation in a Laser-induced Retinal Degeneration and } \\
\text { Regeneration Model in Zebrafish | Protocol (jove.com) }\end{array}$ & Conedera et al., 2017 \\
\hline $\begin{array}{l}\text { Examining muscle regeneration in } \\
\text { zebrafish models of muscle disease }\end{array}$ & $\begin{array}{l}\text { Examining Muscle Regeneration in Zebrafish Models of Muscle Disease | Protocol } \\
\text { (jove.com) }\end{array}$ & $\begin{array}{l}\text { Au - Montandon et al., } \\
2021\end{array}$ \\
\hline $\begin{array}{l}\text { Hepatocyte-specific ablation in } \\
\text { zebrafish to study biliary-driven liver } \\
\text { regeneration }\end{array}$ & $\begin{array}{l}\text { Hepatocyte-specific Ablation in Zebrafish to Study Biliary-driven Liver Regeneration } \\
\text { | Protocol (jove.com) }\end{array}$ & Choi et al., 2015 \\
\hline Intraperitoneal injection in zebrafish & $\begin{array}{l}\text { Intraperitoneal Injection: A Method of Solution Delivery into the Abdominal Cavity of } \\
\text { an Adult Zebrafish | Protocol (jove.com) }\end{array}$ & Kinkel et al., 2010 \\
\hline $\begin{array}{l}\text { Intrathoracic injection for the study of } \\
\text { adult zebrafish heart }\end{array}$ & Intrathoracic Injection for the Study of Adult Zebrafish Heart | Protocol (jove.com) & Bise and Jazwinska, 2019 \\
\hline Retro-orbital injection in adult zebrafish & Retro-orbital Injection in Adult Zebrafish | Protocol (jove.com) & Pugach et al., 2009 \\
\hline $\begin{array}{l}\text { Nanoparticle-mediated siRNA } \\
\text { gene-silencing in adult zebrafish heart }\end{array}$ & $\begin{array}{l}\text { Nanoparticle-mediated siRNA Gene-silencing in Adult Zebrafish Heart | Protocol } \\
\text { (jove.com) }\end{array}$ & Xiao et al., 2018 \\
\hline $\begin{array}{l}\text { CRISPR/Cas9-generated gene } \\
\text { knockouts in zebrafish }\end{array}$ & $\begin{array}{l}\text { Efficient Production and Identification of CRISPR/Cas9-generated Gene Knockouts } \\
\text { in the Model System Danio rerio | Protocol (jove.com) }\end{array}$ & Sorlien et al., 2018 \\
\hline $\begin{array}{l}\text { Imaging blood vessels and lymphatic } \\
\text { vessels in the zebrafish }\end{array}$ & $\begin{array}{l}\text { Methods in Cell Biology | The Zebrafish - Cellular and Developmental Biology, Part A } \\
\text { Cellular Biology | ScienceDirect.com by Elsevier }\end{array}$ & Jung et al., 2016 \\
\hline $\begin{array}{l}\text { Microinjection of medaka embryos for } \\
\text { use as a model genetic organism }\end{array}$ & $\begin{array}{l}\text { Microinjection of Medaka Embryos for use as a Model Genetic Organism | Protocol } \\
\text { (jove.com) }\end{array}$ & Porazinski et al., 2010b \\
\hline $\begin{array}{l}\text { Dechorionation of medaka embryos } \\
\text { and cell transplantation for the } \\
\text { generation of chimeras }\end{array}$ & $\begin{array}{l}\text { Dechorionation of Medaka Embryos and Cell Transplantation for the Generation of } \\
\text { Chimeras | Protocol (jove.com) }\end{array}$ & Porazinski et al., 2010a \\
\hline $\begin{array}{l}\text { Medaka: Biology, Management, and } \\
\text { Experimental protocols }\end{array}$ & $\begin{array}{l}\text { Volume } 1 \text { and } 2 \\
\text { (https://onlinelibrary.wiley.com/doi/book/10.1002/9781119575399\#) }\end{array}$ & $\begin{array}{l}\text { Kinoshita et al., 2009; } \\
\text { Murata et al., } 2019\end{array}$ \\
\hline
\end{tabular}

animal models (Yang and Kang, 2019). Early findings in zebrafish suggest epigenetic modifications ranging from histone modifications to initiation of enhancer-induced activation of regenerative programs (Kang et al., 2016; Pfefferli and Jaźwińska, 2017). Growing evidence support the compatibility of zebrafish and medaka for comparative transcriptomic analyses (Tena et al., 2014; Lai et al., 2017). Moreover, with the advances of epigenetic profiling, medaka has also been explored for epigenetic changes associated with embryogenesis, development, and evolution (Nakamura et al., 2014; Tena et al., 2014; Ichikawa et al., 2017; Marletaz et al., 2018; Uesaka et al., 2019; Li et al., 2020). These properties may bring medaka as a new teleost model in epigenetics for comparative studies in tissue regeneration.

\section{Hybrid/Chimera Fish and Cell Transplantations}

Among various teleost fishes that come in different shapes and sizes, zebrafish and medaka have a similar developmental process overall. However, medaka shows a slower pace and hatch at 9 days compared to 3 days in zebrafish. Considering the similarities and differences between zebrafish and medaka, inter-species blastula transplantation was explored to study the genetic developmental timing during organogenesis (Hong et al., 2012; Fuhrmann et al., 2020). Generating chimeric organisms named "Zebraka” or "Medrafish" involves cell transplantation at the blastula stage and ectopic formation of chimeric organs like retina from zebrafish donor cells in the medaka host. This approach helps researchers determine the transcriptional dynamics of retinal organogenesis and further state the existence of organ-intrinsic mechanisms independent of the development pace of the host (Fuhrmann et al., 2020). It will be intriguing to consider the differential regenerative capacity of each organ in these hybrid animals. For example, if the heart was contributed by zebrafish donor cells and grows in medaka, would it still be regenerative (and why)? Hybrid animals may help researchers dissect the intrinsic and extrinsic properties of tissue regeneration, and zebrafish and medaka chimeras may provide a unique opportunity for such study. 
TABLE 7 | Resources for zebrafish and medaka research.

\begin{tabular}{|c|c|c|c|}
\hline Fish & Resource & Description & Website and references \\
\hline \multirow[t]{9}{*}{ Zebrafish } & The Zebrafish Information Network (ZFIN) & $\begin{array}{l}\text { Central database of zebrafish } \\
\text { resources, studies and protocols }\end{array}$ & http://zfin.org/ (Ruzicka et al., 2019) \\
\hline & Ensembl: Danio rerio & Genome assembly, GRCz11 & http://asia.ensembl.org/Danio_rerio/Info/Index \\
\hline & zfRegeneration & $\begin{array}{l}\text { Dataset for zebrafish associated } \\
\text { regeneration studies }\end{array}$ & $\begin{array}{l}\text { http://www.zfregeneration.org/ (Nieto-Arellano and } \\
\text { Sanchez-Iranzo, 2019) }\end{array}$ \\
\hline & CreZoo & Database of Zebrafish Cre driver lines & Zebrafish CreZoo (Jungke et al., 2013) \\
\hline & Zebrafish International Resource Center & Zebrafish stock center, United States & https://zebrafish.org/home/guide.php \\
\hline & $\begin{array}{l}\text { European Zebrafish Resource Center } \\
\text { (EZRC) }\end{array}$ & Zebrafish stock center, KIT-Europe & https://www.ezrc.kit.edu/index.php \\
\hline & The Taiwan Zebrafish Core Facility (TZCF) & Core facility for Zebrafish stock & http://www.tzcf-tzenh.org/ (You et al., 2016) \\
\hline & NBRP-Zebrafish & $\begin{array}{l}\text { Japan stock center for zebrafish } \\
\text { resource }\end{array}$ & https://shigen.nig.ac.jp/zebra/index_en.html \\
\hline & China Zebrafish Resource Center (CZRC) & $\begin{array}{l}\text { Zebrafish resources, developing new } \\
\text { lines and technology }\end{array}$ & http://en.zfish.cn/ \\
\hline \multirow[t]{6}{*}{ Medaka } & NBRP medaka & $\begin{array}{l}\text { Central repository and achieve for } \\
\text { medaka resources }\end{array}$ & $\begin{array}{l}\text { https://shigen.nig.ac.jp/medaka/ \penalty- \@M (Sasado } \\
\text { et al., 2010) }\end{array}$ \\
\hline & NBRP strains & Repository for strains and transgenics & https://shigen.nig.ac.jp/medaka/strain/strainTop.jsp \\
\hline & Ensembl: Japanese medaka HdrR & $\begin{array}{l}\text { Gene assembly and gene annotation } \\
\text { (ASM223467v1) }\end{array}$ & http://asia.ensembl.org/Oryzias_latipes/Info/Index \\
\hline & NBRP genome tools & Genome Mapping & http://viewer.shigen.info/medakavw/mapview/ \\
\hline & MEPD & $\begin{array}{l}\text { Gene expression data by in situ } \\
\text { hybridization }\end{array}$ & $\begin{array}{l}\text { http://mepd.cos.uni-heidelberg.de/mepd/ (Alonso-Barba } \\
\text { et al., 2016) }\end{array}$ \\
\hline & mODP & $\begin{array}{l}\text { OMICs data and epigenetic } \\
\text { modification database }\end{array}$ & $\begin{array}{l}\text { http: } \\
\text { //tulab.genetics.ac.cn/modp/\#/Browser?species=medaka } \\
\text { (Li et al., 2020) }\end{array}$ \\
\hline \multirow[t]{2}{*}{ Both Models } & CCTop & CRISPR/Cas9 design tool & $\begin{array}{l}\text { https://cctop.cos.uni-heidelberg.de:8043/index.html } \\
\text { (Stemmer et al., 2015) }\end{array}$ \\
\hline & CRISPRscan & CRISPR/Cas9 design tool & https://www.crisprscan.org/ (Moreno-Mateos et al., 2015) \\
\hline
\end{tabular}

Similar ideas have been exploited in the intra-species blastula transplantation in embryonic and adoptive transfer in adult zebrafish to determine the cellular contribution of specific biological processes (cell-autonomous vs. non-cellautonomous actions). The concept was recently adopted in a heart regeneration study where macrophages were isolated from zebrafish larvae donors and adoptively transferred into adult hosts. Larval macrophages were found to infiltrate the injured hearts and contribute to scar formation by directly secreting collagens in adults (Simoes et al., 2020). Similar strategies may pave the way for future research, in which zebrafish donor cells might be transferred in medaka host or vice-versa and determine the cellular contributions in tissue regeneration.

\section{LIMITATIONS, FUTURE DIRECTIONS, AND CONCLUDING REMARKS}

In this review, we illustrated the concept of comparative study in tissue regeneration and highlighted the examples in zebrafish and medaka models. Zebrafish and medaka are phylogenetically close model organisms compared to animals from different phyla across the animal kingdom yet possess a distinct tissue regeneration capacity. Various tools and techniques commonly used in zebrafish and medaka were summarized here, supporting the unique strength of conducting comparative tissue regeneration research. Nevertheless, we cannot ignore some technical challenges and conceptual oversight that must be addressed or overcome.

On a technical aspect, orthologous gene annotation and identification are critical for inter-species comparisons. The Zebrafish genome has been well annotated and referenced due to a broad research interest with orthologous genes identified and translatable to the mammalian system (Howe et al., 2013). However, the medaka genome is less annotated than zebrafish. The limitation may sometimes be overcome by mapping the medaka genome against zebrafish to identify the orthologous genes. Though this might not be the optimal approach for genome annotation, it is currently the most feasible method to translate genetic information to the zebrafish and the mammalian context. Using such a method, Lai et al. (2017) have identified more than 15,000 orthologous genes across zebrafish and medaka in a comparative transcriptomic analysis.

On a conceptual aspect, it is still unclear how the trait of regeneration evolved along with all the other physiological and anatomical differences among species under the pressure of natural selection. Following the same logic, the similarities and differences between zebrafish and medaka might not necessarily associate with their regenerative capacity, which 
confounds the causal relationship between candidate factors and tissue regeneration. In addition, the concept of zebrafish and medaka comparison is based on the existence of conserved mechanisms underly tissue regeneration between these organisms, which might not be accurate, and the same blindside also exists for other inter-species comparisons. In light of this, potential factors identified from the comparative analyses must be further examined in both gainof-function and loss-of-function experiments to determine their exact role in tissue regeneration. Comparative studies in the heart and retina provide nice examples of such practice (Lai et al., 2017; Lust and Wittbrodt, 2018). To gain translational opportunities, candidate factors (biological processes/signaling pathways) should be further tested to regulate regenerative capacity in mammals. Overall, the comparative approach in different models may gain basic knowledge in tissue regeneration and hint at new therapeutic strategies.

Since the pioneer studies in zebrafish tissue regeneration, broad interests have been invested in the regenerative program and other mechanistic insights underlying various tissue regeneration, hoping that the knowledge will hint or translate into therapeutics in regenerative medicine. Although the medaka has only begun to enter the stage of regenerative biology, their similar characteristics to zebrafish and abundant resources as a model animal draw more and more attention for inter-species and inter-organ comparisons in tissue regeneration and await further exploration.

\section{REFERENCES}

Adolf, B., Chapouton, P., Lam, C. S., Topp, S., Tannhauser, B., Strahle, U., et al. (2006). Conserved and acquired features of adult neurogenesis in the zebrafish telencephalon. Dev. Biol. 295, 278-293. doi: 10.1016/j.ydbio.2006.03.023

Aghaallaei, N., Bajoghli, B., Schwarz, H., Schorpp, M., and Boehm, T. (2010). Characterization of mononuclear phagocytic cells in medaka fish transgenic for a cxcr3a:gfp reporter. Proc. Natl. Acad. Sci. U.S.A. 107, 18079-18084. doi: 10.1073/pnas. 1000467107

Agrawal, A. A., Conner, J. K., and Rasmann, S. (2010). “Tradeoffs and negative correlations in evolutionary ecology," in Evolution Since Darwin: The First, eds M. A. Bell, W. F. Eanes, D. J. Futuyma, and J. S. Levinton (Sunderland, MA: Sinauer Associates), 243-268.

Alibardi, L., and Toni, M. (2005). Wound keratins in the regenerating epidermis of lizard suggest that the wound reaction is similar in the tail and limb. J. Exp. Zool. A. Comp. Exp. Biol. 303, 845-860. doi: 10.1002/jez.a.213

Alonso-Barba, J. I., Rahman, R. U., Wittbrodt, J., and Mateo, J. L. (2016). MEPD: medaka expression pattern database, genes and more. Nucleic Acids Res. 44, D819-D821. doi: 10.1093/nar/gkv1029

Alunni, A., Hermel, J. M., Heuze, A., Bourrat, F., Jamen, F., and Joly, J. S. (2010). Evidence for neural stem cells in the medaka optic tectum proliferation zones. Dev. Neurobiol. 70, 693-713. doi: 10.1002/dneu.20799

Ansai, S., Inohaya, K., Yoshiura, Y., Schartl, M., Uemura, N., Takahashi, R., et al. (2014). Design, evaluation, and screening methods for efficient targeted mutagenesis with transcription activator-like effector nucleases in medaka. Dev. Growth Differ. 56, 98-107. doi: 10.1111/dgd.12104

Ansai, S., and Kinoshita, M. (2014). Targeted mutagenesis using CRISPR/Cas system in medaka. Biol. Open 3, 362-371. doi: 10.1242/bio.20148177

Ansai, S., Ochiai, H., Kanie, Y., Kamei, Y., Gou, Y., Kitano, T., et al. (2012). Targeted disruption of exogenous EGFP gene in medaka using zinc-finger nucleases. Dev. Growth Differ. 54, 546-556. doi: 10.1111/j.1440-169X.2012.01357.x

\section{AUTHOR CONTRIBUTIONS}

KC, SL, and S-LL contributed to the conception, writing and revision of the manuscript. KC drafted the manuscript and prepared the tables and figures. S-LL reviewed, edited, and oversaw the manuscript preparation. All the authors read and approved the submitted version.

\section{FUNDING}

The research in the S-LL group was supported by the Ministry of Science and Technology (MOST 108-2320-B-001-032-MY2), the IBMS/Academia Sinica (IBMS-CRC108-P03), and the Grand Challenge Project, Academia Sinica (AS-GC-110-L06) in Taiwan. $\mathrm{KC}$ is the recipient of the Academia Sinica-Taiwan International Graduate Program (AS-TIGP) Research Progress Fellowship.

\section{ACKNOWLEDGMENTS}

We thank Tsung-Hung Hung from the Medical Art Room, IBMS for the artwork, and I-Ting Lin, Khai-Lone Lim, WeiHan Lang, and Ke-Hsuan Wei for their critical comments and suggestions during the manuscript preparation. We apologize to our colleagues whose articles we could not cite due to space limitations. We also thank the reviewers' time and efforts during the manuscript revision.

Ansai, S., Sakuma, T., Yamamoto, T., Ariga, H., Uemura, N., Takahashi, R., et al. (2013). Efficient targeted mutagenesis in medaka using custom-designed transcription activator-like effector nucleases. Genetics 193, 739-749. doi: 10. 1534/genetics.112.147645

Asakawa, K., and Kawakami, K. (2008). Targeted gene expression by the Gal4-UAS system in zebrafish. Dev. Growth Differ. 50, 391-399. doi: 10.1111/j.1440-169X. 2008.01044.x

Au - Montandon, M., Au - Currie, P. D., and Au - Ruparelia, A. A. (2021). Examining muscle regeneration in Zebrafish Models of Muscle Disease. J. Vis. Exp. 167:e62071. doi: 10.3791/62071

Aurora, A. B., Porrello, E. R., Tan, W., Mahmoud, A. I., Hill, J. A., Bassel-Duby, R., et al. (2014). Macrophages are required for neonatal heart regeneration. J. Clin. Invest. 124, 1382-1392. doi: 10.1172/JCI72181

Bajoghli, B., Aghaallaei, N., Hess, I., Rode, I., Netuschil, N., Tay, B. H., et al. (2009). Evolution of genetic networks underlying the emergence of thymopoiesis in vertebrates. Cell 138, 186-197. doi: 10.1016/j.cell.2009. 04.017

Bajoghli, B., Dick, A. M., Claasen, A., Doll, L., and Aghaallaei, N. (2019). Zebrafish and Medaka: two Teleost Models of T-Cell and Thymic Development. Int. J. Mol. Sci. 20:4179. doi: 10.3390/ijms20174179

Bajoghli, B., Kuri, P., Inoue, D., Aghaallaei, N., Hanelt, M., Thumberger, T., et al. (2015). Noninvasive in toto imaging of the thymus reveals heterogeneous migratory behavior of developing T cells. J. Immunol. 195, 2177-2186. doi: 10.4049/jimmunol.1500361

Becker, C., Lust, K., and Wittbrodt, J. (2021). Igf signaling couples retina growth with body growth by modulating progenitor cell division. Development 148:dev199133. doi: 10.1242/dev.199133

Becker, T., and Becker, C. G. (2001). Regenerating descending axons preferentially reroute to the gray matter in the presence of a general macrophage/microglial reaction caudal to a spinal transection in adult zebrafish. J. Comp. Neurol. 433, 131-147. doi: 10.1002/cne.1131 
Becker, T., Wullimann, M. F., Becker, C. G., Bernhardt, R. R., and Schachner, M. (1997). Axonal regrowth after spinal cord transection in adult zebrafish. J. Comp. Neurol. 377, 577-595. doi: 10.1002/(sici)1096-9861(19970127)377: 4\&lt;577::aid-cne8\&gt;3.0.co;2-\#

Bedell, V. M., Wang, Y., Campbell, J. M., Poshusta, T. L., Starker, C. G., Krug, R. G. II, et al. (2012). In vivo genome editing using a high-efficiency TALEN system. Nature 491, 114-118.

Beffagna, G. (2019). Zebrafish as a smart model to understand regeneration after heart injury: how fish could help humans. Front. Cardiovasc. Med. 6:107. doi: $10.3389 /$ fcvm.2019.00107

Bely, A. E. (2010). Evolutionary loss of animal regeneration: pattern and process. Integr. Comp. Biol. 50, 515-527. doi: 10.1093/icb/icq118

Bely, A. E., and Nyberg, K. G. (2010). Evolution of animal regeneration: reemergence of a field. Trends Ecol. Evol. 25, 161-170. doi: 10.1016/j.tree.2009. 08.005

Benjamin, D. C., and Hynes, R. O. (2017). Intravital imaging of metastasis in adult Zebrafish. BMC Cancer 17:660. doi: 10.1186/s12885-017-3647-0

Bensimon-Brito, A., Ramkumar, S., Boezio, G. L., Guenther, S., Kuenne, C., Helker, C. S., et al. (2020). TGF- $\beta$ signaling promotes tissue formation during cardiac valve regeneration in adult zebrafish. Dev. Cell 52, 9-20.e7. doi: 10.1016/j.devcel. 2019.10.027

Bergmann, O., Zdunek, S., Felker, A., Salehpour, M., Alkass, K., Bernard, S., et al. (2015). Dynamics of cell generation and turnover in the human heart. Cell 161, 1566-1575. doi: 10.1016/j.cell.2015.05.026

Bernardo, J., and Agosta, S. J. (2005). Evolutionary implications of hierarchical impacts of nonlethal injury on reproduction, including maternal effects. Biol. J. Linn. Soc. 86, 309-331.

Bernstein, J. J. (1964). Relation of spinal cord regeneration to age in adult goldfish. Exp. Neurol. 9, 161-174. doi: 10.1016/0014-4886(64)90014-7

Bernut, A., Herrmann, J. L., Kissa, K., Dubremetz, J. F., Gaillard, J. L., Lutfalla, G., et al. (2014). Mycobacterium abscessus cording prevents phagocytosis and promotes abscess formation. Proc. Natl. Acad. Sci. U.S.A. 111, E943-E952. doi: 10.1073/pnas.1321390111

Bertrand, J. Y., Chi, N. C., Santoso, B., Teng, S., Stainier, D. Y., and Traver, D. (2010). Haematopoietic stem cells derive directly from aortic endothelium during development. Nature 464, 108-111. doi: 10.1038/nature08738

Bertrand, J. Y., Kim, A. D., Teng, S., and Traver, D. (2008). CD41+ cmyb+ precursors colonize the zebrafish pronephros by a novel migration route to initiate adult hematopoiesis. Development 135, 1853-1862. doi: 10.1242/dev. 015297

Bevan, L., Lim, Z. W., Venkatesh, B., Riley, P. R., Martin, P., and Richardson, R. J. (2020). Specific macrophage populations promote both cardiac scar deposition and subsequent resolution in adult zebrafish. Cardiovasc. Res. 116, 1357-1371. doi: $10.1093 / \mathrm{cvr} / \mathrm{cvz} 221$

Bise, T., and Jazwinska, A. (2019). Intrathoracic Injection for the Study of Adult Zebrafish Heart. J. Vis. Exp. 147:e59724. doi: 10.3791/59724

Bollig, F., Perner, B., Besenbeck, B., Kothe, S., Ebert, C., Taudien, S., et al. (2009). A highly conserved retinoic acid responsive element controls wtla expression in the zebrafish pronephros. Development 136, 2883-2892. doi: 10.1242/dev. 031773

Briona, L. K., and Dorsky, R. I. (2014). Spinal cord transection in the larval zebrafish. J. Vis. Exp. 87:51479. doi: 10.3791/51479

Brockes, J. P., Kumar, A., and Velloso, C. P. (2001). Regeneration as an evolutionary variable. J. Anat. 199(Pt 1-2), 3-11. doi: 10.1046/j.1469-7580.2001.199 10003.x

Broussonet, M. (1786). Observations sur la régénérations de quelques parties du corps des poissons. Hist. Acad. R. Des. Sci. 105, 625-641.

Broussonet, M. (1789). Memoir on the Regeneration of Certain Parts of the Bodies of Fishes. (London: Printed for the Proprietors and Sold by C. Forster), 111-113.

Burg, L., Palmer, N., Kikhi, K., Miroshnik, E. S., Rueckert, H., Gaddy, E., et al. (2018). Conditional mutagenesis by oligonucleotide-mediated integration of loxP sites in zebrafish. PLoS Genet. 14:e1007754. doi: 10.1371/journal.pgen. 1007754

Bussmann, J., and Schulte-Merker, S. (2011). Rapid BAC selection for tol2mediated transgenesis in zebrafish. Development 138, 4327-4332. doi: 10.1242/ dev.068080

Caldwell, L. J., Davies, N. O., Cavone, L., Mysiak, K. S., Semenova, S. A., Panula, P., et al. (2019). Regeneration of Dopaminergic Neurons in Adult Zebrafish depends on immune system activation and differs for distinct populations. J. Neurosci. 39, 4694-4713. doi: 10.1523/JNEUROSCI.2706-18.2019

Cano-Martinez, A., Vargas-Gonzalez, A., Guarner-Lans, V., Prado-Zayago, E., Leon-Oleda, M., and Nieto-Lima, B. (2010). Functional and structural regeneration in the axolotl heart (Ambystoma mexicanum) after partial ventricular amputation. Arch. Cardiol. Mex. 80, 79-86.

Cao, J., and Poss, K. D. (2018). The epicardium as a hub for heart regeneration. Nat. Rev. Cardiol. 15, 631-647. doi: 10.1038/s41569-018-0046-4

Carl, M., Loosli, F., and Wittbrodt, J. (2002). Six3 inactivation reveals its essential role for the formation and patterning of the vertebrate eye. Development 129 , 4057-4063.

Centanin, L., Ander, J. J., Hoeckendorf, B., Lust, K., Kellner, T., Kraemer, I., et al. (2014). Exclusive multipotency and preferential asymmetric divisions in postembryonic neural stem cells of the fish retina. Development 141, 3472-3482. doi: 10.1242/dev.109892

Centanin, L., Hoeckendorf, B., and Wittbrodt, J. (2011). Fate restriction and multipotency in retinal stem cells. Cell Stem Cell 9, 553-562. doi: 10.1016/j.stem. 2011.11.004

Chablais, F., and Jaźwińska, A. (2012a). Induction of myocardial infarction in adult zebrafish using cryoinjury. J. Vis. Exp. 62:3666. doi: 10.3791/3666

Chablais, F., and Jaźwińska, A. (2012b). The regenerative capacity of the zebrafish heart is dependent on TGF $\beta$ signaling. Development 139, 1921-1930. doi: 10. 1242/dev.078543

Chablais, F., Veit, J., Rainer, G., and Jaźwińska, A. (2011). The zebrafish heart regenerates after cryoinjury-induced myocardial infarction. BMC Dev. Biol. 11:21. doi: 10.1186/1471-213X-11-21

Chassot, B., Pury, D., and Jazwinska, A. (2016). Zebrafish fin regeneration after cryoinjury-induced tissue damage. Biol. Open 5, 819-828. doi: 10.1242/bio. 016865

Chatani, M., Takano, Y., and Kudo, A. (2011). Osteoclasts in bone modeling, as revealed by in vivo imaging, are essential for organogenesis in fish. Dev. Biol. 360, 96-109. doi: 10.1016/j.ydbio.2011.09.013

Chavez, M. N., Morales, R. A., Lopez-Crisosto, C., Roa, J. C., Allende, M. L., and Lavandero, S. (2020). Autophagy activation in Zebrafish heart regeneration. Sci. Rep. 10:2191. doi: 10.1038/s41598-020-59106-z

Chen, B., Dodge, M. E., Tang, W., Lu, J., Ma, Z., Fan, C. W., et al. (2009). Small molecule-mediated disruption of Wnt-dependent signaling in tissue regeneration and cancer. Nat. Chem. Biol. 5, 100-107. doi: 10.1038/nchembio. 137

Chen, C. F., Chu, C. Y., Chen, T. H., Lee, S. J., Shen, C. N., and Hsiao, C. D. (2011). Establishment of a transgenic zebrafish line for superficial skin ablation and functional validation of apoptosis modulators in vivo. PLoS One 6:e20654. doi: 10.1371/journal.pone.0020654

Chen, W. C., Wang, Z., Missinato, M. A., Park, D. W., Long, D. W., Liu, H. J., et al. (2016). Decellularized zebrafish cardiac extracellular matrix induces mammalian heart regeneration. Sci. Adv. 2:e1600844. doi: 10.1126/sciadv. 1600844

Childs, S., Chen, J. N., Garrity, D. M., and Fishman, M. C. (2002). Patterning of angiogenesis in the zebrafish embryo. Development 129, 973-982.

Choi, T.-Y., Khaliq, M., Ko, S., So, J., and Shin, D. (2015). Hepatocyte-specific ablation in zebrafish to study biliary-driven liver regeneration. J. Vis. Exp. 99:e52785. doi: 10.3791/52785

Chou, C.-Y., Horng, L.-S., and Tsai, H.-J. (2001). Uniform GFP-expression in transgenic medaka (Oryzias latipes) at the F0 generation. Transgenic Res. 10, 303-315. doi: 10.1023/a:1016671513425

Collery, R. F., Volberding, P. J., Bostrom, J. R., Link, B. A., and Besharse, J. C. (2016). Loss of Zebrafish Mfrp causes nanophthalmia, hyperopia, and accumulation of subretinal macrophages. Invest. Ophthalmol. Vis. Sci. 57, 68056814. doi: 10.1167/iovs.16-19593

Conedera, F. M., Arendt, P., Trepp, C., Tschopp, M., and Enzmann, V. (2017). Muller Glia cell activation in a laser-induced retinal degeneration and regeneration model in Zebrafish. J. Vis. Exp. 128:e56249. doi: 10.3791/56249

Cox, A. G., Saunders, D. C., Kelsey, P. B. Jr., Conway, A. A., Tesmenitsky, Y., Marchini, J. F., et al. (2014). S-nitrosothiol signaling regulates liver development and improves outcome following toxic liver injury. Cell Rep. 6, 56-69. doi: 10.1016/j.celrep.2013.12.007

Crespo, C. L., Vernieri, C., Keller, P. J., Garre, M., Bender, J. R., Wittbrodt, J., et al. (2014). The PAR complex controls the spatiotemporal dynamics of F-actin 
and the MTOC in directionally migrating leukocytes. J. Cell Sci. 127(Pt 20), 4381-4395. doi: 10.1242/jcs. 146217

Crippa, S., Nemir, M., Ounzain, S., Ibberson, M., Berthonneche, C., Sarre, A., et al. (2016). Comparative transcriptome profiling of the injured zebrafish and mouse hearts identifies miRNA-dependent repair pathways. Cardiovasc. Res. 110, 73-84. doi: 10.1093/cvr/cvw031

Cruz, I. A., Kappedal, R., Mackenzie, S. M., Hailey, D. W., Hoffman, T. L., Schilling, T. F., et al. (2015). Robust regeneration of adult zebrafish lateral line hair cells reflects continued precursor pool maintenance. Dev. Biol. 402, 229-238. doi: 10.1016/j.ydbio.2015.03.019

Cuervo, R., Hernandez-Martinez, R., Chimal-Monroy, J., Merchant-Larios, H., and Covarrubias, L. (2012). Full regeneration of the tribasal Polypterus fin. Proc. Natl. Acad. Sci. U.S.A. 109, 3838-3843. doi: 10.1073/pnas.100661 9109

Curado, S., Anderson, R. M., Jungblut, B., Mumm, J., Schroeter, E., and Stainier, D. Y. (2007). Conditional targeted cell ablation in zebrafish: a new tool for regeneration studies. Dev. Dyn. 236, 1025-1035. doi: 10.1002/dvdy.21100

Dambroise, E., Simion, M., Bourquard, T., Bouffard, S., Rizzi, B., Jaszczyszyn, Y., et al. (2017). Postembryonic fish brain proliferation zones exhibit neuroepithelial-type gene expression profile. Stem Cells 35, 1505-1518. doi: $10.1002 /$ stem. 2588

Daponte, V., Tylzanowski, P., and Forlino, A. (2021). Appendage Regeneration in Vertebrates: What Makes This Possible? Cells 10:242. doi: 10.3390/ cells10020242

Darehzereshki, A., Rubin, N., Gamba, L., Kim, J., Fraser, J., Huang, Y., et al. (2015). Differential regenerative capacity of neonatal mouse hearts after cryoinjury. Dev. Biol. 399, 91-99. doi: 10.1016/j.ydbio.2014.12.018

Darnet, S., Dragalzew, A. C., Amaral, D. B., Sousa, J. F., Thompson, A. W., Cass, A. N., et al. (2019). Deep evolutionary origin of limb and fin regeneration. Proc. Natl. Acad. Sci. U.S.A. 116, 15106-15115. doi: 10.1073/pnas. 1900475116

Dasyani, M., Tan, W. H., Sundaram, S., Imangali, N., Centanin, L., Wittbrodt, J., et al. (2019). Lineage tracing of col10al cells identifies distinct progenitor populations for osteoblasts and joint cells in the regenerating fin of medaka (Oryzias latipes). Dev. Biol. 455, 85-99. doi: 10.1016/j.ydbio.2019.07.012

Davidson, A. E., Balciunas, D., Mohn, D., Shaffer, J., Hermanson, S., Sivasubbu, S., et al. (2003). Efficient gene delivery and gene expression in zebrafish using the Sleeping Beauty transposon. Dev. Biol. 263, 191-202. doi: 10.1016/j.ydbio.2003. 07.013

de Koning, C., Beekhuijzen, M., Tobor-Kaplon, M., de Vries-Buitenweg, S., Schoutsen, D., Leeijen, N., et al. (2015). Visualizing Compound Distribution during Zebrafish Embryo Development: the Effects of Lipophilicity and DMSO. Birth Defects Res. B. Dev. Reprod. Toxicol. 104, 253-272. doi: 10.1002/bdrb. 21166

de Preux Charles, A. S., Bise, T., Baier, F., Marro, J., and Jazwinska, A. (2016). Distinct effects of inflammation on preconditioning and regeneration of the adult zebrafish heart. Open Biol. 6:160102. doi: 10.1098/rsob.160102

Deguchi, T., Fujimori, K. E., Kawasaki, T., Maruyama, K., and Yuba, S. (2012), In vivo visualization of the lymphatic vessels in pFLT4-EGFP transgenic medaka. Genesis 50, 625-634. doi: 10.1002/dvg.22018

DeLaurier, A., Eames, B. F., Blanco-Sanchez, B., Peng, G., He, X., Swartz, M. E., et al. (2010). Zebrafish sp7:EGFP: a transgenic for studying otic vesicle formation, skeletogenesis, and bone regeneration. Genesis 48, 505-511. doi: 10.1002/dvg.20639

DiCicco, R. M., Bell, B. A., Kaul, C., Hollyfield, J. G., Anand-Apte, B., Perkins, B. D., et al. (2014). Retinal regeneration following OCT-guided laser injury in zebrafish. Invest. Ophthalmol. Vis. Sci. 55, 6281-6288. doi: 10.1167/iovs.1414724

Diep, C. Q., Ma, D., Deo, R. C., Holm, T. M., Naylor, R. W., Arora, N., et al. (2011). Identification of adult nephron progenitors capable of kidney regeneration in zebrafish. Nature 470, 95-100. doi: 10.1038/nature09669

Diotel, N., Lubke, L., Strahle, U., and Rastegar, S. (2020). Common and Distinct Features of Adult Neurogenesis and Regeneration in the Telencephalon of Zebrafish and Mammals. Front. Neurosci. 14:568930. doi: 10.3389/fnins.2020. 568930

Doyon, Y., McCammon, J. M., Miller, J. C., Faraji, F., Ngo, C., Katibah, G. E., et al. (2008). Heritable targeted gene disruption in zebrafish using designed zinc-finger nucleases. Nat. Biotechnol. 26, 702-708. doi: 10.1038/nbt1409
Driever, W., Solnica-Krezel, L., Schier, A. F., Neuhauss, S. C., Malicki, J., Stemple, D. L., et al. (1996). A genetic screen for mutations affecting embryogenesis in zebrafish. Development 123, 37-46.

Du, S. J., and Dienhart, M. (2001). Zebrafish tiggy-winkle hedgehog promoter directs notochord and floor plate green fluorescence protein expression in transgenic zebrafish embryos. Dev. Dyn. 222, 655-666. doi: 10.1002/dvdy.1219

Dwaraka, V. B., and Voss, S. R. (2021). Towards comparative analyses of salamander limb regeneration. J. Exp. Zool. B Mol. Dev. Evol. 336, 129-144. doi: $10.1002 /$ jez.b.22902

Dyck, P. K. V., Hockaden, N., Nelson, E. C., Koch, A. R., Hester, K. L., Pillai, N., et al. (2020). Cauterization as a simple method for regeneration studies in the zebrafish heart. J. Cardiovasc. Dev. Dis. 7:41. doi: 10.3390/jcdd7040041

Elbaz, I., Yelin-Bekerman, L., Nicenboim, J., Vatine, G., and Appelbaum, L. (2012). Genetic ablation of hypocretin neurons alters behavioral state transitions in zebrafish. J. Neurosci. 32, 12961-12972. doi: 10.1523/JNEUROSCI.1284-12. 2012

Elchaninov, A., Sukhikh, G., and Fatkhudinov, T. (2021). Evolution of regeneration in animals: a tangled story. Front. Ecol. Evol. 9:621686. doi: 10.3389/fevo.2021. 621686

Elhelaly, W. M., Lam, N. T., Hamza, M., Xia, S., and Sadek, H. A. (2016). Redox regulation of heart regeneration: an evolutionary Tradeoff. Front. Cell Dev. Biol. 4:137. doi: $10.3389 /$ fcell.2016.00137

Ellett, F., Pase, L., Hayman, J., Andrianopoulos, A., and Lieschke, G. (2011). mpeg1 promoter transgenes direct macrophage-lineage expression in zebrafish. Blood 117, E49-E56. doi: 10.1182/blood-2010-10-314120

Emelyanov, A., Gao, Y., Naqvi, N. I., and Parinov, S. (2006). Trans-kingdom transposition of the maize dissociation element. Genetics 174, 1095-1104. doi: 10.1534/genetics.106.061184

Eschenhagen, T., Bolli, R., Braun, T., Field, L. J., Fleischmann, B. K., Frisén, J., et al. (2017). Cardiomyocyte regeneration: a consensus statement. Circulation 136, 680-686. doi: 10.1161/circulationaha.117.029343

Fadool, J. M. (2003). Development of a rod photoreceptor mosaic revealed in transgenic zebrafish. Dev. Biol. 258, 277-290. doi: 10.1016/s0012-1606(03) 00125-8

Feil, R., Brocard, J., Mascrez, B., LeMeur, M., Metzger, D., and Chambon, P. (1996). Ligand-activated site-specific recombination in mice. Proc. Natl. Acad. Sci. U.S.A. 93, 10887-10890. doi: 10.1073/pnas.93.20.10887

Felker, A., and Mosimann, C. (2016). "Chapter 11 - Contemporary zebrafish transgenesis with Tol2 and application for Cre/lox recombination experiments," in Methods in Cell Biology, eds H. William Detrich, M. Westerfield, and L. I. Zon (Amsterdam: Elsevier), 219-244. doi: 10.1016/bs.mcb.2016.01.009

Ferguson, H., Kongtorp, R., Taksdal, T., Graham, D., and Falk, K. (2005). An outbreak of disease resembling heart and skeletal muscle inflammation in Scottish farmed salmon, Salmo salar L., with observations on myocardial regeneration. J. Fish Dis. 28, 119-123. doi: 10.1111/j.1365-2761.2004.00602.x

Fimbel, S. M., Montgomery, J. E., Burket, C. T., and Hyde, D. R. (2007). Regeneration of inner retinal neurons after intravitreal injection of ouabain in zebrafish. J. Neurosci. 27, 1712-1724. doi: 10.1523/JNEUROSCI.5317-06.2007

Fox, S. F., and McCoy, J. K. (2000). The effects of tail loss on survival, growth, reproduction, and sex ratio of offspring in the lizard Uta stansburiana in the field. Oecologia 122, 327-334. doi: 10.1007/s004420050038

Froschauer, A., Sprott, D., Gerwien, F., Henker, Y., Rudolph, F., Pfennig, F., et al. (2012). Effective generation of transgenic reporter and gene trap lines of the medaka (Oryzias latipes) using the Ac/Ds transposon system. Transgenic Res. 21, 149-162. doi: 10.1007/s11248-011-9514-x

Fuhrmann, J. F., Buono, L., Adelmann, L., Martinez-Morales, J. R., and Centanin, L. (2020). Genetic developmental timing revealed by inter-species transplantations in fish. Development 147:dev192500. doi: 10.1242/dev.192500

Furutani-Seiki, M., Sasado, T., Morinaga, C., Suwa, H., Niwa, K., Yoda, H., et al. (2004). A systematic genome-wide screen for mutations affecting organogenesis in Medaka, Oryzias latipes. Mech. Dev. 121, 647-658. doi: 10.1016/j.mod.2004. 04.016

Furutani-Seiki, M., and Wittbrodt, J. (2004). Medaka and zebrafish, an evolutionary twin study. Mech. Dev. 121, 629-637. doi: 10.1016/j.mod.2004.05.010

Galis, F., Wagner, G. P., and Jockusch, E. L. (2003). Why is limb regeneration possible in amphibians but not in reptiles, birds, and mammals? Evol. Dev. 5, 208-220. doi: 10.1046/j.1525-142x.2003.03028.x 
Garcia, J., Bagwell, J., Njaine, B., Norman, J., Levic, D. S., Wopat, S., et al. (2017). Sheath cell invasion and trans-differentiation repair mechanical damage caused by Loss of Caveolae in the Zebrafish Notochord. Curr. Biol. 27, 1982-1989.e3. doi: 10.1016/j.cub.2017.05.035

Gemberling, M., Bailey, T. J., Hyde, D. R., and Poss, K. D. (2013). The zebrafish as a model for complex tissue regeneration. Trends Genet. 29, 611-620. doi: 10.1016/j.tig.2013.07.003

Gemberling, M., Karra, R., Dickson, A. L., and Poss, K. D. (2015). Nrg1 is an injury-induced cardiomyocyte mitogen for the endogenous heart regeneration program in zebrafish. eLife 4:e05871. doi: 10.7554/eLife.05871

Géraudie, J., Brulfert, A., Monnot, M. J., and Ferretti, P. (1994). Teratogenic and morphogenetic effects of retinoic acid on the regenerating pectoral fin in zebrafish. J. Exp. Zool. 269, 12-22.

Gerlach, G. F., Schrader, L. N., and Wingert, R. A. (2011). Dissection of the adult zebrafish kidney. J. Vis. Exp. 54:e2839. doi: 10.3791/2839

Ghosh, S., and Hui, S. P. (2018). Axonal regeneration in zebrafish spinal cord. Regeneration 5, 43-60. doi: 10.1002/reg2.99

Godoy, R., Noble, S., Yoon, K., Anisman, H., and Ekker, M. (2015). Chemogenetic ablation of dopaminergic neurons leads to transient locomotor impairments in zebrafish larvae. J. Neurochem. 135, 249-260. doi: 10.1111/jnc.13214

Godwin, J. W., Pinto, A. R., and Rosenthal, N. A. (2013). Macrophages are required for adult salamander limb regeneration. Proc. Natl. Acad. Sci. U.S.A. 110, 9415-9420. doi: 10.1073/pnas.1300290110

Godwin, J. W., and Rosenthal, N. (2014). Scar-free wound healing and regeneration in amphibians: immunological influences on regenerative success. Differentiation 87, 66-75. doi: 10.1016/j.diff.2014.02.002

Goldman, D. (2014). Muller glial cell reprogramming and retina regeneration. Nat. Rev. Neurosci. 15, 431-442. doi: 10.1038/nrn3723

Goldman, D., Hankin, M., Li, Z., Dai, X., and Ding, J. (2001). Transgenic zebrafish for studying nervous system development and regeneration. Transgenic Res. 10, 21-33. doi: 10.1023/a:1008998832552

Goldstein, A. M., and Fishman, M. C. (1998). Notochord regulates cardiac lineage in zebrafish embryos. Dev. Biol. 201, 247-252. doi: 10.1006/dbio.1998.8976

Gonzalez-Rosa, J. M., Martín, V., Peralta, M., Torres, M., and Mercader, N. (2011). Extensive scar formation and regression during heart regeneration after cryoinjury in zebrafish. Development 138, 1663-1674. doi: 10.1242/dev. 060897

González-Rosa, J. M., Peralta, M., and Mercader, N. (2012). Pan-epicardial lineage tracing reveals that epicardium derived cells give rise to myofibroblasts and perivascular cells during zebrafish heart regeneration. Dev. Biol. 370, 173-186. doi: 10.1016/j.ydbio.2012.07.007

Gordon, K., Schulte, D., Brice, G., Simpson, M. A., Roukens, M. G., Van Impel, A., et al. (2013). Mutation in vascular endothelial growth factor-C, a ligand for vascular endothelial growth factor receptor-3, is associated with autosomal dominant milroy-like primary lymphedema. Circ. Res. 112, 956-960. doi: 10. 1161/CIRCRESAHA.113.300350

Gorsuch, R. A., and Hyde, D. R. (2014). Regulation of muller glial dependent neuronal regeneration in the damaged adult zebrafish retina. Exp. Eye Res. 123, 131-140. doi: 10.1016/j.exer.2013.07.012

Gorsuch, R. A., Lahne, M., Yarka, C. E., Petravick, M. E., Li, J., and Hyde, D. R. (2017). Sox2 regulates muller glia reprogramming and proliferation in the regenerating zebrafish retina via Lin28 and Asclla. Exp. Eye Res. 161, 174-192. doi: 10.1016/j.exer.2017.05.012

Grabher, C., Cliffe, A., Miura, K., Hayflick, J., Pepperkok, R., Rorth, P., et al. (2007). Birth and life of tissue macrophages and their migration in embryogenesis and inflammation in medaka. J. Leukoc. Biol. 81, 263-271. doi: 10.1189/jlb.08 06526

Grabher, C., Henrich, T., Sasado, T., Arenz, A., Wittbrodt, J., and Furutani-Seiki, M. (2003). Transposon-mediated enhancer trapping in medaka. Gene 322, 57-66. doi: 10.1016/j.gene.2003.09.009

Grabher, C., Joly, J.-S., and Wittbrodt, J. (2004). Highly efficient zebrafish transgenesis mediated by the meganuclease I-SceI. Methods Cell Biol. 77, 381-401. doi: 10.1016/s0091-679x(04)77021-1

Grabher, C., and Wittbrodt, J. (2004). Efficient activation of gene expression using a heat-shock inducible Gal4/Vp16-UAS system in medaka. BMC Biotechnol. 4:26. doi: 10.1186/1472-6750-4-26

Grabher, C., and Wittbrodt, J. (2007). Meganuclease and transposon mediated transgenesis in medaka. Genome Biol. 8, (Suppl 1):S10.
Grabher, C., and Wittbrodt, J. (2008). Recent advances in meganuclease-and transposon-mediated transgenesis of medaka and zebrafish. Methods Mol. Biol. 461, 521-539. doi: 10.1007/978-1-60327-483-8_36

Grandel, H., Kaslin, J., Ganz, J., Wenzel, I., and Brand, M. (2006). Neural stem cells and neurogenesis in the adult zebrafish brain: origin, proliferation dynamics, migration and cell fate. Dev. Biol. 295, 263-277. doi: 10.1016/j.ydbio.2006. 03.040

Grandel, H., and Schulte-Merker, S. (1998). The development of the paired fins in the zebrafish (Danio rerio). Mech. Dev. 79, 99-120. doi: 10.1016/s0925-4773(98) 00176-2

Grivas, J., Haag, M., Johnson, A., Manalo, T., Roell, J., Das, T. L., et al. (2014). Cardiac repair and regenerative potential in the goldfish (Carassius auratus) heart. Comp. Biochem. Physiol. C Toxicol. Pharmacol. 163, 14-23. doi: 10.1016/ j.cbpc.2014.02.002

Gulías, P., Guerra-Varela, J., Gonzalez-Aparicio, M., Ricobaraza, A., Vales, A., Gonzalez-Aseguinolaza, G., et al. (2019). Danio rerio as model organism for adenoviral vector evaluation. Genes 10:1053. doi: 10.3390/genes10121053

Gupta, T., and Mullins, M. C. (2010). Dissection of organs from the adult zebrafish. J. Vis. Exp. 37:1717. doi: 10.3791/1717

Hamada, K., Tamaki, K., Sasado, T., Watai, Y., Kani, S., Wakamatsu, Y., et al. (1998). Usefulness of the medaka beta-actin promoter investigated using a mutant GFP reporter gene in transgenic medaka (Oryzias latipes). Mol. Mar. Biol. Biotechnol. 7, 173-180.

Hanovice, N. J., Leach, L. L., Slater, K., Gabriel, A. E., Romanovicz, D., Shao, E., et al. (2019). Regeneration of the zebrafish retinal pigment epithelium after widespread genetic ablation. PLoS Genet. 15:e1007939. doi: 10.1371/journal. pgen.1007939

Hans, S., Freudenreich, D., Geffarth, M., Kaslin, J., Machate, A., and Brand, M. (2011). Generation of a non-leaky heat shock-inducible Cre line for conditional Cre/lox strategies in zebrafish. Dev. Dyn. 240, 108-115. doi: 10.1002/dvdy.22497

Hans, S., Kaslin, J., Freudenreich, D., and Brand, M. (2009). Temporally-controlled site-specific recombination in zebrafish. PLoS One 4:e4640. doi: 10.1371/ journal.pone.0004640

Harris, J. A., Cheng, A. G., Cunningham, L. L., MacDonald, G., Raible, D. W., and Rubel, E. W. (2003). Neomycin-induced hair cell death and rapid regeneration in the lateral line of zebrafish (Danio rerio). J. Assoc. Res. Otolaryngol. 4, 219-234. doi: 10.1007/s10162-002-3022-x

Haubner, B. J., Adamowicz-Brice, M., Khadayate, S., Tiefenthaler, V., Metzler, B., Aitman, T., et al. (2012). Complete cardiac regeneration in a mouse model of myocardial infarction. Aging 4, 966-977. doi: 10.18632/aging. 100526

Haubner, B. J., Schneider, J., Schweigmann, U., Schuetz, T., Dichtl, W., VelikSalchner, C., et al. (2016). Functional recovery of a human neonatal heart after severe myocardial infarction. Circ. Res. 118, 216-221. doi: 10.1161/ CIRCRESAHA.115.307017

Hawkins, M. B., Henke, K., and Harris, M. P. (2021). Latent developmental potential to form limb-like skeletal structures in zebrafish. Cell 184, 899911.e13. doi: 10.1016/j.cell.2021.01.003

Her, G. M., Yeh, Y. H., and Wu, J. L. (2003). 435-bp liver regulatory sequence in the liver fatty acid binding protein (L-FABP) gene is sufficient to modulate liver regional expression in transgenic zebrafish. Dev. Dyn. 227, 347-356. doi: 10.1002/dvdy.10324

Higashijima, S.-I., Okamoto, H., Ueno, N., Hotta, Y., and Eguchi, G. (1997). Highfrequency generation of transgenic zebrafish which reliably express GFP in whole muscles or the whole body by using promoters of zebrafish origin. Dev. Biol. 192, 289-299. doi: 10.1006/dbio.1997.8779

Hilgers, L., and Schwarzer, J. (2019). The natural history of model organisms: the untapped potential of medaka and its wild relatives. eLife 8:e46994. doi: 10.7554/eLife.46994

Hirose, K., Payumo, A. Y., Cutie, S., Hoang, A., Zhang, H., Guyot, R., et al. (2019). Evidence for hormonal control of heart regenerative capacity during endothermy acquisition. Science 364, 184-188. doi: 10.1126/science.aar2038

Hoang, T., Wang, J., Boyd, P., Wang, F., Santiago, C., Jiang, L., et al. (2020). Gene regulatory networks controlling vertebrate retinal regeneration. Science 370:eabb8598. doi: 10.1126/science.abb8598

Hoeppner, L. H., Sinha, S., Wang, Y., Bhattacharya, R., Dutta, S., Gong, X., et al. (2015). RhoC maintains vascular homeostasis by regulating VEGF-induced signaling in endothelial cells. J. Cell Sci. 128, 3556-3568. 
Hogan, B. M., Bos, F. L., Bussmann, J., Witte, M., Chi, N. C., Duckers, H. J., et al. (2009). Ccbel is required for embryonic lymphangiogenesis and venous sprouting. Nat. Genet. 41, 396-398. doi: 10.1038/ng.321

Hong, N., Chen, S., Ge, R., Song, J., Yi, M., and Hong, Y. (2012). Interordinal chimera formation between medaka and zebrafish for analyzing stem cell differentiation. Stem Cells Dev. 21, 2333-2341. doi: 10.1089/scd.2011.0630

Honkoop, H., de Bakker, D. E., Aharonov, A., Kruse, F., Shakked, A., Nguyen, P. D., et al. (2019). Single-cell analysis uncovers that metabolic reprogramming by ErbB2 signaling is essential for cardiomyocyte proliferation in the regenerating heart. eLife 8:e50163. doi: 10.7554/eLife.50163

Hosoya, O., Chung, M., Ansai, S., Takeuchi, H., and Miyaji, M. (2021). A modified Tet-ON system minimizing leaky expression for cell-type specific gene induction in medaka fish. Dev. Growth Differ. 63, 397-405. doi: 10.1111/dgd. 12743

Howe, K., Clark, M. D., Torroja, C. F., Torrance, J., Berthelot, C., Muffato, M., et al. (2013). The zebrafish reference genome sequence and its relationship to the human genome. Nature 496, 498-503. doi: 10.1038/nature 12111

Hruscha, A., Krawitz, P., Rechenberg, A., Heinrich, V., Hecht, J., Haass, C., et al. (2013). Efficient CRISPR/Cas9 genome editing with low off-target effects in zebrafish. Development 140, 4982-4987. doi: 10.1242/dev.099085

Huang, C. J., Tu, C. T., Hsiao, C. D., Hsieh, F. J., and Tsai, H. J. (2003). Germline transmission of a myocardium-specific GFP transgene reveals critical regulatory elements in the cardiac myosin light chain 2 promoter of zebrafish. Dev. Dyn. 228, 30-40. doi: 10.1002/dvdy.10356

Huang, H., Vogel, S. S., Liu, N., Melton, D. A., and Lin, S. (2001). Analysis of pancreatic development in living transgenic zebrafish embryos. Mol. Cell Endocrinol. 177, 117-124. doi: 10.1016/s0303-7207(01)00408-7

Huang, P., Xiao, A., Zhou, M., Zhu, Z., Lin, S., and Zhang, B. (2011). Heritable gene targeting in zebrafish using customized TALENs. Nat. Biotechnol. 29, 699-700. doi: $10.1038 /$ nbt.1939

Hui, S. P., Sheng, D. Z., Sugimoto, K., Gonzalez-Rajal, A., Nakagawa, S., Hesselson, D., et al. (2017). Zebrafish regulatory T cells mediate organ-specific regenerative programs. Dev. Cell 43, 659-672.e5. doi: 10.1016/j.devcel.2017.11.010

Hwang, W. Y., Fu, Y., Reyon, D., Maeder, M. L., Tsai, S. Q., Sander, J. D., et al. (2013). Efficient genome editing in zebrafish using a CRISPR-Cas system. Nat. Biotechnol. 31, 227-229. doi: 10.1038/nbt.2501

Ichikawa, K., Tomioka, S., Suzuki, Y., Nakamura, R., Doi, K., Yoshimura, J., et al. (2017). Centromere evolution and CpG methylation during vertebrate speciation. Nat. Commun. 8:1833. doi: 10.1038/s41467-017-01982-7

Iismaa, S. E., Kaidonis, X., Nicks, A. M., Bogush, N., Kikuchi, K., Naqvi, N., et al. (2018). Comparative regenerative mechanisms across different mammalian tissues. NPJ Regen. Med. 3:6. doi: 10.1038/s41536-018-0044-5

Inoue, D., and Wittbrodt, J. (2011). One for all-a highly efficient and versatile method for fluorescent immunostaining in fish embryos. PLoS One 6:e19713. doi: 10.1371/journal.pone.0019713

Ishikawa, Y. (2000). Medakafish as a model system for vertebrate developmental genetics. Bioessays 22, 487-495. doi: 10.1002/(SICI)1521-1878(200005)22:5\&lt; 487::AID-BIES11\&gt;3.0.CO;2-8

Ito, K., Morioka, M., Kimura, S., Tasaki, M., Inohaya, K., and Kudo, A. (2014). Differential reparative phenotypes between zebrafish and medaka after cardiac injury. Dev. Dyn. 243, 1106-1115. doi: 10.1002/dvdy.24154

Ito, Y., Tanaka, H., Okamoto, H., and Ohshima, T. (2010). Characterization of neural stem cells and their progeny in the adult zebrafish optic tectum. Dev. Biol. 342, 26-38. doi: 10.1016/j.ydbio.2010.03.008

Jaźwińska, A., Badakov, R., and Keating, M. T. (2007). Activin- $\beta$ A signaling is required for zebrafish fin regeneration. Curr. Biol. 17, 1390-1395. doi: 10.1016/ j.cub.2007.07.019

Jaźwińska, A., and Blanchoud, S. (2020). Towards deciphering variations of heart regeneration in fish. Curr. Opin. Physiol. 14, 21-26. doi: 10.1016/j.cophys.2019. 11.007

Jessen, J. R., Jessen, T. N., Vogel, S. S., and Lin, S. (2001). Concurrent expression of recombination activating genes 1 and 2 in zebrafish olfactory sensory neurons. Genesis 29, 156-162. doi: 10.1002/gene.1019

Jessen, J. R., Willett, C. E., and Lin, S. (1999). Artificial chromosome transgenesis reveals long-distance negative regulation of rag1 in zebrafish. Nat. Genet. 23, 15-16. doi: 10.1038/12609
Jh, B. (1947). Regeneration and transplantation of fin rays in the goldfish. Anat. Rec. 99, 648-648.

Jimenez, E., Slevin, C. C., Colón-Cruz, L., and Burgess, S. M. (2021). Vestibular and auditory hair cell regeneration following targeted ablation of hair cells with diphtheria toxin in zebrafish. bioRxiv [Preprint]. doi: 10.1101/2021.06.08. 447587

Jopling, C., Boue, S., and Izpisua Belmonte, J. C. (2011). Dedifferentiation, transdifferentiation and reprogramming: three routes to regeneration. Nat. Rev. Mol. Cell Biol. 12, 79-89. doi: 10.1038/nrm3043

Ju, B., Chong, S. W., He, J., Wang, X., Xu, Y., Wan, H., et al. (2003). Recapitulation of fast skeletal muscle development in zebrafish by transgenic expression of GFP under the mylz2 promoter. Dev. Dyn. 227, 14-26. doi: 10.1002/dvdy.10273

Julier, Z., Park, A. J., Briquez, P. S., and Martino, M. M. (2017). Promoting tissue regeneration by modulating the immune system. Acta Biomater. 53, 13-28. doi: 10.1016/j.actbio.2017.01.056

Jung, H. M., Castranova, D., Swift, M. R., Pham, V. N., Venero Galanternik, M., Isogai, S., et al. (2017). Development of the larval lymphatic system in zebrafish. Development 144, 2070-2081. doi: 10.1242/dev.145755

Jung, H. M., Isogai, S., Kamei, M., Castranova, D., Gore, A. V., and Weinstein, B. M. (2016). Imaging blood vessels and lymphatic vessels in the zebrafish. Methods Cell Biol. 133, 69-103. doi: 10.1016/bs.mcb.2016.03.023

Jung, S., and Kleinheinz, J. (2013). “Angiogenesis-the key to regeneration,” in Regenerative Medicine and Tissue Engineering, ed. J. A. Andrades (London: IntechOpen). doi: 10.5772/55542

Jungke, P., Hammer, J., Hans, S., and Brand, M. (2015). Isolation of novel CreERT2driver lines in zebrafish using an unbiased gene trap approach. PLoS One 10:e0129072. doi: 10.1371/journal.pone.0129072

Jungke, P., Hans, S., and Brand, M. (2013). The zebrafish CreZoo: an easy-tohandle database for novel CreERT2-driver lines. Zebrafish 10, 259-263. doi: 10.1089/zeb.2012.0834

Kanagaraj, P., Chen, J. Y., Skaggs, K., Qadeer, Y., Conner, M., Cutler, N., et al. (2020). Microglia Stimulate Zebrafish Brain Repair Via a Specific Inflammatory Cascade. bioRxiv [Preprint]. doi: 10.1101/2020.10.08.330662

Kang, J., Hu, J., Karra, R., Dickson, A. L., Tornini, V. A., Nachtrab, G., et al. (2016). Modulation of tissue repair by regeneration enhancer elements. Nature 532, 201-206. doi: 10.1038/nature17644

Kasahara, M., Naruse, K., Sasaki, S., Nakatani, Y., Qu, W., Ahsan, B., et al. (2007). The medaka draft genome and insights into vertebrate genome evolution. Nature 447, 714-719. doi: 10.1038/nature05846

Katogi, R., Nakatani, Y., Shin-i, T., Kohara, Y., Inohaya, K., and Kudo, A. (2004). Large-scale analysis of the genes involved in fin regeneration and blastema formation in the medaka, Oryzias latipes. Mech. Dev. 121, 861-872. doi: 10. 1016/j.mod.2004.03.015

Kawakami, K. (2007). Tol2: a versatile gene transfer vector in vertebrates. Genome Biol. 8(Suppl. 1):S7. doi: 10.1186/gb-2007-8-s1-s7

Kawakami, K., and Shima, A. (1999). Identification of the Tol2 transposase of the medaka fish Oryzias latipes that catalyzes excision of a nonautonomous Tol2 element in zebrafish Danio rerio. Gene 240, 239-244. doi: 10.1016/s03781119(99)00444-8

Kawakami, Y., Rodriguez Esteban, C., Raya, M., Kawakami, H., Marti, M., Dubova, I., et al. (2006). Wnt/beta-catenin signaling regulates vertebrate limb regeneration. Genes. Dev. 20, 3232-3237. doi: 10.1101/gad.1475106

Kawasaki, T., Kurauchi, K., Higashihata, A., Deguchi, T., Ishikawa, Y., Yamauchi, M., et al. (2012). Transgenic medaka fish which mimic the endogenous expression of neuronal kinesin, KIF5A. Brain Res. 1480, 12-21. doi: 10.1016/ j.brainres.2012.08.047

Kettleborough, R. N., Busch-Nentwich, E. M., Harvey, S. A., Dooley, C. M., de Bruijn, E., van Eeden, F., et al. (2013). A systematic genome-wide analysis of zebrafish protein-coding gene function. Nature 496, 494-497. doi: 10.1038/ nature 11992

Khyeam, S., Lee, S., and Huang, G. N. (2021). Genetic, epigenetic, and post-transcriptional basis of divergent tissue regenerative capacities among vertebrates. Adv. Genet. 7:e10042. doi: 10.1002/ggn2.10042

Kikuchi, K., Holdway, J. E., Major, R. J., Blum, N., Dahn, R. D., Begemann, G., et al. (2011b). Retinoic acid production by endocardium and epicardium is an injury response essential for zebrafish heart regeneration. Dev. Cell 20, 397-404. doi: 10.1016/j.devcel.2011.01.010 
Kikuchi, K., Gupta, V., Wang, J., Holdway, J. E., Wills, A. A., Fang, Y., et al. (2011a). tcf21 + epicardial cells adopt non-myocardial fates during zebrafish heart development and regeneration. Development 138, 2895-2902. doi: 10. 1242/dev.067041

Kikuchi, K., Holdway, J. E., Werdich, A. A., Anderson, R. M., Fang, Y., Egnaczyk, G. F., et al. (2010). Primary contribution to zebrafish heart regeneration by gata4(+) cardiomyocytes. Nature 464, 601-605. doi: 10.1038/nature08804

Kimura, Y., Hisano, Y., Kawahara, A., and Higashijima, S. (2014). Efficient generation of knock-in transgenic zebrafish carrying reporter/driver genes by CRISPR/Cas9-mediated genome engineering. Sci. Rep. 4:6545. doi: 10.1038/ srep06545

Kinkel, M. D., Eames, S. C., Philipson, L. H., and Prince, V. E. (2010). Intraperitoneal injection into adult zebrafish. J. Vis. Exp. 42:2126. doi: 10.3791/ 2126

Kinoshita, M., Kani, S., Ozato, K., and Wakamatsu, Y. (2000). Activity of the medaka translation elongation factor $1 \alpha$-A promoter examined using the GFP gene as a reporter. Dev. Growth Differ. 42, 469-478. doi: 10.1046/j.1440-169x. 2000.00530.x

Kinoshita, M., Murata, K., Naruse, K., and Tanaka, M. (2009). Medaka: Biology, Management, and Experimental Protocols. Honoken, NJ: John Wiley \& Sons.

Kirchmaier, S., Höckendorf, B., Möller, E. K., Bornhorst, D., Spitz, F., and Wittbrodt, J. (2013). Efficient site-specific transgenesis and enhancer activity tests in medaka using PhiC31 integrase. Development 140, 4287-4295. doi: 10.1242/dev.096081

Kirchmaier, S., Naruse, K., Wittbrodt, J., and Loosli, F. (2015). The genomic and genetic toolbox of the teleost medaka (Oryzias latipes). Genetics 199, 905-918. doi: 10.1534/genetics.114.173849

Kishimoto, N., Shimizu, K., and Sawamoto, K. (2012). Neuronal regeneration in a zebrafish model of adult brain injury. Dis. Model. Mech. 5, 200-209. doi: 10.1242/dmm.007336

Kizil, C., and Brand, M. (2011). Cerebroventricular microinjection (CVMI) into adult zebrafish brain is an efficient misexpression method for forebrain ventricular cells. PLoS One 6:e27395. doi: 10.1371/journal.pone.00 27395

Knopf, F., Hammond, C., Chekuru, A., Kurth, T., Hans, S., Weber, C. W., et al. (2011). Bone regenerates via dedifferentiation of osteoblasts in the zebrafish fin. Dev. Cell 20, 713-724. doi: 10.1016/j.devcel.2011.04.014

Knopf, F., Schnabel, K., Haase, C., Pfeifer, K., Anastassiadis, K., and Weidinger, G. (2010). Dually inducible TetON systems for tissue-specific conditional gene expression in zebrafish. Proc. Natl. Acad. Sci. U.S.A. 107, 19933-19938. doi: 10.1073/pnas.1007799107

Kobayashi, D., and Takeda, H. (2008). Medaka genome project. Brief Funct. Genomic. Proteomic. 7, 415-426. doi: 10.1093/bfgp/eln044

Koga, A., Hori, H., and Sakaizumi, M. (2002). Gene transfer and cloning of flanking chromosomal regions using the medaka fish Tol2 transposable element. Mar. Biotechnol. 4, 6-11. doi: 10.1007/s10126-001-0086-2

Kong, P., Christia, P., and Frangogiannis, N. G. (2014). The pathogenesis of cardiac fibrosis. Cell. Mol. Life Sci. 71, 549-574.

Kroehne, V., Freudenreich, D., Hans, S., Kaslin, J., and Brand, M. (2011). Regeneration of the adult zebrafish brain from neurogenic radial glia-type progenitors. Development 138, 4831-4841. doi: 10.1242/dev.072587

Kucenas, S., Takada, N., Park, H. C., Woodruff, E., Broadie, K., and Appel, B. (2008). CNS-derived glia ensheath peripheral nerves and mediate motor root development. Nat. Neurosci. 11, 143-151. doi: 10.1038/nn 2025

Kumar, S., Stecher, G., Suleski, M., and Hedges, S. B. (2017). TimeTree: a resource for timelines, timetrees, and divergence times. Mol. Biol. Evol. 34, 1812-1819. doi: 10.1093/molbev/msx116

Kurita, R., Sagara, H., Aoki, Y., Link, B. A., Arai, K.-I., and Watanabe, S. (2003). Suppression of lens growth by $\alpha \mathrm{A}$-crystallin promoter-driven expression of diphtheria toxin results in disruption of retinal cell organization in zebrafish. Dev. Biol. 255, 113-127. doi: 10.1016/s0012-1606(02)00079-9

Kuroyanagi, Y., Okuyama, T., Suehiro, Y., Imada, H., Shimada, A., Naruse, K., et al. (2010). Proliferation zones in adult medaka (Oryzias latipes) brain. Brain Res. 1323, 33-40. doi: 10.1016/j.brainres.2010.01.045

Kyritsis, N., Kizil, C., Zocher, S., Kroehne, V., Kaslin, J., Freudenreich, D., et al. (2012). Acute inflammation initiates the regenerative response in the adult zebrafish brain. Science 338, 1353-1356. doi: 10.1126/science.1228773
Labusch, M., Mancini, L., Morizet, D., and Bally-Cuif, L. (2020). Conserved and Divergent Features of Adult Neurogenesis in Zebrafish. Front. Cell Dev. Biol. 8:525. doi: $10.3389 /$ fcell.2020.00525

Lafontant, P. J., Burns, A. R., Grivas, J. A., Lesch, M. A., Lala, T. D., Reuter, S. P., et al. (2012). The giant danio (D. aequipinnatus) as a model of cardiac remodeling and regeneration. Anat. Rec. 295, 234-248. doi: 10.1002/ar. 21492

Lai, S.-L., Marín-Juez, R., Moura, P. L., Kuenne, C., Lai, J. K. H., Tsedeke, A. T., et al. (2017). Reciprocal analyses in zebrafish and medaka reveal that harnessing the immune response promotes cardiac regeneration. eLife 6:e25605. doi: 10 . 7554/eLife. 25605

Langenau, D. M., Ferrando, A. A., Traver, D., Kutok, J. L., Hezel, J. P., Kanki, J. P., et al. (2004). In vivo tracking of T cell development, ablation, and engraftment in transgenic zebrafish. Proc. Natl. Acad. Sci. U.S.A. 101, 7369-7374. doi: 10. 1073/pnas.0402248101

Laube, F., Heister, M., Scholz, C., Borchardt, T., and Braun, T. (2006). Reprogramming of newt cardiomyocytes is induced by tissue regeneration. J. Cell Sci. 119(Pt 22), 4719-4729. doi: 10.1242/jcs.03252

Lawson, N. D., and Weinstein, B. M. (2002). In vivo imaging of embryonic vascular development using transgenic zebrafish. Dev. Biol. 248, 307-318. doi: 10.1006/ dbio.2002.0711

Le, X., Langenau, D. M., Keefe, M. D., Kutok, J. L., Neuberg, D. S., and Zon, L. I. (2007). Heat shock-inducible Cre/Lox approaches to induce diverse types of tumors and hyperplasia in transgenic zebrafish. Proc. Natl. Acad. Sci. U.S.A. 104, 9410-9415. doi: 10.1073/pnas.0611302104

Leach, L. L., Hanovice, N. J., George, S. M., Gabriel, A. E., and Gross, J. M. (2021). The immune response is a critical regulator of zebrafish retinal pigment epithelium regeneration. Proc. Natl. Acad. Sci. U.S.A. 118, e2017198118. doi: $10.1073 /$ pnas.2017198118

Lenkowski, J. R., and Raymond, P. A. (2014). Müller glia: stem cells for generation and regeneration of retinal neurons in teleost fish. Prog. Retin. Eye Res. 40, 94-123. doi: 10.1016/j.preteyeres.2013.12.007

Letunic, I., and Bork, P. (2021). Interactive Tree Of Life (iTOL) v5: an online tool for phylogenetic tree display and annotation. Nucleic Acids Res. 49, W293W296. doi: 10.1093/nar/gkab301

Li, J., Iwanami, N., Hoa, V. Q., Furutani-Seiki, M., and Takahama, Y. (2007). Noninvasive intravital imaging of thymocyte dynamics in medaka. J. Immunol. 179, 1605-1615. doi: 10.4049/jimmunol.179.3.1605

Li, L., Yan, B., Shi, Y. Q., Zhang, W. Q., and Wen, Z. L. (2012). Live imaging reveals differing roles of macrophages and neutrophils during zebrafish tail fin regeneration. J. Biol. Chem. 287, 25353-25360. doi: 10.1074/jbc.M112.349126

Li, Y., Liu, Y., Yang, H., Zhang, T., Naruse, K., and Tu, Q. (2020). Dynamic transcriptional and chromatin accessibility landscape of medaka embryogenesis. Genome Res. 30, 924-937. doi: 10.1101/gr.258871.119

Lin, H.-F., Traver, D., Zhu, H., Dooley, K., Paw, B. H., Zon, L. I., et al. (2005). Analysis of thrombocyte development in CD41-GFP transgenic zebrafish. Blood 106, 3803-3810. doi: 10.1182/blood-2005-01-0179

Lin, J.-W., Chen, Y.-R., Wang, Y.-H., Hung, K.-C., and Lin, S.-M. (2017). Tail regeneration after autotomy revives survival: a case from a long-term monitored lizard population under avian predation. Proc. R. Soc. B Biol. Sci. 284:20162538. doi: $10.1098 /$ rspb.2016.2538

Lindmark, D. G., and Müller, M. (1976). Antitrichomonad action, mutagenicity, and reduction of metronidazole and other nitroimidazoles. Antimicrob. Agents Chemother. 10, 476-482. doi: 10.1128/AAC.10.3.476

Lindsey, B. W., Aitken, G. E., Tang, J. K., Khabooshan, M., Douek, A. M., Vandestadt, C., et al. (2019). Midbrain tectal stem cells display diverse regenerative capacities in zebrafish. Sci. Rep. 9:4420. doi: 10.1038/s41598-01940734-Z

Liu, K., Petree, C., Requena, T., Varshney, P., and Varshney, G. K. (2019). Expanding the CRISPR Toolbox in Zebrafish for studying development and disease. Front. Cell Dev. Biol. 7:13. doi: 10.3389/fcell.2019.00013

Liu, X., Li, Y.-S., Shinton, S. A., Rhodes, J., Tang, L., Feng, H., et al. (2017). Zebrafish B cell development without a pre-B cell stage, revealed by CD79 fluorescence reporter transgenes. J. Immunol. 199, 1706-1715. doi: 10.4049/ jimmunol.1700552

Long, D. W., Webb, C. H., and Wang, Y. (2019). Persistent fibrosis and decreased cardiac function following cardiac injury in the Ctenopharyngodon idella (grass carp). bioRxiv [Preprint]. doi: 10.1101/627752 
Loosli, F., Koster, R. W., Carl, M., Kuhnlein, R., Henrich, T., Mucke, M., et al. (2000). A genetic screen for mutations affecting embryonic development in medaka fish (Oryzias latipes). Mech. Dev. 97, 133-139. doi: 10.1016/s09254773(00)00406-8

Lopez-Baez, J. C., Simpson, D. J., LLeras Forero, L., Zeng, Z., Brunsdon, H., Salzano, A., et al. (2018). Wilms Tumor 1b defines a wound-specific sheath cell subpopulation associated with notochord repair. eLife 7:e30657. doi: 10.7554/ eLife.30657

Lush, M. E., and Piotrowski, T. (2014). Sensory hair cell regeneration in the zebrafish lateral line. Dev. Dyn. 243, 1187-1202. doi: 10.1002/dvdy.24167

Lust, K., and Wittbrodt, J. (2018). Activating the regenerative potential of Müller glia cells in a regeneration-deficient retina. eLife 7:e32319. doi: 10.7554/eLife. 32319

Maekawa, S., Chiang, Y.-A., Hikima, J.-I., Sakai, M., Lo, C.-F., Wang, H.-C., et al. (2016). Expression and biological activity of two types of interferon genes in medaka (Oryzias latipes). Fish Shellfish Immunol. 48, 20-29. doi: 10.1016/j.fsi. 2015.11.036

Maginnis, T. L. (2006). The costs of autotomy and regeneration in animals: a review and framework for future research. Behav. Ecol. 17, 857-872. doi: 10. 1093/beheco/arl010

Maheras, A. L., Dix, B., Carmo, O. M., Young, A. E., Gill, V. N., Sun, J. L., et al. (2018). Genetic pathways of neuroregeneration in a novel mild traumatic brain injury model in adult zebrafish. Eneuro 5:ENEURO.0208-17.2017. doi: 10.1523/ENEURO.0208-17

Marín-Juez, R., El-Sammak, H., Helker, C. S., Kamezaki, A., Mullapuli, S. T., Bibli, S.-I., et al. (2019). Coronary revascularization during heart regeneration is regulated by epicardial and endocardial cues and forms a scaffold for cardiomyocyte repopulation. Dev. Cell 51, 503-515.e4. doi: 10.1016/j.devcel. 2019.10.019

Marín-Juez, R., Marass, M., Gauvrit, S., Rossi, A., Lai, S.-L., Materna, S. C., et al. (2016). Fast revascularization of the injured area is essential to support zebrafish heart regeneration. Proc. Natl. Acad. Sci. U.S.A. 113, 11237-11242. doi: 10.1073/ pnas. 1605431113

Marletaz, F., Firbas, P. N., Maeso, I., Tena, J. J., Bogdanovic, O., Perry, M., et al. (2018). Amphioxus functional genomics and the origins of vertebrate gene regulation. Nature 564, 64-70. doi: 10.1038/s41586-018-0734-6

Marques, I. J., Lupi, E., and Mercader, N. (2019). Model systems for regeneration: zebrafish. Development 146:dev167692. doi: 10.1242/dev.167692

Martinez-Morales, J. R., Rembold, M., Greger, K., Simpson, J. C., Brown, K. E., Quiring, R., et al. (2009). Ojoplano-mediated basal constriction is essential for optic cup morphogenesis. Development 136, 2165-2175. doi: 10.1242/dev. 033563

Martins, R. R., Ellis, P. S., MacDonald, R. B., Richardson, R. J., and Henriques, C. M. (2019). Resident immunity in tissue repair and maintenance: the zebrafish model coming of age. Front. Cell Dev. Biol. 7:12. doi: 10.3389/fcell.2019. 00012

Marz, M., Schmidt, R., Rastegar, S., and Strahle, U. (2011). Regenerative response following stab injury in the adult zebrafish telencephalon. Dev. Dyn. 240, 2221-2231. doi: 10.1002/dvdy.22710

Matias Santos, D., Rita, A. M., Casanellas, I., Brito Ova, A., Araujo, I. M., Power, D., et al. (2016). Ear wound regeneration in the African spiny mouse Acomys cahirinus. Regeneration 3, 52-61. doi: 10.1002/reg2.50

McDonald, B., Pittman, K., Menezes, G. B., Hirota, S. A., Slaba, I., Waterhouse, C. C., et al. (2010). Intravascular danger signals guide neutrophils to sites of sterile inflammation. Science 330, 362-366. doi: 10.1126/science.1195491

Mekdara, P. J., Schwalbe, M. A., Coughlin, L. L., and Tytell, E. D. (2018). The effects of lateral line ablation and regeneration in schooling giant danios. J. Exp. Biol. 221:jeb175166. doi: 10.1242/jeb.175166

Meng, X., Noyes, M. B., Zhu, L. J., Lawson, N. D., and Wolfe, S. A. (2008). Targeted gene inactivation in zebrafish using engineered zinc-finger nucleases. Nat. Biotechnol. 26, 695-701. doi: 10.1038/nbt1398

Mescher, A. L., and Neff, A. W. (2005). "Regenerative capacity and the developing immune system," in Regenerative Medicine I: Theories, Models and Methods, ed. I. V. Yannas (Berlin: Springer), 39-66. doi: 10.1007/b99966

Metzger, D., Clifford, J., Chiba, H., and Chambon, P. (1995). Conditional sitespecific recombination in mammalian cells using a ligand-dependent chimeric Cre recombinase. Proc. Natl. Acad. Sci. U.S.A. 92, 6991-6995. doi: 10.1073/pnas. 92.15 .6991
Mierzwa, A. S., Nguyen, F., Xue, M., and Jonz, M. G. (2020). Regeneration of the gill filaments and replacement of serotonergic neuroepithelial cells in adult zebrafish (Danio rerio). Respir. Physiol. Neurobiol. 274:103366. doi: 10.1016/j. resp.2019.103366

Miskey, C., Izsvák, Z., Plasterk, R. H., and Ivics, Z. (2003). The Frog Prince: a reconstructed transposon from Rana pipiens with high transpositional activity in vertebrate cells. Nucleic Acids Res. 31, 6873-6881. doi: 10.1093/nar/ gkg910

Mitchell, D. M., Sun, C., Hunter, S. S., New, D. D., and Stenkamp, D. L. (2019). Regeneration associated transcriptional signature of retinal microglia and macrophages. Sci. Rep. 9:4768. doi: 10.1038/s41598-019-41298-8

Moens, C. B., Donn, T. M., Wolf-Saxon, E. R., and Ma, T. P. (2008). Reverse genetics in zebrafish by TILLING. Brief Funct. Genomic Proteomic 7, 454-459. doi: 10.1093/bfgp/eln046

Mollova, M., Bersell, K., Walsh, S., Savla, J., Das, L. T., Park, S. Y., et al. (2013). Cardiomyocyte proliferation contributes to heart growth in young humans. Proc. Natl. Acad. Sci. U.S.A. 110, 1446-1451. doi: 10.1073/pnas.1214608110

Moreno, R. L., Josey, M., and Ribera, A. B. (2017). Zebrafish in Situ spinal cord preparation for electrophysiological recordings from spinal sensory and Motor Neurons. J. Vis. Exp. 122:e55507. doi: 10.3791/55507

Moreno-Mateos, M. A., Vejnar, C. E., Beaudoin, J. D., Fernandez, J. P., Mis, E. K., Khokha, M. K., et al. (2015). CRISPRscan: designing highly efficient sgRNAs for CRISPR-Cas9 targeting in vivo. Nat. Methods 12, 982-988. doi: 10.1038/nmeth. 3543

Morgan, T. H. (1901). Regeneration and liability to injury. Science 14, 235-248. doi: $10.1126 /$ science.14.346.235

Moriyama, A., Inohaya, K., Maruyama, K., and Kudo, A. (2010). Bef medaka mutant reveals the essential role of $c$-myb in both primitive and definitive hematopoiesis. Dev. Biol. 345, 133-143. doi: 10.1016/j.ydbio.2010.06.031

Mosimann, C., Kaufman, C. K., Li, P., Pugach, E. K., Tamplin, O. J., and Zon, L. I. (2011). Ubiquitous transgene expression and Cre-based recombination driven by the ubiquitin promoter in zebrafish. Development 138, 169-177. doi: 10.1242/dev.059345

Mosimann, C., Puller, A. C., Lawson, K. L., Tschopp, P., Amsterdam, A., and Zon, L. I. (2013). Site-directed zebrafish transgenesis into single landing sites with the phiC31 integrase system. Dev. Dyn. 242, 949-963. doi: 10.1002/dvdy.23989

Moss, J. B., Koustubhan, P., Greenman, M., Parsons, M. J., Walter, I., and Moss, L. G. (2009). Regeneration of the pancreas in adult zebrafish. Diabetes 58, 1844-1851. doi: 10.2337/db08-0628

Motoike, T., Loughna, S., Perens, E., Roman, B. L., Liao, W., Chau, T. C., et al. (2000). Universal GFP reporter for the study of vascular development. Genesis 28, 75-81. doi: 10.1002/1526-968x(200010)28:2\&lt;75::aid-gene50\&gt; 3.0.co;2-s

Mukherjee, K., and Liao, E. C. (2018). Generation and characterization of a zebrafish muscle specific inducible Cre line. Transgenic Res. 27, 559-569. doi: 10.1007/s11248-018-0098-6

Murakami, Y., Ansai, S., Yonemura, A., and Kinoshita, M. (2017). An efficient system for homology-dependent targeted gene integration in medaka (Oryzias latipes). Zool. Lett. 3:10. doi: 10.1186/s40851-017-0071-x

Murata, K., Kinoshita, M., Naruse, K., Tanaka, M., and Kamei, Y. (2019). Medaka: Biology, Management, and Experimental Protocols. Honoken, NJ: John Wiley \& Sons, Incorporated.

Nakamura, R., Tsukahara, T., Qu, W., Ichikawa, K., Otsuka, T., Ogoshi, K., et al. (2014). Large hypomethylated domains serve as strong repressive machinery for key developmental genes in vertebrates. Development 141, 2568-2580. doi: 10.1242/dev.108548

Nakamura, S., Saito, D., and Tanaka, M. (2008). Generation of transgenic medaka using modified bacterial artificial chromosome. Dev. Growth Differ. 50, 415419. doi: 10.1111/j.1440-169X.2008.01027.x

Nakatani, Y., Kawakami, A., and Kudo, A. (2007). Cellular and molecular processes of regeneration, with special emphasis on fish fins. Dev. Growth Differ. 49, 145-154. doi: 10.1111/j.1440-169X.2007.00917.x

Nakatani, Y., Nishidate, M., Fujita, M., Kawakami, A., and Kudo, A. (2008). Migration of mesenchymal cell fated to blastema is necessary for fish fin regeneration. Dev. Growth Differ. 50, 71-83. doi: 10.1111/j.1440-169X.2007. 00977.x

Nasevicius, A., and Ekker, S. C. (2000). Effective targeted gene 'knockdown'in zebrafish. Nat. Genet. 26, 216-220. doi: 10.1038/79951 
Ng, G. H. B., and Gong, Z. (2011). Maize Ac/Ds transposon system leads to highly efficient germline transmission of transgenes in medaka (Oryzias latipes). Biochimie 93, 1858-1864. doi: 10.1016/j.biochi.2011.07.006

Nguyen-Chi, M., Laplace-Builhe, B., Travnickova, J., Luz-Crawford, P., Tejedor, G., Phan, Q. T., et al. (2015). Identification of polarized macrophage subsets in zebrafish. eLife 4:e07288. doi: 10.7554/eLife.07288

Nieto-Arellano, R., and Sanchez-Iranzo, H. (2019). zfRegeneration: a database for gene expression profiling during regeneration. Bioinformatics 35, 703-705. doi: 10.1093/bioinformatics/bty659

Offen, N., Blum, N., Meyer, A., and Begemann, G. (2008). Fgfr1 signalling in the development of a sexually selected trait in vertebrates, the sword of swordtail fish. BMC Dev. Biol. 8:98. doi: 10.1186/1471-213X-8-98

Okuda, K. S., Astin, J. W., Misa, J. P., Flores, M. V., Crosier, K. E., and Crosier, P. S. (2012). lyvel expression reveals novel lymphatic vessels and new mechanisms for lymphatic vessel development in zebrafish. Development 139, 2381-2391. doi: 10.1242/dev.077701

Okuyama, T., Isoe, Y., Hoki, M., Suehiro, Y., Yamagishi, G., Naruse, K., et al. (2013). Controlled Cre/loxP site-specific recombination in the developing brain in medaka fish, Oryzias latipes. PLoS One 8:e66597. doi: 10.1371/journal.pone. 0066597

Otsuka, T., and Takeda, H. (2017). Targeted Ablation of Pancreatic beta Cells in Medaka. Zool. Sci. 34, 179-184. doi: 10.2108/zs170004

Otsuka, T., Tsukahara, T., and Takeda, H. (2015). Development of the pancreas in medaka, Oryzias latipes, from embryo to adult. Dev. Growth Differ. 57, 557-569. doi: $10.1111 /$ dgd.12237

Ozato, K., Kondoh, H., Inohara, H., Iwamatsu, T., Wakamatsu, Y., and Okada, T. S. (1986). Production of transgenic fish: introduction and expression of chicken delta-crystallin gene in medaka embryos. Cell Differ. 19, 237-244. doi: 10.1016/0045-6039(86)90100-4

Page, D. M., Wittamer, V., Bertrand, J. Y., Lewis, K. L., Pratt, D. N., Delgado, N., et al. (2013). An evolutionarily conserved program of B-cell development and activation in zebrafish. Blood J. Am. Soc. Hematol. 122, el-e11. doi: 10.1182/ blood-2012-12-471029

Park, H. C., Kim, C. H., Bae, Y. K., Yeo, S. Y., Kim, S. H., Hong, S. K., et al. (2000). Analysis of upstream elements in the $\mathrm{HuC}$ promoter leads to the establishment of transgenic zebrafish with fluorescent neurons. Dev. Biol. 227, 279-293. doi: 10.1006/dbio. 2000.9898

Perner, B., Englert, C., and Bollig, F. (2007). The Wilms tumor genes wtla and wt1b control different steps during formation of the zebrafish pronephros. Dev. Biol. 309, 87-96. doi: 10.1016/j.ydbio.2007.06.022

Petrie, T. A., Strand, N. S., Yang, C. T., Rabinowitz, J. S., and Moon, R. T. (2014). Macrophages modulate adult zebrafish tail fin regeneration. Development 141, 2581-2591. doi: 10.1242/dev.098459

Pfefferli, C., and Jazwinska, A. (2015). The art of fin regeneration in zebrafish. Regeneration 2, 72-83. doi: 10.1002/reg2.33

Pfefferli, C., and Jaźwińska, A. (2017). The careg element reveals a common regulation of regeneration in the zebrafish myocardium and fin. Nat. Commun. 8:15151. doi: $10.1038 /$ ncomms 15151

Phan, Q. T., Tan, W. H., Liu, R., Sundaram, S., Buettner, A., Kneitz, S., et al. (2020). Cxcl9l and Cxcr3.2 regulate recruitment of osteoclast progenitors to bone matrix in a medaka osteoporosis model. Proc. Natl. Acad. Sci. U.S.A. 117, 19276-19286. doi: 10.1073/pnas.2006093117

Pisharath, H., Rhee, J. M., Swanson, M. A., Leach, S. D., and Parsons, M. J. (2007). Targeted ablation of beta cells in the embryonic zebrafish pancreas using E. coli nitroreductase. Mech. Dev. 124, 218-229. doi: 10.1016/j.mod.2006. 11.005

Poleo, G., Brown, C. W., Laforest, L., and Akimenko, M. A. (2001). Cell proliferation and movement during early fin regeneration in zebrafish. Dev. Dyn. 221, 380-390. doi: 10.1002/dvdy.1152

Polizzotti, B. D., Ganapathy, B., Haubner, B. J., Penninger, J. M., and Kühn, B. (2016). A cryoinjury model in neonatal mice for cardiac translational and regeneration research. Nat. Protoc. 11, 542-552. doi: 10.1038/nprot.2016.031

Porazinski, S. R., Wang, H., and Furutani-Seiki, M. (2010b). Microinjection of medaka embryos for use as a model genetic organism. J. Vis. Exp. 46:e1937. doi: 10.3791/1937

Porazinski, S. R., Wang, H., and Furutani-Seiki, M. (2010a). Dechorionation of medaka embryos and cell transplantation for the generation of chimeras. J. Vis. Exp. 46:e2055. doi: 10.3791/2055
Porrello, E. R., Mahmoud, A. I., Simpson, E., Hill, J. A., Richardson, J. A., Olson, E. N., et al. (2011). Transient regenerative potential of the neonatal mouse heart. Science 331, 1078-1080. doi: 10.1126/science. 1200708

Poss, K. D., Keating, M. T., and Nechiporuk, A. (2003). Tales of regeneration in zebrafish. Dev. Dyn. 226, 202-210. doi: 10.1002/dvdy.10220

Poss, K. D., Wilson, L. G., and Keating, M. T. (2002). Heart regeneration in zebrafish. Science 298, 2188-2190. doi: 10.1126/science.107 7857

Potts, H. G., Stockdale, W. T., and Mommersteeg, M. T. M. (2021). Unlocking the secrets of the regenerating fish heart: comparing regenerative models to shed light on successful regeneration. J. Cardiovasc. Dev. Dis. 8:10004. doi: $10.3390 /$ jcdd 8010004

Powell, C., Cornblath, E., Elsaeidi, F., Wan, J., and Goldman, D. (2016). Zebrafish Müller glia-derived progenitors are multipotent, exhibit proliferative biases and regenerate excess neurons. Sci. Rep. 6:24851. doi: 10.1038/srep24851

Provost, E., Rhee, J., and Leach, S. D. (2007). Viral 2A peptides allow expression of multiple proteins from a single ORF in transgenic zebrafish embryos. Genesis 45, 625-629. doi: 10.1002/dvg.20338

Pugach, E. K., Li, P., White, R., and Zon, L. (2009). Retro-orbital injection in adult zebrafish. J. Vis. Exp. 34:1645. doi: 10.3791/1645

Qi, Y., Dasa, O., Maden, M., Vohra, R., Batra, A., Walter, G., et al. (2021). Functional heart recovery in an adult mammal, the spiny mouse. Int. J. Cardiol. 338, 196-203. doi: 10.1016/j.ijcard.2021.06.015

Ramachandran, R., Fausett, B. V., and Goldman, D. (2010a). Asclla regulates Müller glia dedifferentiation and retinal regeneration through a Lin-28dependent, let-7 microRNA signalling pathway. Nat. Cell Biol. 12, 1101-1107. doi: $10.1038 /$ ncb 2115

Ramachandran, R., Reifler, A., Parent, J. M., and Goldman, D. (2010b). Conditional gene expression and lineage tracing of tubala expressing cells during zebrafish development and retina regeneration. J. Comp. Neurol. 518, 4196-4212. doi: $10.1002 /$ cne. 22448

Ramel, M.-C., Progatzky, F., Rydlova, A., Wane, M., Schymeinsky, J., Williams, C., et al. (2021). Dynamics of repair and regeneration of adult zebrafish respiratory gill tissue after cryoinjury. bioRxiv [Preprint]. doi: 10.1101/2021.05.27.445469

Raymond, P. A., Barthel, L. K., Bernardos, R. L., and Perkowski, J. J. (2006). Molecular characterization of retinal stem cells and their niches in adult zebrafish. BMC Dev. Biol. 6:36. doi: 10.1186/1471-213X-6-36

Raymond, P. A., Reifler, M. J., and Rivlin, P. K. (1988). Regeneration of goldfish retina: rod precursors are a likely source of regenerated cells. J. Neurobiol. 19, 431-463. doi: 10.1002/neu.480190504

Redd, M. J., Kelly, G., Dunn, G., Way, M., and Martin, P. (2006). Imaging macrophage chemotaxis in vivo: studies of microtubule function in zebrafish wound inflammation. Cell Motil. Cytoskeleton 63, 415-422. doi: 10.1002/cm. 20133

Reddien, P. W., and Alvarado, A. S. (2004). Fundamentals of planarian regeneration. Annu. Rev. Cell Dev. Biol. 20, 725-757. doi: 10.1146/annurev. cellbio.20.010403.095114

Reddy, P. C., Gungi, A., and Unni, M. (2019). Cellular and molecular mechanisms of Hydra regeneration. Results Probl. Cell Differ. 68, 259-290. doi: 10.1007/9783-030-23459-1_12

Reimschuessel, R., and Williams, D. (1995). Development of new nephrons in adult kidneys following gentamicin-induced nephrotoxicity. Ren. Fail. 17, 101-106. doi: 10.3109/08860229509026246

Reinhardt, R., Centanin, L., Tavhelidse, T., Inoue, D., Wittbrodt, B., Concordet, J. P., et al. (2015). Sox2, Tlx, Gli3, and Her9 converge on $\mathrm{Rx} 2$ to define retinal stem cells in vivo. EMBO J. 34, 1572-1588. doi: 10.15252/embj.201490706

Renn, J., Büttner, A., To, T. T., Chan, S. J. H., and Winkler, C. (2013). A col10a1: nlGFP transgenic line displays putative osteoblast precursors at the medaka notochordal sheath prior to mineralization. Dev. Biol. 381, 134-143. doi: 10 . 1016/j.ydbio.2013.05.030

Renn, J., and Winkler, C. (2009). Osterix-mCherry transgenic medaka for in vivo imaging of bone formation. Dev. Dyn. 238, 241-248. doi: 10.1002/dvdy. 21836

Renshaw, S. A., Loynes, C. A., Trushell, D. M., Elworthy, S., Ingham, P. W., and Whyte, M. K. (2006). A transgenic zebrafish model of neutrophilic inflammation. Blood 108, 3976-3978. doi: 10.1182/blood-2006-05-024075

Richardson, R., Slanchev, K., Kraus, C., Knyphausen, P., Eming, S., and Hammerschmidt, M. (2013). Adult zebrafish as a model system for cutaneous 
wound-healing research. J. Invest. Dermatol. 133, 1655-1665. doi: 10.1038/jid. 2013.16

Robert, J., and Ohta, Y. (2009). Comparative and developmental study of the immune system in Xenopus. Dev. Dyn. 238, 1249-1270. doi: 10.1002/dvdy. 21891

Roh-Johnson, M., Shah, A. N., Stonick, J. A., Poudel, K. R., Kargl, J., Yang, G. H., et al. (2017). Macrophage-dependent cytoplasmic transfer during melanoma invasion in vivo. Dev. Cell 43, 549-562.e6. doi: 10.1016/j.devcel.2017.11.003

Rottbauer, W., Saurin, A. J., Lickert, H., Shen, X., Burns, C. G., Wo, Z. G., et al. (2002). Reptin and pontin antagonistically regulate heart growth in zebrafish embryos. Cell 111, 661-672. doi: 10.1016/s0092-8674(02)01112-1

Ruyra, A., Cano-Sarabia, M., Garcia-Valtanen, P., Yero, D., Gibert, I., Mackenzie, S. A., et al. (2014). Targeting and stimulation of the zebrafish (Danio rerio) innate immune system with LPS/dsRNA-loaded nanoliposomes. Vaccine 32, 3955-3962. doi: 10.1016/j.vaccine.2014.05.010

Ruzicka, L., Howe, D. G., Ramachandran, S., Toro, S., Van Slyke, C. E., Bradford, Y. M., et al. (2019). The Zebrafish information network: new support for noncoding genes, richer gene ontology annotations and the alliance of genome resources. Nucleic Acids Res. 47, D867-D873. doi: 10.1093/nar/gky1090

Sadler, K. C., Krahn, K. N., Gaur, N. A., and Ukomadu, C. (2007). Liver growth in the embryo and during liver regeneration in zebrafish requires the cell cycle regulator, uhrf1. Proc. Natl. Acad. Sci. U.S.A. 104, 1570-1575. doi: 10.1073/pnas. 0610774104

Sanchez-Iranzo, H., Galardi-Castilla, M., Sanz-Morejon, A., Gonzalez-Rosa, J. M., Costa, R., Ernst, A., et al. (2018). Transient fibrosis resolves via fibroblast inactivation in the regenerating zebrafish heart. Proc. Natl. Acad. Sci. U.S.A. 115, 4188-4193. doi: 10.1073/pnas.1716713115

Sander, J. D., Cade, L., Khayter, C., Reyon, D., Peterson, R. T., Joung, J. K., et al. (2011). Targeted gene disruption in somatic zebrafish cells using engineered TALENs. Nat. Biotechnol. 29, 697-698. doi: 10.1038/nbt.1934

Sanderson, L. E., Chien, A.-T., Astin, J. W., Crosier, K. E., Crosier, P. S., and Hall, C. J. (2015). An inducible transgene reports activation of macrophages in live zebrafish larvae. Dev. Comp. Immunol. 53, 63-69. doi: 10.1016/j.dci.2015. 06.013

Sano, S., Takashima, S., Niwa, H., Yokoi, H., Shimada, A., Arenz, A., et al. (2009). Characterization of teleost Mdgal using a gene-trap approach in medaka (Oryzias latipes). Genesis 47, 505-513. doi: 10.1002/dvg.20528

Sanz-Morejon, A., Garcia-Redondo, A. B., Reuter, H., Marques, I. J., Bates, T., Galardi-Castilla, M., et al. (2019). Wilms Tumor 1b Expression Defines a Proregenerative Macrophage Subtype and Is Required for Organ Regeneration in the Zebrafish. Cell Rep. 28, 1296-1306.e6. doi: 10.1016/j.celrep.2019. 06.091

Sasado, T., Tanaka, M., Kobayashi, K., Sato, T., Sakaizumi, M., and Naruse, K. (2010). The National BioResource Project Medaka (NBRP Medaka): an integrated bioresource for biological and biomedical sciences. Exp. Anim. 59, 13-23. doi: 10.1538/expanim.59.13

Sassen, W. A., and Köster, R. W. (2015). A molecular toolbox for genetic manipulation of zebrafish. Adv. Genomics Genet. 5, 151-163. doi: 10.2147/AGG. S57585

Schaafhausen, M. K., Yang, W.-J., Centanin, L., Wittbrodt, J., Bosserhoff, A., Fischer, A., et al. (2013). Tumor angiogenesis is caused by single melanoma cells in a reactive oxygen species and NF-кB dependent manner. J. Cell Sci. 126, 3862-3872. doi: 10.1242/jcs. 125021

Schall, K. A., Holoyda, K. A., Grant, C. N., Levin, D. E., Torres, E. R., Maxwell, A., et al. (2015). Adult zebrafish intestine resection: a novel model of short bowel syndrome, adaptation, and intestinal stem cell regeneration. Am. J. Physiol. Gastrointest. Liver Physiol. 309, G135-G145. doi: 10.1152/ajpgi.00311. 2014

Schmidt, R., Beil, T., Strähle, U., and Rastegar, S. (2014). Stab wound injury of the zebrafish adult telencephalon: a method to investigate vertebrate brain neurogenesis and regeneration. J. Vis. Exp. 90:e51753. doi: 10.3791/51753

Schnabel, K., Wu, C. C., Kurth, T., and Weidinger, G. (2011). Regeneration of cryoinjury induced necrotic heart lesions in zebrafish is associated with epicardial activation and cardiomyocyte proliferation. PLoS One 6:e18503. doi: 10.1371/journal.pone.0018503

Schuck, J. B., and Smith, M. E. (2009). Cell proliferation follows acousticallyinduced hair cell bundle loss in the zebrafish saccule. Hear. Res. 253, 67-76. doi: 10.1016/j.heares.2009.03.008
Seifert, A. W., Kiama, S. G., Seifert, M. G., Goheen, J. R., Palmer, T. M., and Maden, M. (2012). Skin shedding and tissue regeneration in African spiny mice (Acomys). Nature 489, 561-565. doi: 10.1038/nature11499

Seleit, A., Gross, K., Onistschenko, J., Hoang, O. P., Theelke, J., and Centanin, L. (2022). Local tissue interactions govern pLL patterning in medaka. Dev. Biol. 481, 1-13. doi: 10.1016/j.ydbio.2021.09.002

Seleit, A., Gross, K., Onistschenko, J., Woelk, M., Autorino, C., and Centanin, L. (2020). Development and regeneration dynamics of the Medaka notochord. Dev. Biol. 463, 11-25. doi: 10.1016/j.ydbio.2020.03.001

Seleit, A., Krämer, I., Riebesehl, B. F., Ambrosio, E. M., Stolper, J. S., Lischik, C. Q., et al. (2017b). Neural stem cells induce the formation of their physical niche during organogenesis. eLife 6:e29173. doi: 10.7554/eLife.29173

Seleit, A., Kramer, I., Ambrosio, E., Dross, N., Engel, U., and Centanin, L. (2017a). Sequential organogenesis sets two parallel sensory lines in medaka. Development 144, 687-697. doi: 10.1242/dev.142752

Senut, M.-C., Gulati-Leekha, A., and Goldman, D. (2004). An element in the $\alpha 1$-tubulin promoter is necessary for retinal expression during optic nerve regeneration but not after eye injury in the adult zebrafish. J. Neurosci. 24, 7663-7673. doi: 10.1523/JNEUROSCI.2281-04.2004

Sherpa, T., Fimbel, S. M., Mallory, D. E., Maaswinkel, H., Spritzer, S. D., Sand, J. A., et al. (2008). Ganglion cell regeneration following whole-retina destruction in zebrafish. Dev. Neurobiol. 68, 166-181. doi: 10.1002/dneu. 20568

Shimizu, Y., Ito, Y., Tanaka, H., and Ohshima, T. (2015). Radial glial cell-specific ablation in the adult $\mathrm{Z}$ ebrafish brain. Genesis 53, 431-439. doi: 10.1002/dvg. 22865

Shimizu, Y., and Kawasaki, T. (2021). Differential regenerative capacity of the optic Tectum of Adult Medaka and Zebrafish. Front. Cell Dev. Biol. 9:686755. doi: $10.3389 /$ fcell.2021.686755

Shimizu, Y., Ueda, Y., and Ohshima, T. (2018). Wnt signaling regulates proliferation and differentiation of radial glia in regenerative processes after stab injury in the optic tectum of adult zebrafish. Glia 66, 1382-1394. doi: 10.1002/glia.23311

Simkin, J., Gawriluk, T. R., Gensel, J. C., and Seifert, A. W. (2017). Macrophages are necessary for epimorphic regeneration in African spiny mice. eLife 6:e24623. doi: $10.7554 /$ eLife. 24623

Simoes, F. C., Cahill, T. J., Kenyon, A., Gavriouchkina, D., Vieira, J. M., Sun, X., et al. (2020). Macrophages directly contribute collagen to scar formation during zebrafish heart regeneration and mouse heart repair. Nat. Commun. 11:600. doi: 10.1038/s41467-019-14263-2

Simon, A., and Tanaka, E. M. (2013). Limb regeneration. Wiley Interdiscip. Rev. Dev. Biol. 2, 291-300. doi: 10.1002/wdev.73

Singh, S. P., Holdway, J. E., and Poss, K. D. (2012). Regeneration of amputated zebrafish fin rays from de novo osteoblasts. Dev. Cell 22, 879-886. doi: 10.1016/ j.devcel.2012.03.006

Soehnlein, O., and Lindbom, L. (2010). Phagocyte partnership during the onset and resolution of inflammation. Nat. Rev. Immunol. 10, 427-439. doi: 10.1038/ nri2779

Sorlien, E. L., Witucki, M. A., and Ogas, J. (2018). Efficient Production and Identification of CRISPR/Cas9-generated Gene Knockouts in the Model System Danio rerio. J. Vis. Exp. 138:56969. doi: 10.3791/56969

Steinhauser, M. L., and Lee, R. T. (2011). Regeneration of the heart. EMBO Mol. Med. 3, 701-712.

Stemmer, M., Thumberger, T., Del Sol, Keyer, M., Wittbrodt, J., and Mateo, J. L. (2015). CCTop: an intuitive, flexible and reliable CRISPR/Cas9 target prediction tool. PLoS One 10:e0124633. doi: 10.1371/journal.pone.0124633

Stockdale, W. T., Lemieux, M. E., Killen, A. C., Zhao, J., Hu, Z., Riepsaame, J., et al. (2018). Heart regeneration in the Mexican Cavefish. Cell Rep. 25, 1997-2007.e7. doi: 10.1016/j.celrep.2018.10.072

Stolper, J., Ambrosio, E. M., Danciu, D.-P., Buono, L., Elliott, D. A., Naruse, K., et al. (2019). Stem cell topography splits growth and homeostatic functions in the fish gill. eLife 8:e43747. doi: 10.7554/eLife.43747

Straube, W. L., and Tanaka, E. M. (2006). Reversibility of the differentiated state: regeneration in amphibians. Artif. Organs 30, 743-755. doi: 10.1111/j.15251594.2006.00296.x

Streisinger, G., Singer, F., Walker, C., Knauber, D., and Dower, N. (1986). Segregation analyses and gene-centromere distances in zebrafish. Genetics 112 , 311-319. doi: 10.1093/genetics/112.2.311 
Streisinger, G., Walker, C., Dower, N., Knauber, D., and Singer, F. (1981). Production of clones of homozygous diploid zebra fish (Brachydanio rerio). Nature 291, 293-296. doi: 10.1038/291293a0

Strungs, E. G., Ongstad, E. L., O’Quinn, M. P., Palatinus, J. A., Jourdan, L. J., and Gourdie, R. G. (2013). Cryoinjury models of the adult and neonatal mouse heart for studies of scarring and regeneration. Methods Mol. Biol. 1037, 343-353. doi: 10.1007/978-1-62703-505-7_20

Suehiro, Y., Kinoshita, M., Okuyama, T., Shimada, A., Naruse, K., Takeda, H., et al. (2010). Transient and permanent gene transfer into the brain of the teleost fish medaka (Oryzias latipes) using human adenovirus and the Cre-loxP system. FEBS Lett. 584, 3545-3549. doi: 10.1016/j.febslet.2010.06.047

Suster, M. L., Abe, G., Schouw, A., and Kawakami, K. (2011). Transposon-mediated BAC transgenesis in zebrafish. Nat. Protoc. 6, 1998-2021. doi: 10.1038/nprot. 2011.416

Sveen, L. R., Timmerhaus, G., Krasnov, A., Takle, H., Handeland, S., and Ytteborg, E. (2019). Wound healing in post-smolt Atlantic salmon (Salmo salar L.). Sci. Rep. 9:3565. doi: 10.1038/s41598-019-39080-x

Takahashi, K., Tanabe, K., Ohnuki, M., Narita, M., Ichisaka, T., Tomoda, K., et al. (2007). Induction of pluripotent stem cells from adult human fibroblasts by defined factors. Cell 131, 861-872. doi: 10.1016/j.cell.2007.11.019

Takanezawa, S., Saitou, T., and Imamura, T. (2021). Wide field light-sheet microscopy with lens-axicon controlled two-photon Bessel beam illumination. Nat. Commun. 12:2979. doi: 10.1038/s41467-021-23249-y

Takechi, M., Hamaoka, T., and Kawamura, S. (2003). Fluorescence visualization of ultraviolet-sensitive cone photoreceptor development in living zebrafish. FEBS Lett. 553, 90-94. doi: 10.1016/s0014-5793(03)00977-3

Takeuchi, A., and Okubo, K. (2013). Post-proliferative immature radial glial cells female-specifically express aromatase in the medaka optic tectum. PLoS One 8:e73663. doi: 10.1371/journal.pone.0073663

Taneda, Y., Konno, S., Makino, S., Morioka, M., Fukuda, K., Imai, Y., et al. (2010). Epigenetic control of cardiomyocyte production in response to a stress during the medaka heart development. Dev. Biol. 340, 30-40. doi: 10.1016/j.ydbio.2010. 01.014

Taniguchi, Y., Takeda, S., Furutani-Seiki, M., Kamei, Y., Todo, T., Sasado, T., et al. (2006). Generation of medaka gene knockout models by target-selected mutagenesis. Genome Biol. 7:R116. doi: 10.1186/gb-2006-7-12-r116

Tena, J. J., Gonzalez-Aguilera, C., Fernandez-Minan, A., Vazquez-Marin, J., ParraAcero, H., Cross, J. W., et al. (2014). Comparative epigenomics in distantly related teleost species identifies conserved cis-regulatory nodes active during the vertebrate phylotypic period. Genome Res. 24, 1075-1085. doi: 10.1101/gr. 163915.113

Terzibasi, E., Valenzano, D. R., and Cellerino, A. (2007). The short-lived fish Nothobranchius furzeri as a new model system for aging studies. Exp. Gerontol. 42, 81-89. doi: 10.1016/j.exger.2006.06.039

Thermes, V., Grabher, C., Ristoratore, F., Bourrat, F., Choulika, A., Wittbrodt, J., et al. (2002). I-SceI meganuclease mediates highly efficient transgenesis in fish. Mech. Dev. 118, 91-98. doi: 10.1016/s0925-4773(02)00218-6

Thummel, R., Burket, C. T., Brewer, J. L., Sarras, M. P. Jr., Li, L., Perry, M., et al. (2005). Cre-mediated site-specific recombination in zebrafish embryos. Dev. Dyn. 233, 1366-1377. doi: 10.1002/dvdy.20475

Thummel, R., Kassen, S. C., Enright, J. M., Nelson, C. M., Montgomery, J. E., and Hyde, D. R. (2008). Characterization of Müller glia and neuronal progenitors during adult zebrafish retinal regeneration. Exp. Eye Res. 87, 433-444. doi: 10.1016/j.exer.2008.07.009

To, T. T., Witten, P. E., Renn, J., Bhattacharya, D., Huysseune, A., and Winkler, C. (2012). Rankl-induced osteoclastogenesis leads to loss of mineralization in a medaka osteoporosis model. Development 139, 141-150. doi: 10.1242/dev. 071035

Tong, S. K., Mouriec, K., Kuo, M. W., Pellegrini, E., Gueguen, M. M., Brion, F., et al. (2009). A cyp19alb-gfp (aromatase B) transgenic zebrafish line that expresses GFP in radial glial cells. Genesis 47, 67-73. doi: 10.1002/dvg.20459

Traver, D., Paw, B. H., Poss, K. D., Penberthy, W. T., Lin, S., and Zon, L. I. (2003). Transplantation and in vivo imaging of multilineage engraftment in zebrafish bloodless mutants. Nat. Immunol. 4, 1238-1246. doi: 10.1038/ni1007

Trede, N. S., Langenau, D. M., Traver, D., Look, A. T., and Zon, L. I. (2004). The use of zebrafish to understand immunity. Immunity 20, 367-379. doi: 10.1016/s1074-7613(04)00084-6
Ueno, T., Yasumasu, S., Hayashi, S., and Iuchi, I. (2004). Identification of choriogenin cis-regulatory elements and production of estrogen-inducible, liver-specific transgenic Medaka. Mech. Dev. 121, 803-815. doi: 10.1016/j.mod. 2004.03.027

Uesaka, M., Kuratani, S., Takeda, H., and Irie, N. (2019). Recapitulation-like developmental transitions of chromatin accessibility in vertebrates. Zool. Lett. 5:33. doi: 10.1186/s40851-019-0148-9

Underwood, J. L., Hestand, R. S. III, and Thompson, B. Z. (1986). Gonad regeneration in grass carp following bilateral gonadectomy. Prog. Fish Cult. 48, 54-56. doi: 10.1577/1548-8640(1986)48<54:grigcf >2.0.co;2

Van Houcke, J., Mariën, V., Zandecki, C., Vanhunsel, S., Moons, L., Ayana, R., et al. (2021). Aging impairs the essential contributions of non-glial progenitors to neurorepair in the dorsal telencephalon of the Killifish Nothobranchius furzeri. Aging Cell 20:e13464. doi: 10.1111/acel.13464

Van Wettere, A. J., Kullman, S. W., Hinton, D. E., and Law, J. M. (2013). Immunohistochemical characterization of the hepatic progenitor cell compartment in medaka (Oryzias latipes) following hepatic injury. J. Comp. Pathol. 149, 434-445. doi: 10.1016/j.jcpa.2013.03.008

Var, S. R., and Byrd-Jacobs, C. A. (2020). Role of macrophages and microglia in zebrafish regeneration. Int. J. Mol. Sci. 21:4768. doi: 10.3390/ijms21134768

Vihtelic, T. S., and Hyde, D. R. (2000). Light-induced rod and cone cell death and regeneration in the adult albino zebrafish (Danio rerio) retina. J. Neurobiol. 44, 289-307. doi: 10.1002/1097-4695(20000905)44:3\&lt;289::aid-neu1\&gt;3.0. co; $2-\mathrm{h}$

Vivien, C. J., Hudson, J. E., and Porrello, E. R. (2016). Evolution, comparative biology and ontogeny of vertebrate heart regeneration. NPJ Regen. Med. 1:16012. doi: 10.1038/npjregenmed.2016.12

Walton, E. M., Cronan, M. R., Beerman, R. W., and Tobin, D. M. (2015). The macrophage-specific promoter mfap4 allows live, long-term analysis of macrophage behavior during Mycobacterial Infection in Zebrafish. PLoS One 10:e0138949. doi: 10.1371/journal.pone.0138949

Wan, H., Korzh, S., Li, Z., Mudumana, S. P., Korzh, V., Jiang, Y.-J., et al. (2006). Analyses of pancreas development by generation of gfp transgenic zebrafish using an exocrine pancreas-specific elastaseA gene promoter. Exp. Cell Res. 312, 1526-1539. doi: 10.1016/j.yexcr.2006.01.016

Wang, J., Karra, R., Dickson, A. L., and Poss, K. D. (2013). Fibronectin is deposited by injury-activated epicardial cells and is necessary for zebrafish heart regeneration. Dev. Biol. 382, 427-435. doi: 10.1016/j.ydbio.2013.08.012

Wang, J., Panakova, D., Kikuchi, K., Holdway, J. E., Gemberling, M., Burris, J. S., et al. (2011). The regenerative capacity of zebrafish reverses cardiac failure caused by genetic cardiomyocyte depletion. Development 138, 3421-3430. doi: 10.1242/dev.068601

Wang, R., Li, Z., Wang, Y., and Gui, J.-F. (2011). An Apo-14 promoter-driven transgenic zebrafish that marks liver organogenesis. PLoS One 6:e22555. doi: 10.1371/journal.pone.0022555

Wang, Z., Cui, M., Shah, A. M., Tan, W., Liu, N., Bassel-Duby, R., et al. (2020). Cell-type-specific gene regulatory networks underlying murine neonatal heart regeneration at single-cell resolution. Cell Rep. 33:108472.

Wang, W., Hu, C. K., Zeng, A., Alegre, D., Hu, D., Gotting, K., et al. (2020). Changes in regeneration-responsive enhancers shape regenerative capacities in vertebrates. Science 369:eaaz3090. doi: 10.1126/science.aaz3090

Wang, Y., Kaiser, M. S., Larson, J. D., Nasevicius, A., Clark, K. J., Wadman, S. A., et al. (2010). Moesin 1 and Ve-cadherin are required in endothelial cells during in vivo tubulogenesis. Development 137, 3119-3128. doi: 10.1242/dev.048785

Watakabe, I., Hashimoto, H., Kimura, Y., Yokoi, S., Naruse, K., and Higashijima, S. I. (2018). Highly efficient generation of knock-in transgenic medaka by CRISPR/Cas9-mediated genome engineering. Zool. Lett. 4:3. doi: 10.1186/ s40851-017-0086-3

Watanabe, N., Kato, M., Suzuki, N., Inoue, C., Fedorova, S., Hashimoto, H., et al. (2009). Kidney regeneration through nephron neogenesis in medaka. Dev. Growth Differ. 51, 135-143. doi: 10.1111/j.1440-169X.2009.01090.x

Wehner, D., Becker, T., and Becker, C. G. (2018). Restoration of anatomical continuity after spinal cord transection depends on Wnt $/ \beta$-catenin signaling in larval zebrafish. Data Brief 16, 65-70. doi: 10.1016/j.dib.2017.10.068

Wendler, S., Hartmann, N., Hoppe, B., and Englert, C. (2015). Age-dependent decline in fin regenerative capacity in the short-lived fish Nothobranchius furzeri. Aging Cell 14, 857-866. doi: 10.1111/acel.12367 
White, R. M., Sessa, A., Burke, C., Bowman, T., LeBlanc, J., Ceol, C., et al. (2008). Transparent adult zebrafish as a tool for in vivo transplantation analysis. Cell Stem Cell 2, 183-189. doi: 10.1016/j.stem.2007.11.002

Wienholds, E., Van Eeden, F., Kosters, M., Mudde, J., Plasterk, R. H., and Cuppen, E. (2003). Efficient target-selected mutagenesis in zebrafish. Genome Res. 13, 2700-2707. doi: 10.1101/gr.1725103

Wierson, W. A., Welker, J. M., Almeida, M. P., Mann, C. M., Webster, D. A., Torrie, M. E., et al. (2020). Efficient targeted integration directed by short homology in zebrafish and mammalian cells. eLife 9:e53968. doi: 10.7554/eLife. 53968

Willems, B., Buttner, A., Huysseune, A., Renn, J., Witten, P. E., and Winkler, C. (2012). Conditional ablation of osteoblasts in medaka. Dev. Biol. 364, 128-137. doi: 10.1016/j.ydbio.2012.01.023

Wittamer, V., Bertrand, J. Y., Gutschow, P. W., and Traver, D. (2011). Characterization of the mononuclear phagocyte system in zebrafish. Blood J. Am. Soc. Hematol. 117, 7126-7135. doi: 10.1182/blood-2010-11321448

Wittbrodt, J., Shima, A., and Schartl, M. (2002). Medaka-a model organism from the far East. Nat. Rev. Genet. 3, 53-64. doi: 10.1038/nrg704

Xiao, C., Wang, F., Hou, J., Zhu, X., Luo, Y., and Xiong, J. W. (2018). Nanoparticlemediated siRNA gene-silencing in adult zebrafish heart. J. Vis. Exp. 137:58054. doi: $10.3791 / 58054$

Xiao, T., Roeser, T., Staub, W., and Baier, H. (2005). A GFP-based genetic screen reveals mutations that disrupt the architecture of the zebrafish retinotectal projection. doi: 10.1242/dev.01861

Yamamoto, T. (1975). Medaka (killifish): Biology and Strains. Tokyo: Keigaku Pub. Co.

Yang, K., and Kang, J. (2019). Tissue regeneration enhancer elements: a way to unlock endogenous healing power. Dev. Dyn. 248, 34-42. doi: 10.1002/dvdy. 24676

Yano, T., and Tamura, K. (2013). The making of differences between fins and limbs. J. Anat. 222, 100-113. doi: 10.1111/j.1469-7580.2012. 01491.x

Yi, Ni Lam, E., Chau, J. Y., Kalev-Zylinska, M. L., Fountaine, T. M., Mead, R. S., et al. (2009). Zebrafish runx1 promoter-EGFP transgenics mark discrete sites of definitive blood progenitors. Blood J. Am. Soc. Hematol. 113, 1241-1249. doi: 10.1182/blood-2008-04-149898

Yokoyama, H., Ogino, H., Stoick-Cooper, C. L., Grainger, R. M., and Moon, R. T. (2007). Wnt/ $\beta$-catenin signaling has an essential role in the initiation of limb regeneration. Dev. Biol. 306, 170-178.

Yoshinari, N., Ando, K., Kudo, A., Kinoshita, M., and Kawakami, A. (2012). Colored medaka and zebrafish: transgenics with ubiquitous and strong transgene expression driven by the medaka beta-actin promoter. Dev. Growth Differ. 54, 818-828. doi: 10.1111/dgd.12013

You, M. S., Jiang, Y. J., Yuh, C. H., Wang, C. M., Tang, C. H., Chuang, Y. J., et al. (2016). A Sketch of the Taiwan Zebrafish Core Facility. Zebrafish 13(Suppl. 1), S24-S29. doi: 10.1089/zeb.2015.1208

Yun, M. H. (2015). Changes in regenerative capacity through lifespan. Int. J. Mol. Sci. 16, 25392-25432. doi: 10.3390/ijms161025392

Zattara, E. E., Fernandez-Alvarez, F. A., Hiebert, T. C., Bely, A. E., and Norenburg, J. L. (2019). A phylum-wide survey reveals multiple independent gains of head regeneration in Nemertea. Proc. Biol. Sci. 286:20182524. doi: 10.1098/rspb.2018. 2524

Zecchin, E., Filippi, A., Biemar, F., Tiso, N., Pauls, S., Ellertsdottir, E., et al. (2007). Distinct delta and jagged genes control sequential segregation of pancreatic cell types from precursor pools in zebrafish. Dev. Biol. 301, 192-204. doi: 10.1016/j. ydbio.2006.09.041

Zeng, Z., Liu, X., Seebah, S., and Gong, Z. (2005). Faithful expression of living color reporter genes in transgenic medaka under two tissue-specific zebrafish promoters. Dev. Dyn. 234, 387-392. doi: 10.1002/dvdy.20491

Zhang, R., Han, P., Yang, H., Ouyang, K., Lee, D., Lin, Y. F., et al. (2013). In vivo cardiac reprogramming contributes to zebrafish heart regeneration. Nature 498, 497-501. doi: 10.1038/nature12322

Zhao, L., Ben-Yair, R., Burns, C. E., and Burns, C. G. (2019). Endocardial Notch signaling promotes cardiomyocyte proliferation in the regenerating zebrafish heart through Wnt pathway antagonism. Cell Rep. 26, 546-554.e5. doi: 10.1016/ j.celrep.2018.12.048

Conflict of Interest: The authors declare that the research was conducted in the absence of any commercial or financial relationships that could be construed as a potential conflict of interest.

Publisher's Note: All claims expressed in this article are solely those of the authors and do not necessarily represent those of their affiliated organizations, or those of the publisher, the editors and the reviewers. Any product that may be evaluated in this article, or claim that may be made by its manufacturer, is not guaranteed or endorsed by the publisher.

Copyright (C) 2022 Chowdhury, Lin and Lai. This is an open-access article distributed under the terms of the Creative Commons Attribution License (CC BY). The use, distribution or reproduction in other forums is permitted, provided the original author(s) and the copyright owner(s) are credited and that the original publication in this journal is cited, in accordance with accepted academic practice. No use, distribution or reproduction is permitted which does not comply with these terms. 